\title{
The Measurement of Pion Double Charge Exchange on Carbon-13, Carbon-14, Magnesium-26, and Iron-56
}

\author{
Peter Anthony Seidl ${ }^{*}$
}

\section{DISCLAIMER}

\begin{abstract}
This report was prepared as an aceount of work sponsored by an agency of the United States Government. Neither the United Statcs Government nor any agency thereof, nor any of their employees, makes any warranty, express or implied, or assumes any legal liability or responsibility for the accuracy, completeness, or usefulness of any information, apparatus, product, or process disclosed, or represents that its use would not infriage privately owned rights. Reference herein to any specific cemmercial pioduct, process, or service by trade name, trademark, manufacturer, or otherwise does not necessarily constitute or imply its endorsement, recommendation, or favoring by the United States Government or any agency thereof. The views and opinions of authors expressed herein do not necessarily state or reflect those of the United States Gevernment or any agency thereof.
\end{abstract}

•Department of Physics, University of Texas at Austin, Austin, TX 78712.

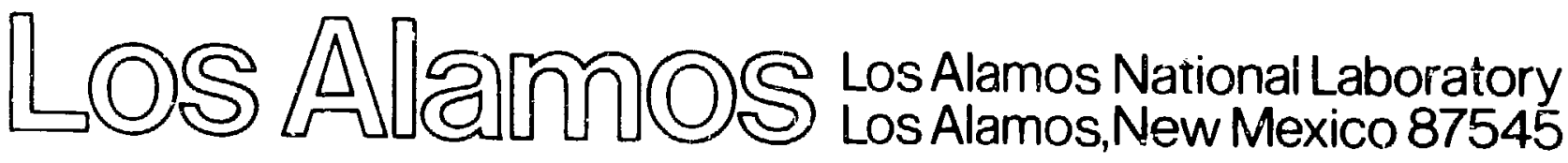


TAELE OF CONTENTS

LIST OF TABLES

$\mathrm{V}$

LIST OF FIGURES

vi

ABSTRACT

1

I. INTRODUCTION

I I. EXPERIMENT

A. EPICS channel 15

B. Spectrometer 17

C. Electronics and data acquisition 24

D. Targets 27

III. DATA REDUCTION

$\begin{array}{lr}\text { IV. RESULTS } & 49\end{array}$

A. Transitions to the DIAS 49

1. Excitation functions 49

2. Angular distributions 53

3. A dependence 55

B. Nonanalog transitions 58

1. $0^{+} \rightarrow 0^{+}$transitions 58

2. ${ }^{14} \mathrm{C}\left(\pi^{+}, \pi^{-}\right){ }^{14} \mathrm{O}\left(2^{+}, 7.77 \mathrm{MeV}\right)$

3. ${ }^{13} \mathrm{C}\left(\pi^{+}, \pi^{-}\right) 13006$

V. ANALYSIS OF THE DIAS TRANSITIONS

A. Second order optical potential phenomenology 72

B. Second order optical potential and core excitation 91

$\begin{array}{ll}\text { VI. SUMMARY AND CONCLUSION } & 98\end{array}$

APPENDIX A: Tabulation of Data for Experiment $558 \quad 102$

AP PENDIX B : Energy Dependence of $180\left(\pi^{+}, \pi^{-}\right)^{18} \mathrm{Ne}(\mathrm{gs}) \quad 107$

APPENDIX C: ISIst of Dissertation Papers 122

$\begin{array}{ll}\text { ACKNOWLEDGEMENTS } & 123\end{array}$

$\begin{array}{ll}\text { REFERENCES } & 124\end{array}$ 


\section{LIST OF TABLES}

II-1: EPICS spectfications.

II-2: ${ }^{14} \mathrm{C}$ target properties.

II-3: Nuclear g.s. Q values for double-charge-exchange reactions 0 curring in the ${ }^{14} \mathrm{C},{ }^{13} \mathrm{C},{ }^{26} \mathrm{Mg}$, and ${ }^{56} \mathrm{Pe}$ targets.

II-4: ${ }^{13} \mathrm{C},{ }^{26} \mathrm{Mg},{ }^{56} \mathrm{Fe}$, and ${ }^{1} \mathrm{H}$ target propert1es.

V-1: DCX and SCX center-of-mass cross sections 1nput to the PIESDEX Iits.

A-1: Center-of-mass cross sections for

${ }^{14} \mathrm{C}\left(\pi^{+}, \pi^{-}\right)^{14} \mathrm{O}$ (DIAS).

A-2: Center-of-mass cross sections for ${ }^{14} \mathrm{C}\left(\pi^{+},--\right)^{14} \mathrm{O}\left(0^{+}\right.$, $5.92 \mathrm{MeV})$.

A-3: Center-of-mass cross sectlons for ${ }^{14} \mathrm{C}\left(\pi^{+}, \pi^{-}\right)^{14} \mathrm{C}\left(2^{+}\right.$, $7.77 \mathrm{MeV}$ ).

A-4: Center-of-mass cross sections for ${ }^{26} \mathrm{Mg}\left(\pi^{+}, \pi^{-}\right)^{26} \mathrm{SI}$ (DIAS). 104

A-5: Center-of-angs cross gections for $56 \mathrm{Fe}\left(\pi^{+}, \pi^{-}\right)^{56} \mathrm{N1}(8 \varepsilon)$ and $56 \mathrm{Fe}\left(\pi^{+}, \pi^{-}\right)^{56} \mathrm{NI}$ (DIAS).

A-6: Center-of-mags cross sections for ${ }^{13} \mathrm{C}\left(\pi^{+}, \pi^{-}\right)^{13} \mathrm{O}\left(\mathrm{g}^{8}\right)$.

A-7: Center-of-mass cross sections for $\left.{ }^{13} \mathrm{C}_{\left(\pi^{+}\right.}{ }_{0} \pi^{-}\right)^{13} \mathrm{O}\left(1 / 2^{-}\right.$, 4.21 MeV). 
I-1: Excitation functions measured at $\theta_{1 \mathrm{ab}}=5^{\circ}$ for ${ }^{18} \mathrm{O}\left(\pi^{+}, \pi^{-}\right)^{18} \mathrm{Ne}(\mathrm{gs})$ and ${ }^{26} \mathrm{Mg}\left(\pi^{+}, \pi^{-}\right)^{26} \mathrm{SI}(\mathrm{gs})$.

II-1: Schematic of the EPICS channel.

II-2a: The EPICS spectrometer.

II-2b: Block diagram of the EPICS spectrometer detection system. 20

II-3: Block diagram of the F.FICS electronics setup.

II-4: New ${ }^{14} \mathrm{C}$ target cell desig?.

II-5: Schematic of the target arrangement in the EPICS momentum dispersed pion beam.

III-1: HIsrogram of $x_{\text {tgt }}$.

II:-2: S1 to $(S 2 \cdot S 3)$ time of flight spectrum at $T_{\pi}=164 \mathrm{MeJ}$

III-3: S2 to S3 time of flight versus the geometric mean of the $S 2$ and $S 3$ pulse heights for $\mathrm{I}_{H}\left(\pi^{+}, \pi^{+}\right)$at $\mathrm{T}_{\pi}=292 \mathrm{MeV}$.

III-4: Cerenkov Pulse Helght Sum versus SI Corrected Time of Flight. Electrons with large pulse helght sums were hardware refected.

III-5: Spectrometer acceptance for the ${ }^{56} \mathrm{Fe},{ }^{14} \mathrm{C}, 26^{\mathrm{ig}}$, and ${ }^{13} \mathrm{C}$ rargets.

$\begin{aligned} & \text { iII-6: } \text { M1ssing } \\ &{ }_{13} \mathrm{C},{ }^{4} \mathrm{C},{ }^{26} \mathrm{Mg}\left(\pi^{+}, \pi^{-}\right)^{13} 0,{ }^{14} 0,{ }^{26} \mathrm{SI} \text { at } \mathrm{T}_{\pi}=164 \mathrm{MeV}, \theta=5^{\circ} .\end{aligned}$ 
IrI-7: Comparison of spectra for the ${ }^{56} \mathrm{Fe}\left(\pi^{+}, \pi^{-}\right)^{56} \mathrm{N1}$ reaction at $T_{\pi}=140,164,220,260,292 \mathrm{MeV}$.

III-8: Energy level dlagrams of 140 and ${ }^{26} \mathrm{S1}$. Excttation energles are in units of MeV.

IV-1: New DIAS excitation function data for $14 \mathrm{C}\left(\pi^{+}, \pi^{-}\right)^{140} 0$, $26 \mathrm{Mg}\left(\pi^{+}, \pi^{-}\right)^{26} \mathrm{Si}$, and $56 \mathrm{Fe}\left(\pi^{+}, \pi^{-}\right)^{56} \mathrm{N1}$ (DIAS, $\left.9.6 \mathrm{MeV}\right)$.

IV-2: Excltation functions for $A\left(\pi^{+}: \pi^{-}\right) A^{\prime}$ (DIAS).

IV-3: Angular distributions at $T_{F}=164$ and 292 Mel! for the reactions: $14 \mathrm{C}\left(\pi^{+}, \pi^{-}\right)^{14} \mathrm{O}\left(\mathrm{gs}^{\pi}\right),{ }^{18} \mathrm{O}\left(\pi^{+}, \pi^{-}\right)^{16} \mathrm{Ne}(\mathrm{gs})$, and $26 \mathrm{Mg}\left(\pi^{+}, \pi^{-}\right)^{26} \mathrm{SI}(\mathrm{gs})$. The data are compared to lowest order optical potential calculations from the theory of [ Jo-83].

IV-4: The same data as in FIg. IV -3 plotted versus $q R$.

IV-5: Forward angle cross seations as a function of target mass for DIAS transitions at $T_{\pi}=164 \mathrm{MeV}$ and $292 \mathrm{MeV}$.

IV-6: DIAS, exc1tation functions of $14 \mathrm{C}\left(\pi^{+}, \pi^{-}\right)^{14} 0$, $180\left(\pi^{+}, \pi^{-}\right)^{18} \mathrm{Ne}$, and $26 \mathrm{Mg}\left(\pi^{+}, \pi^{-}\right)^{26} \mathrm{SI}$. By multiplying by ratios of $\mathrm{A}^{-10 / 3}$, the data for ${ }^{14} \mathrm{C}$ and $26 \mathrm{Mg}$ are displayed on the scale of the 180 data.

IV-7. Excitation functions for ${ }^{14} \mathrm{C}\left(\pi^{+}, \pi^{-}\right)^{14} \mathrm{O}\left(\mathrm{O}^{+}, 5.92 \mathrm{MeV}\right)$, and ${ }^{56} \mathrm{Fe}\left(\pi^{+}, \pi^{-}\right)^{56} \mathrm{NI}(8 \mathrm{~s})$.

IV-8: Angular distribution for $\left.{ }^{14} \mathrm{C}\left(\pi^{+}, \pi^{-}\right)^{14} \mathrm{O}^{+}, 5.92 \mathrm{MeV}\right)$.

IV-9: The excitation function for ${ }^{14} \mathrm{C}\left(\pi^{+}, \pi^{-}\right)^{14} \mathrm{O}\left(2^{+}, 7.7^{7} \mathrm{MeV}\right)$ is compared to that for the $18 \hat{O}^{\prime}\left(\pi^{+}, \pi^{-}\right) 18 \dot{\mathrm{Ne}}\left(2^{+}, 1.89 \mathrm{MeV}\right)$ react $10 \mathrm{n}$.

IV-10: Angular d1stribution for ${ }^{14} \mathrm{C}\left(\pi^{+}, \pi^{-}\right)^{14} 0\left(2^{+}, 7.77 \mathrm{MeV}\right)$ 
at $T_{\pi}=292 \mathrm{MeV}$ and $164 \mathrm{MeV}$.

IV-11: M1sa1ng mass spectra for ${ }^{13} \mathrm{C}\left(\pi^{+}, \pi^{-}\right)^{13} \mathrm{O}$ at $\mathrm{T}_{\pi}=164 \mathrm{MeV}$ and $292 \mathrm{MeV}$, measured with the target of aresl density $1489 \mathrm{mg} / \mathrm{cm}^{2}$. The spectra are the raw number of counts sumed over all angleg for which data were taken.

IV-12: Excltation function for ${ }^{13} \mathrm{C}\left(\pi^{+}, \pi^{-}\right)^{13} \mathrm{O}(\mathrm{gs})$. The ${ }^{13} \mathrm{C}\left(\pi^{+}, \pi^{-}\right)^{13} \mathrm{O}(4.21 \mathrm{MeV})$ reaction 19 compared to a Brelt-Wigner parameterlation of the ${ }^{12} \mathrm{C}\left(\pi^{+}, \pi^{-}\right)^{12} \mathrm{O}(\mathrm{gs})$ axcitation function.

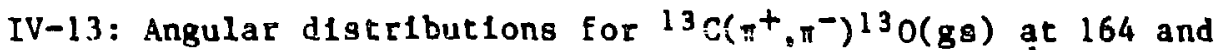
$292 \mathrm{MeV}$. The curves are $\sigma(\hat{\theta})=\mathrm{NJ}^{2}(\mathrm{qR}) \mathrm{e}^{-q d}$, fir to the ${ }^{13} \mathrm{C}\left(\pi^{+}, \pi^{-}\right)^{13} \mathrm{O}(4.21 \mathrm{MeV})$ data at $964 \mathrm{MeV}$.

V-1a: Real and imaginary parts of the lowest order scattering amplitude for ${ }^{26} \mathrm{Mg}\left(\pi^{+}, \pi^{-}\right)^{26} \mathrm{SI}$ (DIAS).

$v-1 b$ : Contributions to the scattering amplitude from the $\lambda\left\{^{2}\right.$ terms of Eq. V-17,18,19.

V-2: Comparison of forward angle SCX differential cross sections to the PIESUEX results.

V-3: Comparison of forward angle DCX differential cross sections to the PIESDEX results. The $90 \mathrm{Zr}$ point is a prediction.

V-4: Comparison of DCX data at $T_{\pi}=164 \mathrm{MeV}$ to the 1sobaric Inverlant model PIESDEX calculations.

V-5: Calculations for ${ }^{15} \mathrm{~N}\left(\pi^{+}, \pi^{\circ}\right)$ data with $\left.\left.\lambda\right\}^{2}\right)$ and $\Delta E$ from Eq. V-17, 18, 19 .

V-6: Calculations for ${ }^{14} \mathrm{C}\left(\pi^{+}, \pi^{-}\right)^{14}$ O(DIis) with $\lambda(2)$ and $\Delta \mathrm{E}$ from Eq. $V-17,18,19$. The dashed line is for a 
Skyrme-III Hartree-Fock density and the solld line is for a Negele-Vauther1n DME denstty [ $\mathrm{Ne}-72]$.

V-7: DCX coupled channels calculations of L. C. L1u [L1-84] rompared to the ${ }^{14} \mathrm{C}\left(\pi^{+}, \pi^{-}\right)^{14} \mathrm{O}$ (DIAS) excitationfunction data.

V-8: DCX coupled channels calculations of L. C. L1u [L1-84] compared to the ${ }^{14} \mathrm{C}\left(\pi^{+}, \pi^{-}\right)^{14}$ O(DIAS) $164-\mathrm{MeV}$ angulardistribution data.

V-9: DCX coupled channels calculations of L. C. LIu [L1-84] compared to the ${ }^{14} \mathrm{C}\left(\pi^{+}, \pi^{-}\right)^{14}$ O(DIAS) $292-\mathrm{MeV}$ anguiardistribution data. 
THE MEASUREMENT OP PION DOUB', CHARGE EXCHANGE ON

CARBON-13, CARBON-14, MAGNESIUN-26 AND IRON-56

by

Peter Anthony Seldl

ABSTRACT

Cross sectlons for the ${ }^{13}, 14 \mathrm{C}, 26 \mathrm{Mg}, 56 \mathrm{Fe}\left(\pi^{+}, \pi^{-}\right) 13,140,26 \mathrm{S1}, 56 \mathrm{N1}$ reactlons were measured with the Energetic Pion Channel and Spectrometer at the clinton P. Andersca Meson Physics Factlity for $120<I_{\pi}<292 \mathrm{MeV}$ and $0<\theta<50$. The double 1sobarlc analog states (DIAS) are of primary interest. In addition, cross sections for transitions to ${ }^{14} \mathrm{O}\left(\mathrm{O}^{+}, 5.92 \mathrm{MeV}\right),{ }^{14} \mathrm{O}\left(2^{+}, 7.77 \mathrm{MeV}\right),{ }^{56} \mathrm{N1}(\mathrm{gs}),{ }^{13} \mathrm{O}(\mathrm{gs})$, and ${ }^{3} O(4.21 \mathrm{MeV})$ are presented. The ${ }^{13} 0(4.21 \mathrm{MeV})$ state $1 \mathrm{~s}$ postulated to have $J^{\pi}=1 / 2^{-}$. The data are compared to previously measured double-charge-exchange cross sections on other nuclei, and the systematics of double charge erchange on $T>1$ target nuclet leading to the DIAS are studled. Near the $\Delta_{33}$ resonance, cross sections for the DIAS transitions are in disagreement with calculations in which the reaction is treated as sequential charge exchange through the free plonnucleon amplitude, whlle for $T_{\pi}>200 \mathrm{MeV}$ the anomalous features of the $164 \mathrm{MeV}$ data are not apparent. Th1s is evidence for significant higher order contributions to the double-charge-exchange amplitude near the resonance energy. Two theoretical approaches that include two nucleon processes are applied to the DIAS data. 


\section{INTRODUCTION}

Pion charge-exchange reactions leading to lsobartc analog states (IAS) provide ar attractive method for studying the mesonnucleus interaction and nuclear structure. The fact that isospin is conserved leads to the expectation that the Inttial and final nuclear states should be closely related -- a relatively simple nuclear situation.

In pion single charge exchange (SCX) leading to the IAS, only one hard Interaction is necessary to cause the transition. Thus, the distorted-wave Impulse approximation (DWIA) is expected to describe angular-distribution and excltation-function (differential cross section versus plon kinetic energy) data. This expectation is reasonably well founded, the DWIA has been successful in describing many strong tnelastic trausttions observed in $\pi$-nucleus scatering experiments throughout the perindic table [Mo-83]. Thus, the hoped for simplicity of the SCX amplitude, along with the expected sensitivity to neutron density differences motivated early interest in the SCX reaction.

The $\left(\pi^{+}, \pi^{-}\right)$reaction Involves changing two neutrons into protons. Thus, in leading order, the reaction involves two hard interactions. Within the multiple-scattering formalism, this means that the first double-charge-exchange (DCX) term is the product of 
two off-dlagonal matrix elements, which has led to the expectation that DCX would be sensitive to nucleon correlation effects that might not be apparent in transitions tractahle in the lowest order DWIA. In a DCX reaction leading to the double isobaric analog state (DIAS) the coupling to (at least) the intermediate analog state must be present In any lowest order calculation. Consequently, important assumptions must be made about the Intermediate states, as well as the propagation of the intermediate $\pi^{0}$ in the nuclear medium. As in the $\left(\pi^{+}, \pi^{0}\right)$ reaction, $\left(\pi^{+}, \pi^{-}\right)$is also expected to be sensitive to the excess neutron density. Experimental and subsequent theoretical work have shown that large contributions to DCX (and SCX) appear to arfse from nuclear structure and two nucleon processes. The exact nature of the latter are as yet uncertaln, but some candidates are pion absorption [L1-83], nucleon correlations, $\Delta_{33}$-nucleus interactions [Jo-84], and virtual $\Delta_{33}$ components of the nuclear wave function. However, it may be necessary to explain some of the lata with the theory of quarks and gluons. Within a quark plcture, $\left(\pi^{+}, \pi^{-}\right)$occurs by changing two down quarks into two ur quarks. If two nucleons overlap suffictently in the nucleus, such an approach, if tractable, would have the attractive feature of using the nucleus to study extended quark systems [Le-84, M1-84].

The enhancement of SCX cross sections in the $\Delta_{33}$-resonance $(\mathrm{J}=3 / 2, T=3 / 2, E=1232 \mathrm{MeV})$ region was first observed in experiments which measured the radioactivity of the residual nuclel [Ch-69]. In the past four years SCX cross sections have been measucad for transitions to the IAS with high accuracy using the $\pi^{0}$ spectrometer at 
LAMPF [Ba-80,Do-82, Sen-83,Ir-83]. DWJA calculations significantly underestlmate the forward angle cross sections for $T S 200 \mathrm{MeV}$, but experiments have confirmed the expectation that $\sigma(\theta) \propto \mathrm{j}_{0}^{2}(\theta)$. The target mass dependence of $\sigma\left(0^{\circ}\right)$ vartes $3 g=$ funcicion of energy $\cdots$ is smoothest for $\mathrm{T} \geqslant 230 \mathrm{MeV}$, and deviates nost from the power law $\mathrm{A}^{-\alpha(E)}$ at 155 and $100 \mathrm{MeV}$. The puzzling energy dependence of the cross sections has stimulated continued experimental and theoretical woṛk. The earliest measurements of the small-angle excliation function of $\left(\pi^{+}, \pi^{-}\right)$double-charge-exchange (DCX) reactions -- reported for the $T=1$ target nuclel ${ }^{18} 0$ [Bu-78, Gr-79] and ${ }^{26} \mathrm{Mg}$ [Gr-82a] leading to the double-1sobaric-analog states (DIAS) $18 \mathrm{Ne}(\mathrm{gs})$ and ${ }^{26} \mathrm{Si}(\mathrm{gs})$-- exhibit a rapidly varying cross section as a function of plon energy (see Fig. I-1). The energy dependence 1s that of a peak 60-80 MeV wide centered near $140 \mathrm{MeV}$ and a monotontc Increase of the cross section between 200 and $300 \mathrm{MeV}$. At $T_{\pi}=292 \mathrm{MeV}$, angular distributions [Gr-82a] for $180\left(\pi^{+}, \pi^{-}\right)^{18} \mathrm{Ne}(\mathrm{DIAS})$ and $25 \mathrm{Mg}\left(\pi^{+}, \pi^{-}\right)^{26} \mathrm{SI}$ (DIAS) exhibit diffractive shapes with first minima at momentum transfers that agree with simple DCX models that describe the reaction as sequential charge exchange through the free $\pi-A$ amplitude. However, at $T_{\pi}=164 \mathrm{MeV}$ the ${ }^{18} \mathrm{O}\left(\pi^{+}, \pi^{-}\right)^{18} \mathrm{Ne}$ (DIAS) angular distribution has a minimum at $\theta=20^{\circ}$, which corresponds to an unrealistically large radius within the simpler models (see Eq. I-6). The occurience of a minimum at a small scatteriig angle is not explained by any simple [Jo-80,Mi-31] tro-step pion-nucleus calculation. Prior to the present work, there was no $T_{\pi}=164 \mathrm{MeV}$ angular distribution for ${ }^{26} \mathrm{Mg}\left(\pi^{+}, \pi^{-}\right)^{26} \mathrm{SI}$ (DIAS). 


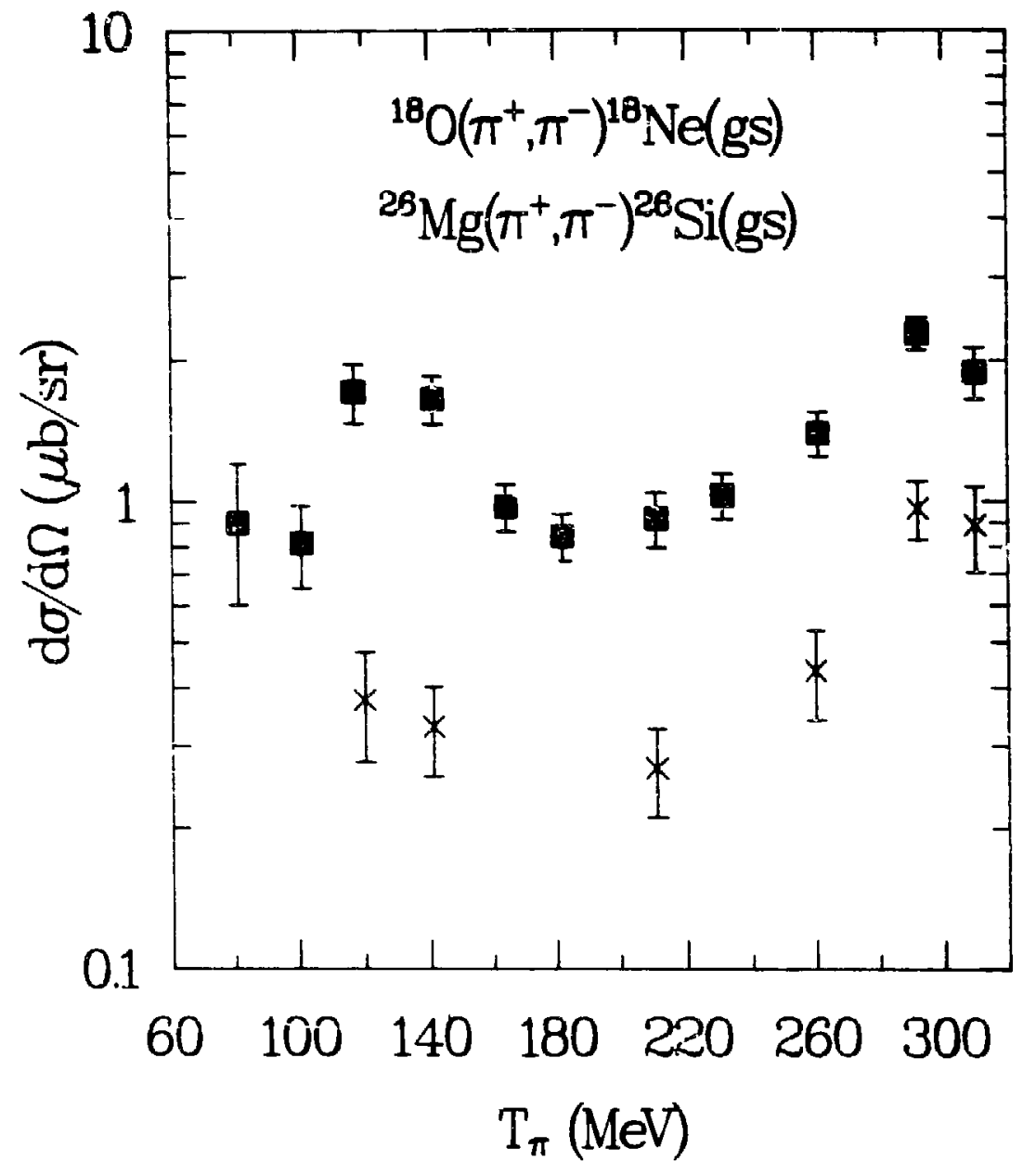

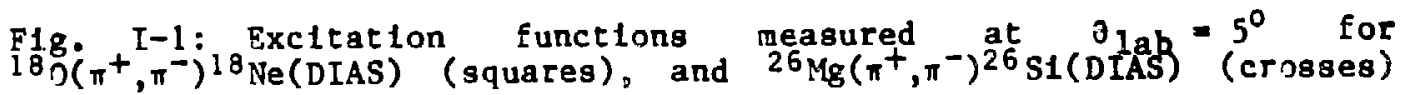
from [Gr-82a]. 
Experimental data have shown the dependence of the forwardangle cross section on target mass to be roughly $A^{-10 / 3}$ [Mo-80], in agreement with the geometric model of Johnson [Jo-80]. For $A=18$, the cross section at $\theta_{1 \mathrm{ab}}=5^{\circ}$ and at energles near the peak of the $\Delta_{33}$ resonance is abcut one $\mu \mathrm{b} / \mathrm{sr}$.

In contrast, DCX on $T=0$ nucle1 (which, of necessity, must be non-analog in character) leading to the ground state of the residual nucleus have exhibited peaked excltation functions with a centrold and width of about $160 \mathrm{MeV}$ and $70 \mathrm{MeV}$, respect1vely [B1-83]. The forward-angle cross section 13 about $0.5 \mu b / 35$ for $A=16$ near the waxtmum of the excltation function and the target mass dependence [Mo-82a] is roughly $A^{-4 / 3}$. The shapes of the angular distributions are well described by the elkonal expression, $\sigma \propto J_{0}^{2}(q R)$, where $q$ is the momentum transfer and $R$ is the strong absorption radius [B]-83, G1-84a].

A phenomenological two-amplitude model has been applied to the $180\left(\pi^{+}, \pi^{-}\right)^{18} \mathrm{Ne}(\mathrm{gs})$ excitation function $[\mathrm{Gr}-82 \mathrm{~b}]$, and $164-\mathrm{MeV}$ angular distribution [G1-84b]. A nonanalog amplitude was inferred from the ${ }^{16} \mathrm{O}\left(\pi^{+}, \pi^{-}\right)^{16} \mathrm{Ne}(\mathrm{gs})$ data, and was added to a calculated amplitude that described the ${ }^{18} 0$ reaction as sequential charge exchange through the intermedlate analog state. The free parameter was an energy dependent phase between the two amplitudes.

Some features of analog SCX and DCX can be understood by Inspecting the SCX amplitude. The lowest order DWIA result for $\left(\pi^{+}, \pi^{0}\right)$ is [E1-80] 


$$
\begin{aligned}
& \left\langle\pi^{0} ; a|T| \pi^{+} ; 0\right\rangle= \\
& \left.\int \chi_{k} S^{-}\right)^{\star}(\vec{r})\left\langle a\left|\sum_{1=1}^{A}\left(f_{0}+f_{1} \vec{\phi} \cdot \vec{\tau}\right) \delta\left(\vec{r}-\vec{r}_{1}\right)\right| 0\right\rangle \psi_{k}^{(+)}(\vec{r}) d^{3} r .
\end{aligned}
$$

The sum over : $\left.F_{0}+E_{1}+\vec{\phi} \cdot t\right)$, the plon-nucleon amplitude, is over all (A.) nucleons. $\vec{\phi}$ is the plon isospin operator, and $\vec{\tau}$ is the nucleon Isospin operator. $\langle a|$ and $|O\rangle$ are the final (IAS) and Initial nuclear states and $\chi_{k}^{(-)}(\vec{r})$ and $\psi_{k}^{(+)}(\vec{r})$ are the outgoing and incoming waves for the $\pi^{0}$ and $\pi^{+}$, respectively. The analog of the ground state is obtalned by an isospin ratsing operation,

$$
\begin{aligned}
& T_{+}\left|T, T_{z}\right\rangle=\sqrt{2} T_{z}\left|T, T_{z}+1\right\rangle=\sqrt{N-Z}\left|T, T_{z}+1\right\rangle . \\
& \text { so, } \\
& |a\rangle=\frac{1}{\sqrt{N-Z}} T+|0\rangle=\frac{1}{\sqrt{N}-\bar{Z} \cdot \frac{1}{2} \cdot \sum_{j=1}^{A}\left(\tau_{x}+1 \tau_{y}\right)_{j}|0\rangle,}
\end{aligned}
$$

where the nucleon isospin ralsing operator has been written in terms of the Paul1 isospin matrices, $\tau_{1}$, with the convention that $\tau_{z}|p\rangle=$ $|p\rangle$. OnIy the 1sovector part of the $\pi-A$ anplitude connects the ground state of the target and the IAS. The $\vec{\phi} \cdot \vec{\tau}$ term of the $\pi-A$ amplitude may be rews 1tten in terms of the Paul 1 matrices.

$$
\begin{aligned}
& \left\langle\left.\pi^{0}\right|_{\phi} ^{+} \tau^{+} \mid \pi^{+}\right\rangle=\left\langle\pi^{0}\left|\left(\phi_{+} \tau_{-}+\phi_{-} \tau_{+}+2 \phi_{z} \tau_{z}\right)\right| \pi^{+}\right\rangle, \\
& =\left\langle\pi^{0}\left|\sqrt{2} \tau_{+}\right| \pi^{0}\right\rangle=\left\langle\pi^{0} \mid \pi^{0}\right\rangle \sqrt{2} \tau_{+} \\
& =\frac{\sqrt{2}}{2}\left(\tau_{x}+1 \tau_{y}\right) .
\end{aligned}
$$


Using this we can evaluate

$$
\begin{aligned}
& \left\langle a\left|\frac{\sqrt{2}}{2} \sum_{i=1}^{A}\left(\tau_{x}+1 \tau_{y}\right)_{1} \delta\left(\vec{r}-\vec{r}_{1}\right)\right| 0\right\rangle \\
& =\frac{\sqrt{2}}{2 \sqrt{N-Z}}\left\langle 0\left|\sum_{i j}^{A}\left(\tau_{x}-1 \tau_{y}\right)_{j}\left(\tau_{x}+1 \tau_{y}\right)_{1} \delta\left(\vec{r}-\vec{r}_{1}\right)\right| 0\right\rangle, \\
& =\frac{\sqrt{2}}{4 \sqrt{\mathrm{N}-Z}}\left\langle 0\left|\sum_{1 j}^{A}\left(\tau_{-}\right)_{j}\left(\tau_{+}\right)_{1} \delta\left(\vec{r}-\vec{r}_{1}\right)\right| 0\right\rangle \\
& =\frac{1 \sqrt{2}}{4 \sqrt{N-Z}}\left\langle 0\left|\sum_{1 j}^{A}\left[\left(\tau_{-}\right)_{j},\left(\tau_{+}\right)_{1}\right] \delta\left(\vec{r}-\vec{r}_{1}\right)\right| 0\right\rangle, \\
& =-\frac{\sqrt{2}}{\sqrt{N-Z}}\left\langle 0\left|\sum_{1=1}^{A}\left(\tau_{z}\right)_{1} \delta\left(\vec{r}-\vec{r}_{1}\right)\right| 0\right\rangle .
\end{aligned}
$$

We have made use of $\left[\left(\tau_{. .}\right)_{j},\left(\tau_{+}\right)_{1}\right]=0$ (for $1 \neq j$ ), and

$$
\begin{aligned}
{\left[\left(\tau_{-}\right)_{1},\left(\tau_{+}\right)_{1}\right]=4\left(\tau_{z}\right)_{1} \text {. For } 1=1, } \\
\quad\left\langle 0\left|\left(\tau_{z}\right)_{1} \delta\left(\vec{r}-\vec{r}_{1}\right)\right| 0\right\rangle \\
\quad=\int \psi \psi_{A}^{*}\left(\vec{r}_{1}, \ldots, \vec{r}_{A}\right) \cdot(+1) \cdot \psi_{A}\left(\vec{r}_{1}, \ldots, \vec{r}_{A}\right) \delta\left(\vec{r}-\vec{r}_{1}\right) d^{3} r_{1} d^{3} r_{2} \ldots d^{3} r_{A} \\
=\int d^{3} r \delta\left(\vec{r}-\vec{r}_{1}\right) \phi_{P l} *\left(\vec{r}_{1}\right) \phi_{p 1}\left(\vec{r}_{1}\right)=\rho_{p 1}(\vec{r}),
\end{aligned}
$$

where $\psi_{\mathrm{A}}$ is the wave function for the A nucleons and $\phi_{\mathrm{Pl}}$ is the wave function for proton \#1. Evaluating the rest of the terms in the sum of (I-4) 1s stralghtforward. Thus,

$$
\begin{aligned}
& \left\langle a\left|\frac{\sqrt{2}}{2} \sum_{1=1}^{A}\left(\tau_{x}+1 \tau_{y}\right)_{1} \delta\left(\vec{r}-\vec{r}_{1}\right)\right| 0\right\rangle= \\
& \frac{\sqrt{2}}{\sqrt{N}-Z}\left(\rho_{p 1}(\vec{r})+\rho_{p 2}(\vec{r})+\ldots+\rho_{p Z}(\vec{r})\right.
\end{aligned}
$$




$$
\begin{aligned}
& \left.-\rho_{n_{1}}(\vec{r})-\rho_{n_{2}}(\vec{r})-\ldots-\rho_{n N}(\vec{r})\right) \\
& =\frac{\sqrt{2}}{\sqrt{N-Z}}\left(N_{p_{\vec{n}}}(\vec{r})-Z \rho_{p}(\vec{r})\right) . \\
& \text { where } \rho_{n}(\vec{r})=\rho_{n_{1}}(\vec{r})+\rho_{n_{2}}(\vec{r})+\ldots+\rho_{n N}(\vec{r}), \\
& \text { and } \rho_{p}(\vec{r})=\rho_{p_{1}}(\vec{r})+\rho_{p 2}(\vec{r})+\ldots+\rho_{p 2}(\vec{r}) .
\end{aligned}
$$

The normalization of the densities is

$$
\int d^{3} r p_{n}(\vec{r})=\int d^{3} r p_{p}(\vec{r})=1 .
$$

Inserting ( $I-5)$ Into ( $I-1)$ gives the result

$$
\left\langle\pi^{0} ; a|\tau| \pi^{+} ; 0\right\rangle=\sqrt{2} f_{i} \int x_{k}^{(-)} *(\vec{r}) \frac{1}{\sqrt{N-Z}}\left(N \rho_{n}(\vec{r})-Z_{p}(\vec{r})\right) \psi_{k}{ }^{(+)}(\vec{r}) d^{3} r .
$$

This lowest order result shows the sellsitivity of SCX to neutronproton density differences. The SCX cross-sections are proportional to $(N-Z)$, and applying the 1sospin-raising operator twice to the target-nucleus wave function st.ows the $N$ and $Z$ dependence of DCX leading to the DIAS.

$$
\begin{aligned}
& T_{+} T_{+}\left|T, T_{z}\right\rangle=\sqrt{N-Z} T_{+}\left|T, T_{z}+1\right\rangle \\
& =\sqrt{2(N-Z)(N-Z-1)}\left|T, T_{z}+2\right\rangle
\end{aligned}
$$

Thus, neglecting nuclear structure differences between nuclel, we expect $\sigma_{D C X} \propto(N-Z)(N-Z-1)$, for transitions to the DIAS. 
Assuming that the dominant intermediate state ts the IAS of the target nucleus, (which 1 s perhaps orily true for $T_{\pi}>230 \mathrm{MeV}$ ) the transition amplitude for DCX is

$$
\begin{aligned}
& \left\langle\pi^{-} ; a|T| \pi^{+} ; 0\right\rangle= \\
& \left.\int x_{k^{\prime}} h^{-*}(\vec{r}) \leqslant b\left|\sum_{1=1}^{A}\left(f_{l} \vec{\phi} \cdot \vec{\tau}\right) \delta\left(\vec{r}-\vec{r}_{1}\right)\right| a>x_{k} S+\right)(\vec{r}) G\left(\vec{r}-\vec{r}^{\prime}\right) x
\end{aligned}
$$

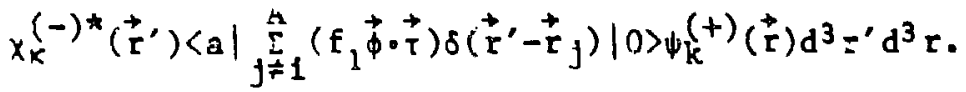

$G\left(\vec{r}-\vec{r}^{\prime}\right)$ describes the propagation of the intermediate $\pi^{0}$ through the nucleus. The fallure of such an amplitude to describe data means that some, or all, of the assumptions concerning nuclear structure, intermedlate states, medium effects, or reaction mechanism, are wrong. Johnson [Jo-30] has calculated analytlc expressions for analog SCX and DCX for $\sigma(\theta)$ in the eikonal approximation, assuming isospin invariance. In this geometrical model, the SCX cross section is shown to be proportions to $(\Delta \rho(R) / \rho(R))^{2}$, while the DCX cross section to $(\Delta \rho(R) / \rho(R))^{4}$, where $R$ is defined by $\rho(R) / \rho(0)=0.1-0.2$, and $\Delta \rho$ is the neutron proton density difference, or the density of the excess neutrons. DCX is assumed to proceed in two steps via a matix element proportional to $A^{-1}$. Under the assumption that $\Delta \rho(R) / \rho(R) \propto(N-$ Z) /A, then

$$
\begin{aligned}
& \sigma_{S C X} \propto(N-Z) A^{-4 / 3}, \text { and } \\
& \sigma_{D C X} \propto(N-Z)(N-Z-1) A^{-10 / 3} .
\end{aligned}
$$


The shapes of the angular distributions are predicted to be given by cylindrlcal Bessel functions.

$$
\begin{aligned}
& \sigma_{S C X}(\theta) \propto J_{0}^{2}(q R), \\
& \sigma_{D C X}(\theta) \propto\left(\left(1-\frac{a}{R}\right) J_{0}(q R)+a q J_{1}(q \bar{R})\right)^{2},
\end{aligned}
$$

where $q$ is the momentum transfer $1 \pi \mathrm{fm}^{-1}$ and a is the nuclear surface diffuseness parameter.

Almost all theoretical DCX work has concentrated on anjlog trans tions $[\mathrm{L} 1-83, \mathrm{Jn}-83 \mathrm{~b}]$. L1u [L1-83] uses a coupled-channels optlcal potential and Includes stquential one-nucleon single-chargeexchange (SCX) processes, wth terms proportional to $p^{2}$ in the potential. True pion absorption and scattering of a pion by two short-range correlated nucleons are the reaction mechanisms considered In the calcuiation of the $\rho^{2}$ terms, though the latter process is estimated to be unimportant at energies below $T_{\pi}=180 \mathrm{MeV}$. In [L1-83], calculations are compared to the measured angular distributions and the excitation function for $180\left(\pi^{+}, \pi^{-}\right)^{18} \mathrm{Ne}$ (DIAS). For these calculations, the effects of core excisation were found to be important. An application of this theory to the ${ }^{14} \mathrm{C}\left(\pi^{+}, \pi^{-}\right)^{14}$ O(DIAS) data reported here 18 presented in Chapter $\mathrm{V}$.

The theoretical work of Johnson and S1c111ano [Jo-83a,b] is also based on a coupled-channels optical potential and includes terms proportional to $\rho^{2}$. Their theory is constructed in an isospin Invarlant framework. The parameters of the first order potential are 
determined by the free plon-nucleon phase shifts. The elastic, SCX and DCX amplitudes are obtalned by taking 11 ne:- combinations of the pion-nucleus scattering amplitudes in channels of total isospln (nuclear plus pion). The coulomb interaction is not included in the1r theory. Their second-order potential is constructed with the purpose of obtalning a set of phenomenological parameters to describe elastc scattering, SCX and liCX reactions from a given nucleus at a given energy. Most of these parameters are raskly dependent on target mass, but are sitrongly energy dependent. DCX reactions that lead to double isobaric analog states were explored within this isobaric multyplec approach of Johnson and Siciliano [Jo-83b]. A systematic analysis of elastic satterlag; single charge exchange and double charge exchange leading to analog states was made [Gr-84], and some of the results of that work are presented in Chapter $V$. The new $14 \mathrm{C}\left(\pi^{+}, \pi^{-\cdots}\right)$ measurements reported herein are part of a study of pion elastic scattering [Ha-84], SCX [Ir-83], and DCX reactions on a single $T=1$ isotope.

This thesis presents angular distributions for ${ }^{14} \mathrm{C},{ }^{26} \mathrm{Mg}\left(\pi^{+}, \pi^{-}\right)^{14} 0,{ }^{26} \mathrm{SI}$ (DIAS) at $\mathrm{T}_{\pi}=164 \mathrm{MeV},{ }^{14} \mathrm{C}\left(\pi^{+}, \pi^{-}\right)^{14} \mathrm{O}$ (DIAS) at $T_{\pi}=292 \mathrm{MeV}$, a $5^{\circ}$ excltation function for ${ }^{14} \mathrm{C}\left(\pi^{+}, \pi^{-}\right)^{14}$ O(DIAS) $\left(120<\mathrm{T}_{\pi}<292 \mathrm{MeV}\right),{ }^{56} \mathrm{Fe}\left(\pi^{+}, \pi^{-}\right)^{56} \mathrm{NI}(\mathrm{gs})$, and ${ }^{56} \mathrm{Fe}\left(\pi^{+}, \pi^{-}\right)^{56} \mathrm{NL}$ (DIAS) $\left(140<\mathrm{T}_{\pi}<292 \mathrm{MeV}\right)$, and forward angle $\left(\theta_{1 \mathrm{ab}}=5^{\circ}\right)$ differential cross sections at $T_{\pi}=120,164,180 \mathrm{MeV}$ for ${ }^{26} \mathrm{Mg}\left(\pi^{+}, \pi^{-}\right)^{26} \mathrm{Mg}$ (DIAS).

The DIAS of the ${ }^{56} \mathrm{Fe}$ ground state is not the ground state of ${ }^{56} \mathrm{N1}$. Previous measurements of ${ }^{58} \mathrm{N1}(\mathrm{p}, \mathrm{t})^{56} \mathrm{N1}$ [Na-74] and ${ }^{54} \mathrm{Fe}\left({ }^{3} \mathrm{He}, \mathrm{n}\right){ }^{56} \mathrm{~N} 1$ [Ev-72] are not in good agreement as to the location of the DIAS in ${ }^{56} \mathrm{~N} 1$, but generally find the state at $\mathrm{E}_{\mathrm{x}} \approx 9.9 \mathrm{MeV}$. As 
was demonstrated earlier by Morrls et al. [Mo-80], plcn Induced DCX enables the selective excitation of the DIAS in heavy nuclei even when the state is in a region having a relatively large level dansity in the residual nucleus. In this $\left(\pi^{+}, \pi^{-}\right)$measurement, the bIAS $(T=2)$ In $56 \mathrm{N1}$ is seen at $E_{X}=9.6 \pm 0.2 \mathrm{MeV}$. These ${ }^{14} \mathrm{C}$ and $56 \mathrm{Fe}$ data are the firgt observation of the energy dependence of DIAS and rionanalog $0^{+}+0^{+}$transitions in the same nucleus. Theoretical erforts to address both DIAS and nonanalög tiansitions slmultaneously w11 be alded in this case ty the absence of entrancs channel differences for the two reactions.

In addition, a $5^{\circ}$ excitation function and an angular djstribution at $T_{\pi}=164 \mathrm{MeV}$ were extracted for the reaction ${ }^{14} \mathrm{C}\left(\pi^{+}, \pi^{-}\right) 140\left(0^{+}, 5.92 \mathrm{MeV}\right) . \quad$ A $5^{\circ}$ excltation function and angular distributions at $T_{\pi}=164$ and $292 \mathrm{MeV}$ for the reaction $14 C\left(\pi^{+}, \pi^{-}\right) 140\left(2^{+}, 7.77 \mathrm{MeV}\right)$ are presented.

It was of interest to measure DCX cross sections on ${ }^{13} \mathrm{C}$, an odd-A target for which data on the netghboring 1 sotopes ${ }^{12} \mathrm{C}$ and $14 \mathrm{C}$ would also be avallabie. Angular distributions $\mathrm{for}{ }^{13} \mathrm{C}\left(\pi^{+}, \pi^{-}\right)^{13} \mathrm{O}(\mathrm{gs})$ at 164 and $292 \mathrm{MeV}$, and ${ }^{13} \mathrm{C}\left(\pi^{+}, \pi^{-}\right)^{13} 0(4.21 \mathrm{MeV})$ at $164 \mathrm{MeV}$ are presented. $\theta=5^{\circ}$ cross sections were measured at $T_{\pi}=120$ and $180 \mathrm{MeV}$. Through comparisons to nonanalog DCX systematics for $T=0$ target nucle1, the ${ }^{13} 0(4.21 \mathrm{MeV})$ state is postulated to have $J^{\pi}=1 / 2^{-}$.

This expertment ( $\$ 558$ ) was performed at the Energetic Plon Channel and Spectrometer (EPICS) at the Clinton P. Anderson Meson Physics Facility (LAMPF). The experimental setup is described in 
Chapter II, and the data reduction in Chapter III. Chepter IV presents the resulta of the experinent and a comparison of the data to previous measurements. The syotematice of the DIAS transitinn are studied, and are compared to sequential charge exchange calculations. 


\section{EXPERIMENT}

A. EPICS Channe1

The A-1 pion production target is a carbon (graphite) wheel that presents a $3 \mathrm{~cm}$ thlck target to the $800 \mathrm{MeV}$ proton beam. The EPICS channel views this target at $35^{\circ}$ with respect to the incident proton beam. Since pion production cross sections increase only as $\mathrm{Z}^{1 / 3}[\mathrm{Co}-72]$, low $\mathrm{Z}$ targets are destied to maximize the number of pions produced per unit energy loss in the target. The low density and thermal characteristics of carbon make it a good target for heat dissipation considerations, while 1 ts relatively low $Z$ helps reduce multiple scattering of the incldent proton beam.

The EPICS channel, shown in Fig. II-1, consists of four dipole bending magnets (BMOl-4) which select a momentum bice of the pions created at the $A^{-1}$ target, four sets of horizontal and vertical jaws (FJ01-4) for controlling the phase space and emittance of the pion beam, and three sets of fleld (quadrupole and sextupole) magnets (FMO1-3) to correct for the effective fleld boundary of the dipole magnets. The energy range of the channel is $80 \mathrm{MeV}$ to $310 \mathrm{MeV}$, whtch spans the $\Delta_{33}$ resonance. A coordinate system is defined in Fig. II-2a. The channel produces a dispersed beam, that 1s, the position in the $x$ - direction is correlated with incident momentum $\left(D_{c h}=\right.$ 


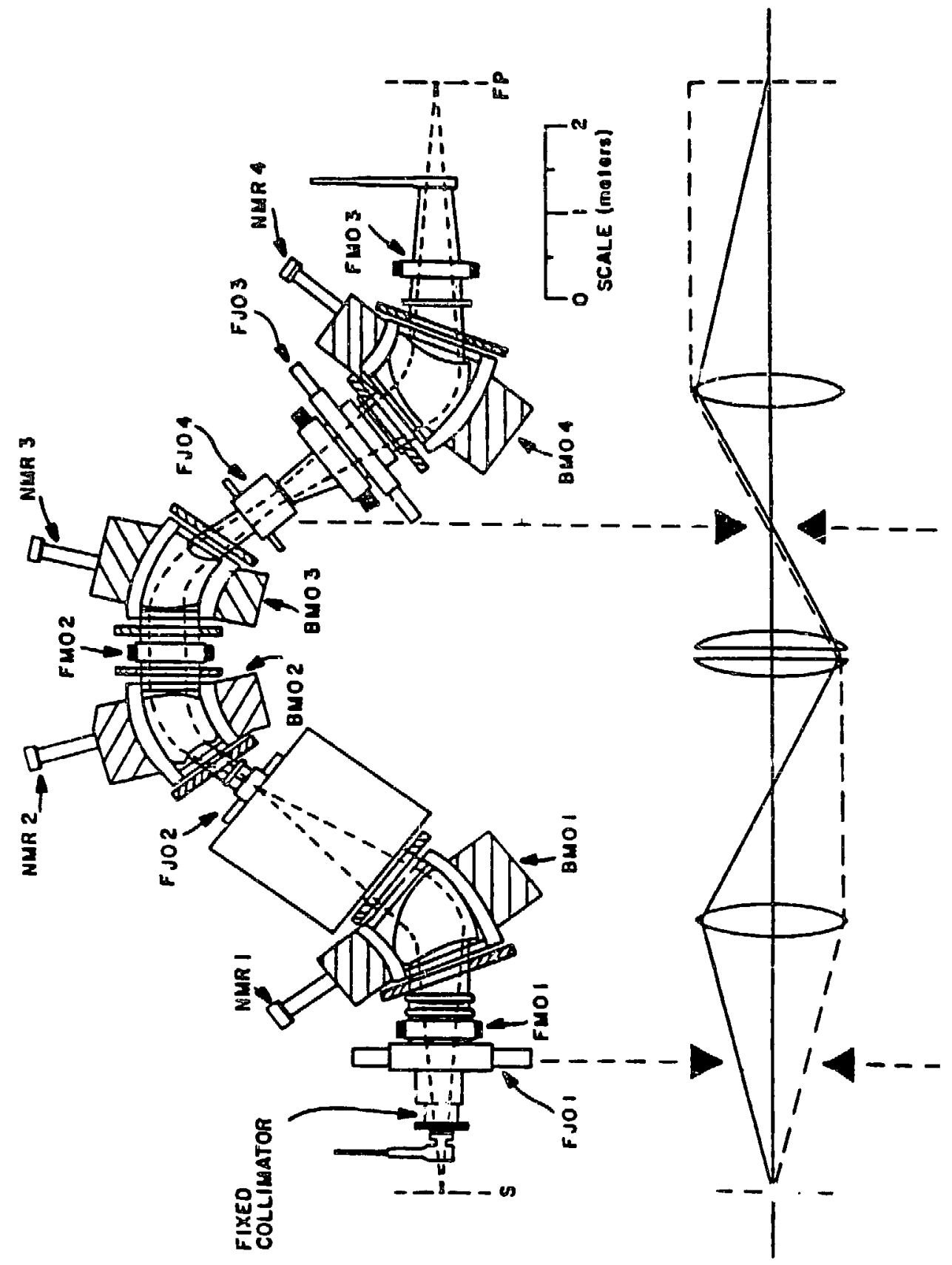

F1g. II-1: Schematic of the EPICS channel. The solid (daghed) line shows the optics in the vertical (horizontal) plane. 
$0.1 \% / \mathrm{cm})$. Although the beam has a $2 \%$ FWLM momentum spread, accurate deternination of the scattering position at the target allows a final momentum resolution of $2 \times 10^{-4}$ FWHM, thus permicting a factor of 200 Increase In Intensity over that of a monochromatic beam. The channel optics are point to point in the vertical plane and point to parallel In the horfzontal plane [Th-70].

The relative intensity of the incident plon beam was monitored In two ways: (1) Pulses from 1ACM02, a charge Integrating toroldal coll located upstream of the Al target In the proton beam, were acaled In CAMAC scalars. The output is proportional to the flux of plons in the the EPICS channel. (2) "Bear on Target", or BOT, 18 an Ionlzation chamber in the A-1 target cell. It is also gated by $\mathrm{Br}$ and its signal is proportional to the produrt of the $\mathrm{H}^{+}$current and the thicknegs of the $\mathrm{A}-1$ target. The rat1o $1 \mathrm{ACM} 02 / \mathrm{BOT}$ did not vary by nore than $2 \%$ over the course of the experiment.

\section{B. Spectrometer}

Some parameters of EPICS are shown in Table II-1. The momentum bite $( \pm 6 \%)$ of the spectrometer allows a large $(-20$ to $-55 \mathrm{MeV}$ ) region of excltation energy to be vlewed at one spectrometer setting. EPICS operates in the VHV mode: verifcal dispersion, horlzontal scattering, vertical analys1s. Three quadrupole magnets (QMOi-3) provide an lmage of the target at the entrance to the two dipole (BM05,6) magnets. The first-order opticy of the quadrupole inagnets from the target to the front focus are polnt-to-point in the 


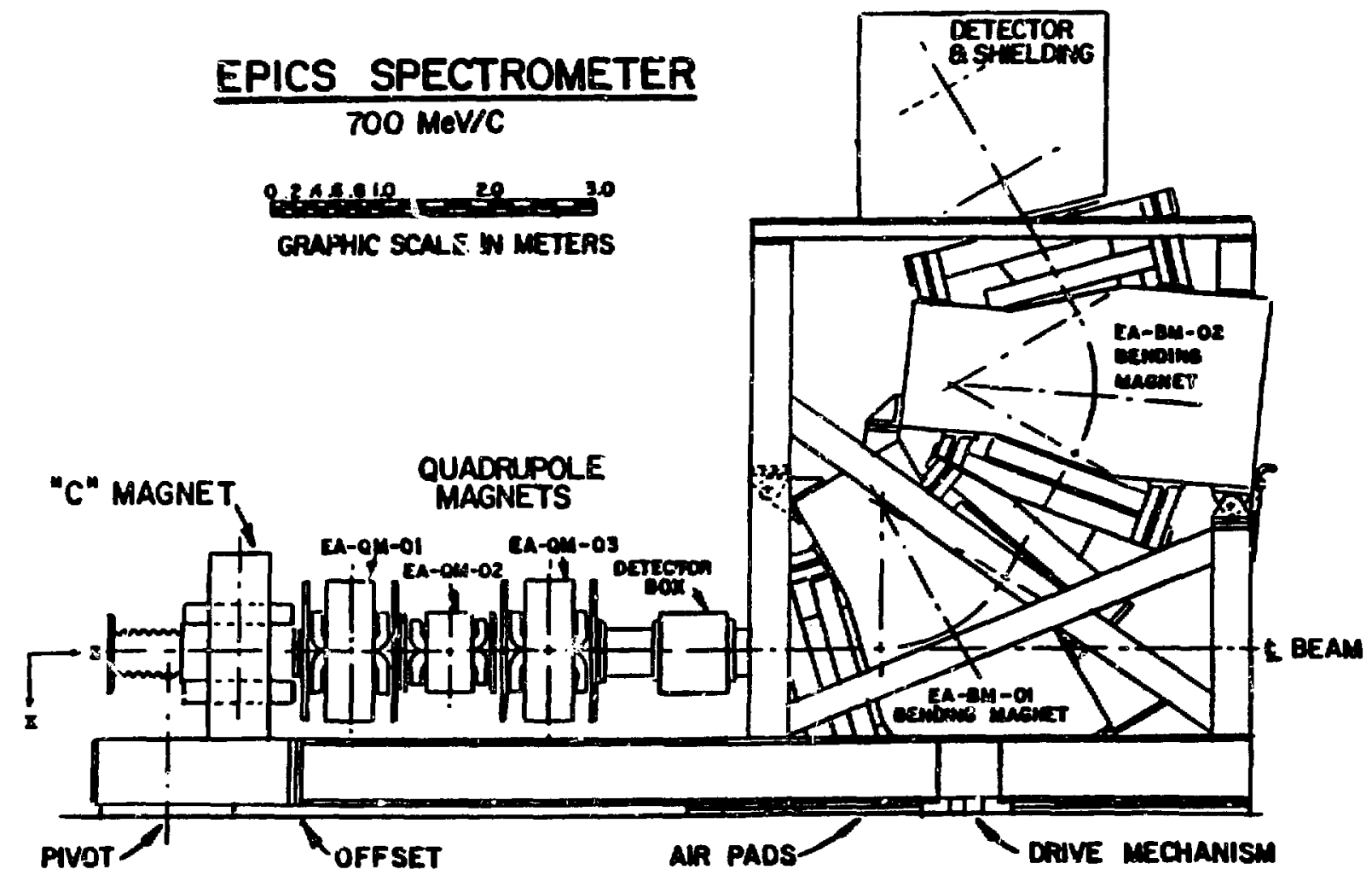


Table II-1: EPICS specifications [MP-80].

Channe1

\section{energy range}

$\Delta \mathrm{p} / \mathrm{p}$

solid angle

beam size ( $\mathrm{H} \times \mathrm{V}$ )

beam divergence

beam divergence $(V)$
80 to $310 \mathrm{MeV}$

2\% FWHM

$3.4 \mathrm{msr}$

$8 \times 20 \mathrm{~cm}^{2}$

$<10$ mrad

$100 \mathrm{mrad}$

Spectrometer

a 90 cn focal plane, useful acceptance.
barget to rear focal plane.

vertical $(x-z)$ plane and parallel-to-point in the horizontal $(y-z)$ plane, while the optics of the dipole magnets are point to point in the $x-z$ plane and polnt-to-para1lel in the $y-z$ plane. The channel and spectrometer are vacuum coupled and a pressure of $-10^{-4}$ Torr was malntained during the experiment, A block diagram of the EPICS spectrometer is shown In Fig. TI-2b.

For DCX a sweep magnet, or " $C$ "-magnet, is Installed in front of the spectrometer, and serves to separate $\pi^{+}$from $\pi^{-}$in the scattered beam by $20^{\circ}$, in order to keep the front-chamber count rates below their $11 \mathrm{mit}$ of $10^{6} \mathrm{~Hz}$. This facilitates measurements at angles less than $-18^{\circ}$ Eor DCX. Detalls of the fleld mapping and performance of the sweep magnet have been described by Greene [Gr-81]. When the sweep magnet is Installed, the spectrometer is offset ten centimeters cowards smaller scattering angles with respect to the plvot. This 


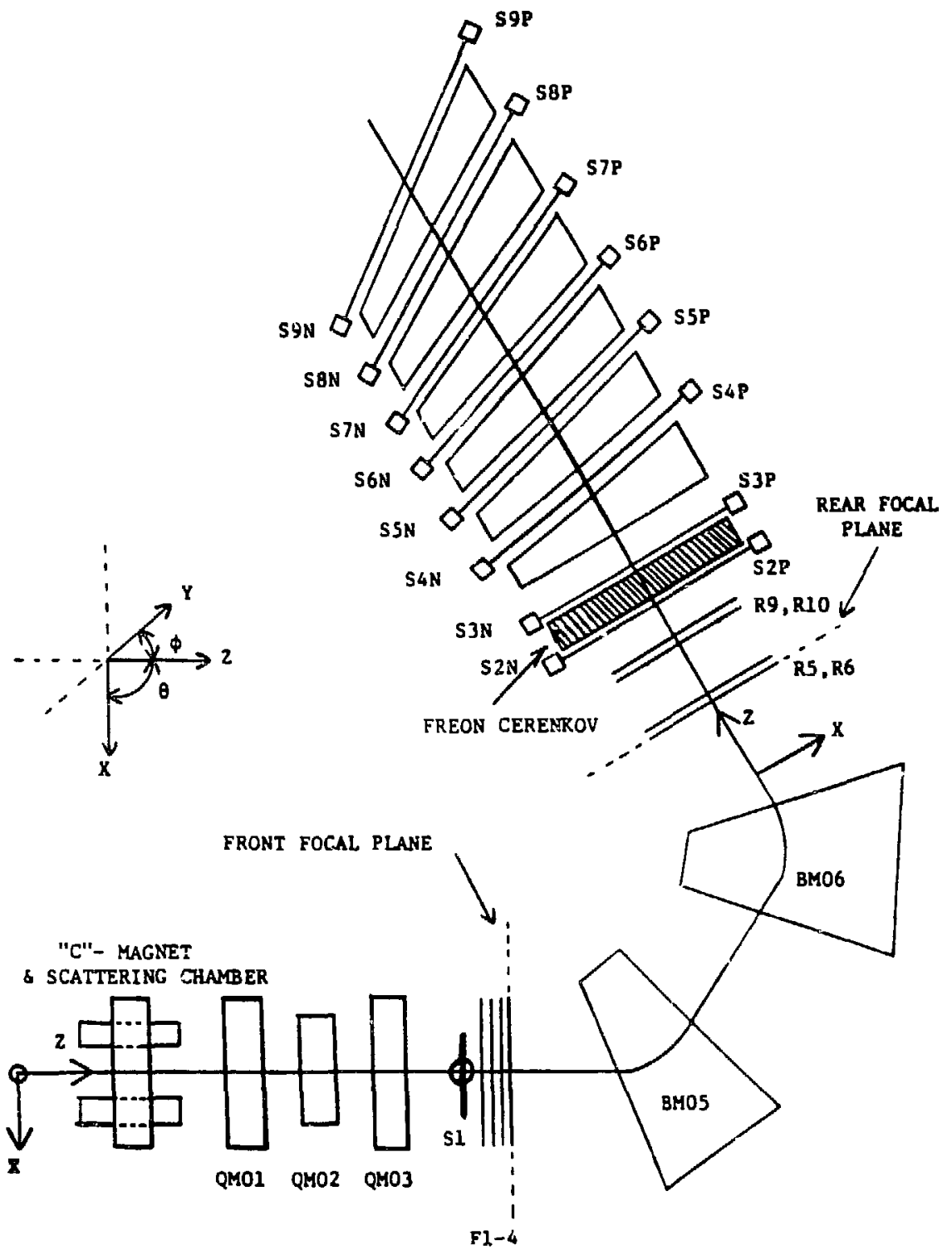

F1g. IJ-2b: Block diagram of the EPICS spectrometer detection system. 
realigne the optic sxis of the spectrometer with the beam exiting from the sweep magnet.

The front detectors consist of four (F1-4) delay-11ne readout drift chambers at the focus of the quadrupoles, and a scintillator (S1) upstream of the front chambers. Each chamber consists of a set of parallel anode and cathode wires in the : and an identical set in the y direction. These four chambers determine the front coordinates: $x_{f}, y_{f}, \theta_{F}(=d x / d z)$, and $\phi_{f}(=d y / d z)$. The design and operaction of the chambers are described in detall by Morris et al. [Mo-82b] and Atencio et al. [At-81]. The drift cell size, or anode (cathode) wire spacing, is $8 \mathrm{~mm}$ in each direction. The anode wires are coupled to a $2.5 \mathrm{~ns} / \mathrm{cm}$ delay $1 \mathrm{ine}$, and alternate fleld-definting cathode wires are bussed together. The outputs are obtained from both ends of the anode delay line and from both bussed cathode lines. Four pairs of chamber planes are used to unamblguously measure the coordinates. Pairs of planes are separated by $0.95 \mathrm{~cm}$, and an aluminized mylar foll connected to the cathode frame provides a ground plane between wire planes.

Two types of information are obtalned from the chamber signals. A time difference from the two ends of the anode delay line,

$$
t_{d}=t_{1}-t_{2},
$$

Is inearly related to anode wire position nearest the position of the Ionizing particle $(x)$. (In practice, a third order polynomial, which accounts for signal dispersion and other non-linearities, is used xar 
position calibrations.) $t_{a}$ determines which wire has fired, and therefore the position to within $\pm 4 \mathrm{~mm}$. The time sum is independent of $x$ and is proportional to the electron drift distance from the lonizing particle to the wire $(20 \mathrm{ng} / \mathrm{mm})$ :

$$
\begin{aligned}
t_{s}= & t_{1}+t_{2}+\text { (signal wire length corrections) } \\
& =2 t_{\text {drift }}+\text { constant. }
\end{aligned}
$$

The remaining ambiguity, the side of the wire on which the pion passed, is determined from the information from adjacent parallel planes, which have thelr wires offset by half a drift cell size, $4 \mathrm{~mm}$. The chambers operate at $+2150 \mathrm{~V}$, with a magic gas mixture of $65 \%$ argon, 35\% 1sobutane, $0.1 \%$ Freon, and $0.5 \%$ 1sopropyl alcohol at atmospheric pressure. The position resolution of these chambers $1 \mathrm{~s}$ $125 \mu \mathrm{m}$ FWHM [Mo-82b].

The S1 scintillator forms part of the good event trigger, and provides time of flight information over the nine meter flight path to the rear scintillators ( 52 and $s 3$ ). The latter information is particularly valuable in $\left(\pi^{ \pm}, \pi^{\mp}\right)$ measurements, where the scattered $\pi^{\mp}$ flux is contaminated by electrons and and muons of similar momenta. Time of flight differences allow efficlent rejection of the electron and some of the muon background. S1, which is a $-150 \mathrm{mg} / \mathrm{cm}^{2}$ thick Pliot B scintillator, contributes roughly $200 \mathrm{keV}$ to missing mass resolution. 
The rear detector system consists of four delay line readout drift chambers (R5-6, R9-10) which determine focal plane positions, $x_{r}, y_{r}, \phi_{r}$, and $\theta_{r}$, in the same manner as the front chambers. Two event defining scintillators ( $S 2$ and $S 3$ ) on elther side of a Freon-12 gas Cherenkov detector are followed by a stack of griphlte blocks and scintillators which are known as the "Muon Refector". S2 and S3, which are separated by $-50 \mathrm{~cm}$, provide time of flight Information and together with SI and the front chambers compose the event trigger:

$$
\begin{aligned}
& \text { EVENT }=S 1 \cdot(S 2 \cdot S 3) \cdot \text { FRONT, } \\
& \text { FRONT }=(F 1 \text { or } F 2) \cdot(F 3 \text { or } F 4) .
\end{aligned}
$$

Electrons passing through the FPICS spectrometer have a velocity $B C$ greater than the Cherenkov threshold velocity in the Freon-12 ges $\left(B_{t}=.999\right)$ of the Cherenkov detector, and thus emlt rierenkov radiation. Plons (and muons), which move too slowly at the same momentum to emit $C^{2}$ renkov radiation, are distingulshed from background electrons.

Many muons may be tagged by the "muon rejector", the design of which [Mo-84] is based on two propertles: At a glvan momentum muons have a $\approx 20 \%$ greater range in matter $\left(-\mathrm{dE} / \mathrm{dX}=1.5 \mathrm{MeV} \cdot \mathrm{cm}^{2} / \mathrm{gm}\right.$ at $300 \mathrm{MeV} / \mathrm{c})$. Also plons are absorbed by nuclear inieractions whlle muons are not. The thickness of graphite before each scintillator is optimized for a particular particle momentum (see Fig. II-2b). For example, most plons of kinetic energy $T_{\pi} \simeq 100 \mathrm{MeV}$ are stopped $1 \mathrm{n}$ the graphlte block before 54 , while muons trigger 54 and can be vetoed. 
s5 through 59 serve the same purpose for plons of kinetlc energies $140,180,220,260$, and $300 \mathrm{MeV}$. Carbon was chosen as the absorbing material because of 1 ts relatively long radiation length (due to 1 ts low 2.), large nuclear cross section (equal for $\pi^{+}$and $\pi^{-}$), and low cost. Four percent of the plons are incorrectly 1dentified when $96 \%$ of the muons are being rejected.

C. Electronics and Data Acquisition

Fast NIM electronics are used to amplify and discriminate mean timed scintillator signals, delay-line readout drift chamber signals, and the gas Cherenkoy counter pulse helght sums. Times and ampiltudes are digitized by $T C^{\prime} s$ and $A D C^{\prime} s$ after which about 55 data words are written directly to magnetic tape and, if sufficlent computer time exists, are analyzed online by the PDP $11 / 45$.

During part of this experlment background electrons (generated partly by the energetic knock-on process, and partly by pair production at the target) were hardware vetoed by discriminating a sum of the Iinear signals from the PMT's of the Cherenkov counter and using the output of an LRS 623 discriminator (threshold $2250 \mathrm{mV}$ ) as the Input to the event trigger sodule. The vetoed electron events were not written to tape and increased the ratio

$$
\frac{\pi+\mu \text { events }}{e^{-} \text {events }}
$$


by a factor of four to five. Remainting electrons were easily eliminated from mlssing mass spectra via a software gate on Cherenkov pulse helght.

A schematic of the EPICS electronics setup is shown in Fig. II-3. The EVENT trigger (Eq. II-3) causes the PDP-11/45 to read and then clear the CAMAC registers. Pertpheral devices attached to the 11/45 were two RK05 disk drives, two Tektronix 4010 terminals, two nine-track 75 LPS $800 / 1600$ BPI Kennedy tape dr1ves, two 40 MB DIVA disk drives and a VERSATEC plotter and printer. A microprogrammable branch driver (MBD) is the Interface between the CAMAC branch highway and the 11/45. The operating system was $\mathrm{RSX}-11 / \mathrm{D}$, and the data acquisition was a modified version of the LAMPF standard data acquisition system, Q.2 [Am-79].

The software was divided into three sections: (1) An ANALYZER calculates coordinates, trajectortes and momenta for each good scattering event that passes a crude particle identification test (PID). Necessazy user input, such as reaction kinematics, was varled by a set of commands and data blocks. (2) The ALLTEST package tests raw data words and data words calculated in the ANALYZER. Tests on single data words are called MICROTESTS and consist of bit pattern tests, limits, and gates. MACROTESTS are logical combinations of MICKOTESTS, namely AND's and OR's. (3) Updating and storing core histograms was handled by the standard LAMPF dispiay package, which, together with DSP -- the user Interface to the display package -- was used to set gates on and display any of the -260 data words in the form of histograms or two dimenslonal scatter plots. 


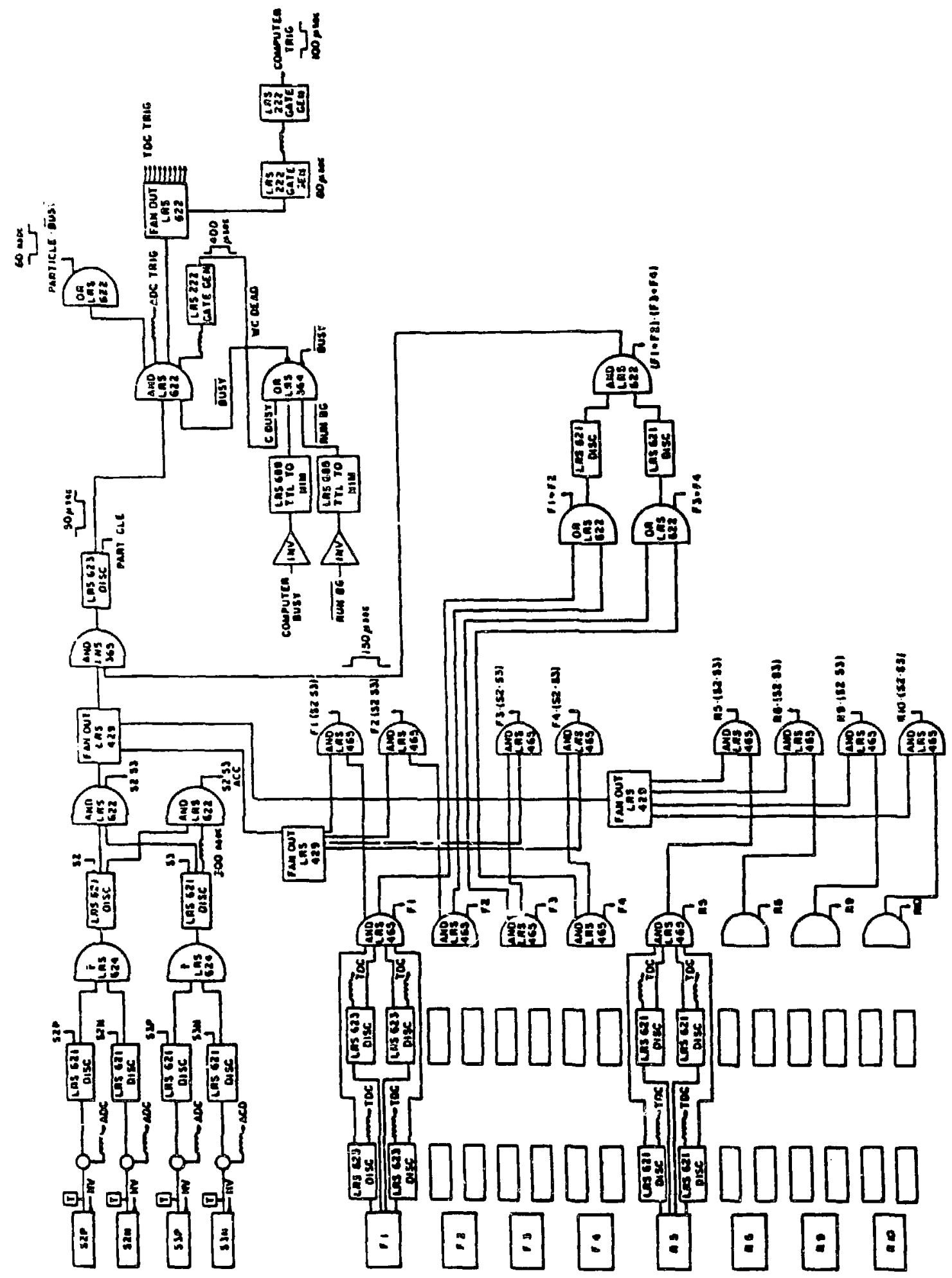

F1g. II-3: Block d1agram of the FPICS electronics setup. 
The ultimate quantity of interest 18 missing mass. Two body relativistlc kinematics are calculated by the CALKIN subroutine of the ANALYZER. For a reaction $m_{1}\left(m_{2}, m_{3}\right) m_{4}\left(m_{1}\right.$ are rest masses) with corresponding momenta and total energles $p_{1}$ and $E_{1}=\sqrt{p_{1}^{2}+m_{1}^{2}}$ we have

$$
\left(Q+m_{4}\right)^{2}+p_{4}^{2}=\left(E_{m}+m_{4}\right)^{2}
$$

$Q$ is the missing mass. Missing energy, $E_{m}$, is calculated from

$$
E_{m}=m_{1}+E_{2}-E_{3}-m_{4}
$$

$E_{2}, m_{1}, m_{2}, m_{3}$, and $m_{4}$ are user Input to the kinematics calculations. $E_{3}$, or $P_{3}$, is determined from the front and rear wire chamber Information, together with the spectrometer magnetic fleld settings.

7. Targets

For the purposes of this and subsequent experiments, new target cells were deslgned and manufactured for the ${ }^{14} \mathrm{C}$. Previously, the -9 gm of ${ }^{14} \mathrm{C}(-40 \mathrm{Cl})$ was contalned $1 \mathrm{n}$ s1x target cells of $3 \mathrm{~mm}$ stalnless steel plcture frame construction with $25 \mu \mathrm{m}$ steel windows. New cells were consrructed of nickel, and the cell walls were $13 \mu \mathrm{m}$ thick, or $11.3 \mathrm{mg} / \mathrm{cm}^{2}$. A schematic of the new cells is shown in Fig. II-4. Nickel was electroplated onto an aluminum mandril of the desired cell size. Then the aluminum was etched out in a bath of sodium hydroxide, leaving the nlckel cells behind. The carbon powder 


\section{"4C Tharget Constrits}
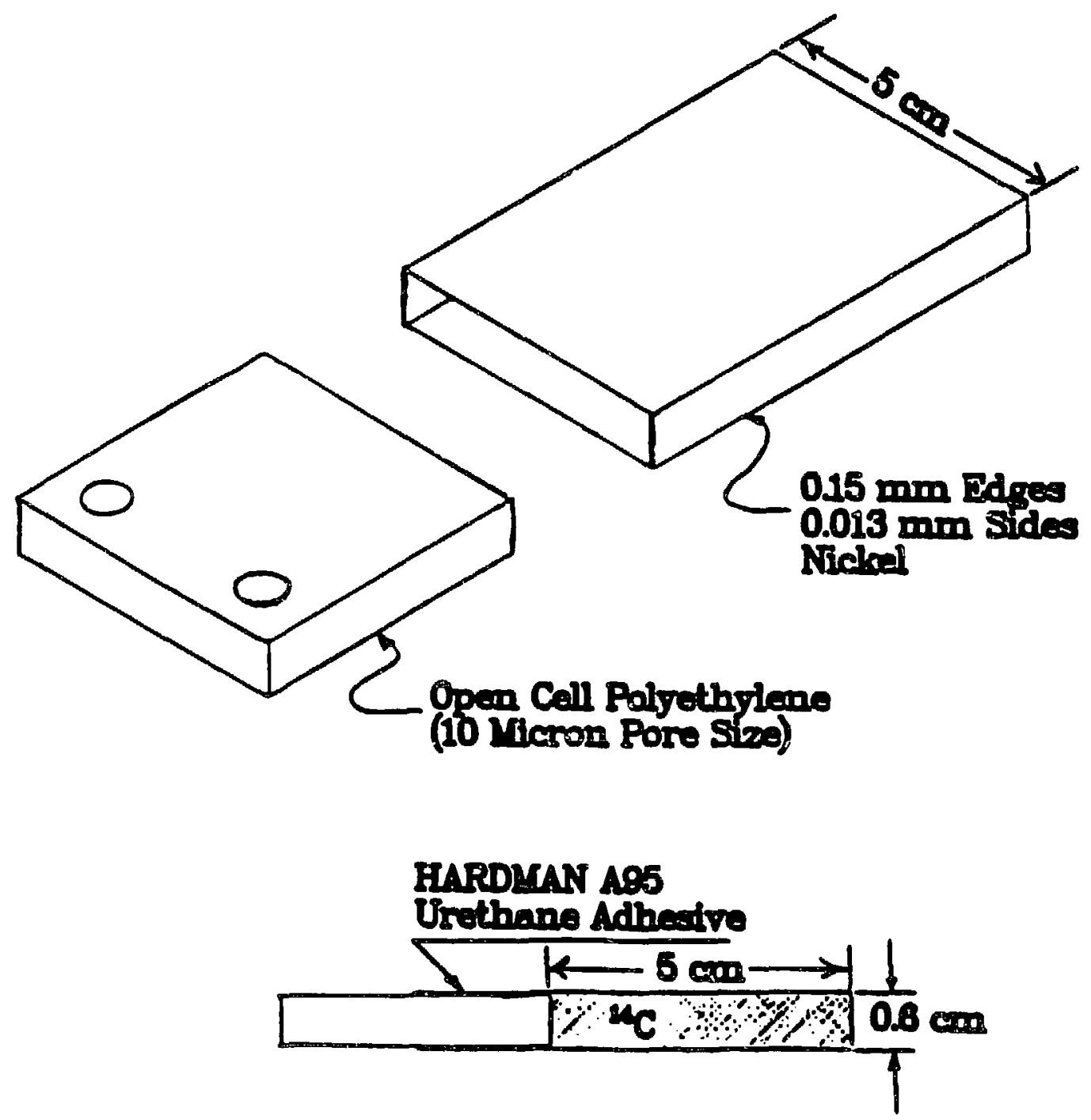

F1g. II-4: New ${ }^{14} \mathrm{C}$ target cell des1gn: 
Table TT-2: ${ }^{14} \mathrm{C}$ target properties. "Impurities" (mostly oxygen and magnesium) constituted $9.0 \pm 3.7 \%$ of the total mass. Oak Ridge National Laboratory measurements of the atom ratio give $n\left({ }^{14} \mathrm{C}\right) / \mathrm{n}\left({ }^{12} \mathrm{C}\right)$ $=4.6 \pm 0.4$.

\begin{tabular}{|c|c|c|c|}
\hline & $\begin{array}{l}\text { Area } \\
\left(\mathrm{cm}^{2}\right)\end{array}$ & $\begin{array}{l}14 \mathrm{C}+12 \mathrm{C}+1 \text { mpurities } \\
\text { (grams) }\end{array}$ & $\begin{array}{l}\rho t(14 \mathrm{C}) \\
\left(\mathrm{mg} / \mathrm{cm}^{2}\right)\end{array}$ \\
\hline $\begin{array}{l}\text { Cell \#1 } \\
\text { Cell \#2 }\end{array}$ & $\begin{array}{l}5.0 \times 5.3 \\
5.0 \times 5.1\end{array}$ & $\begin{array}{l}4.49 \\
4.68\end{array}$ & $\begin{array}{l}130 \pm 6 \\
141 \pm 6\end{array}$ \\
\hline
\end{tabular}

was removed from the six old cells, welghed and packed Into two new cells (see Table II-2). The new cells were sealed with porous polyethylene plugs (10 micron pore size) which allowed the cells to be depressurized safely and rapidly in the EPICS scattering chamber. Vacuum tests showed that the cells could be pumped down to 0.05 Atm In less than thirty seconds and exhibit no evidence of leakage when the outer surface was later swipe tested for contamination. The two new cells, Instead of the old six cells, required fewer software target gates. Also, the ratio

$$
\frac{p t(\text { carbon powder })}{p t(\text { cell walls })}
$$

Increased from 1.8 for the old design to 8.0 for the new cells. This was a great advantage for the $\left(\pi^{+}, \pi^{-}\right)$measurement, (and subsequent $\left(\pi^{-}, \pi^{+}\right)$measurements) where the optimum missing mass resolution did not need to be reallzed ( $\leqslant 120 \mathrm{keV}$ ), but background from the target cells was desired to be at a minimum. 
The 1sotople thickness of the ${ }^{14} \mathrm{C}$ target assumed in this work, $\rho t(14 \mathrm{C})=136 \pm 6 \mathrm{mg} / \mathrm{cm}^{2}$, Is based on the detalled contaminant analysis of Harvey et al. [Ha-84]. Thelr three methods of target 1mpurity analysis give $84.8 \pm 11.9 \%, 75.2 \pm 5.1 \%$ and $76.8 \pm 5.0 \%,{ }^{14} \mathrm{C}$ by weight. As in $[\mathrm{Ha}-84]$, the latter value is used in this work to calculate cross sections. None of the contaminants or nickel cells contributed background to the ground state region of the 140 spectra due to their much more negative $Q$ values (see Table II-3).

Two ${ }^{13} \mathrm{C}$ targets of $90 \%$ 18otoplc purity were used. The thick target $\left(1340 \mathrm{mg} / \mathrm{cm}^{2}\right)$ was used for all of the new measurements reported. The thin target $\left(635 \mathrm{mg} / \mathrm{cm}^{2}\right)$ was included for the measurements at $T_{\pi}=292 \mathrm{MeV}$ and was analyzed separately from the thick target data. The cross sections at $292 \mathrm{MeV}$ are weighted averages of ylelds from the thick and thin targets. Resolutions of

Table II-3: Nuclear g.s. $?$ values for double-charge-exchange reactions occurring in the ${ }^{14} \mathrm{C}$ target (cop $81 \mathrm{x}$ ) and for the ${ }^{13} \mathrm{C}, 26 \mathrm{Mg}$, and $56 \mathrm{Fe}$ targets.

Reaction

Q Value

(MeV)

$$
\begin{aligned}
& { }^{14} \mathrm{C}\left(\pi^{+}, \pi^{-}\right){ }^{14} \mathrm{O} \text { (DIAS) } \\
& 12 \mathrm{C}\left(\pi^{+}, \pi^{-}\right) 12 \mathrm{O} \\
& 16 \mathrm{O}\left(\pi^{+}, \pi^{-}\right) 16 \mathrm{Ne} \\
& 58 \mathrm{N1}\left(\pi^{+}, \pi^{-}, 58 \mathrm{Zn}\right. \\
& 60 \mathrm{N1}\left(\pi^{+}, \pi^{-}, 60 \mathrm{Zn}\right. \\
& 62 \mathrm{N1}\left(\pi^{+}, \pi^{-}\right)^{62} \mathrm{Zn} \\
& 13 \mathrm{C}\left(\pi^{+}, \pi^{-}\right)^{130} \\
& 26 \mathrm{Mg}\left(\pi^{+}, \pi^{-}\right)^{26} \mathrm{SI} \text { (iIAS) } \\
& 56 \mathrm{Fe}\left(\pi^{+}, \pi^{-}\right)^{56} \mathrm{N1}
\end{aligned}
$$$$
-3.96 \% \pm 0.009
$$$$
-31.96 \pm 0.05
$$$$
-28.38 \pm 0.05
$$$$
-16.94 \pm 1.00
$$$$
-9.26 \pm 0.01
$$$$
-5.58 \pm 0.01
$$$$
-18.959 \pm 0.013
$$$$
-8.045 \pm 0.011
$$$$
-5.679 \pm 0.014
$$ 
mlsolng mass spectra for the thick and thin targets are 0.9 and 0.5 Mev, respectively.

A sumary of the ${ }^{13} \mathrm{C},{ }^{26} \mathrm{Mg},{ }^{56} \mathrm{Fe}$, and ${ }^{1} \mathrm{H}$ target properties 18 given in Table II-4, and a schematic of the arrangement of these targets in the scattering chamber is shown in Fig. II-5. Table :..I-3 shows that the $Q$ values for the ${ }^{13} \mathrm{C},{ }^{26} \mathrm{G}$ : and ${ }^{56} \mathrm{Fe}$ DCX reactions allowed all of the states of interest for a given target configuration to be measured simultaneously, consistent with the useful acceptance range of the spectrometer. It should be noted that these new ${ }^{14} \mathrm{C}\left(\pi^{+}, \pi^{-}\right)^{14} 0$ measurements are also reported in [Se-84], where $\rho t(14 \mathrm{C})$ $=144 \mathrm{ng} / \mathrm{cm}^{2}$ was assumed. Thus the ${ }^{14} \mathrm{C}\left(\pi^{+}, \pi^{-}\right)^{14} 0$ cross sections quoted in this dissertation are 6\% larger than those in [Se-84].

Table II-4: ${ }^{13} \mathrm{C},{ }^{26} \mathrm{Mg},{ }^{56} \mathrm{Fe}$, and ${ }^{1} \mathrm{H}$ target properties.

\begin{tabular}{|c|c|c|c|c|}
\hline $\begin{array}{l}\text { Target } \\
\text { Isotope }\end{array}$ & $\begin{array}{l}\text { Chemical } \\
\text { Composition }\end{array}$ & $\begin{array}{l}\text { Isotopic } \\
\text { Purity } \\
(\%)\end{array}$ & $\begin{array}{l}\text { Isotoplc } \\
\text { Th1ckness } \\
\left(g n / c \pi^{2}\right)\end{array}$ & $\begin{array}{l}\text { Dimens Ions } \\
(\mathrm{cm})\end{array}$ \\
\hline${ }^{13} \mathrm{C}$ & C & 90 & $\begin{array}{l}1.340 \\
0.635\end{array}$ & $\begin{array}{l}9.2 \times 10.0^{a} \\
10.2 \times 11.3^{b}\end{array}$ \\
\hline $\begin{array}{l}26 \mathrm{Mg} \\
56 \mathrm{Fe}\end{array}$ & $\begin{array}{l}\mathrm{Mg} \\
\text { carbon steel }\end{array}$ & $\begin{array}{l}100 \\
90.1\end{array}$ & $\begin{array}{l}0.815 \\
2.07\end{array}$ & $\begin{array}{l}7.5 \times 8.0 \\
5.8 \times 12.7^{c} \\
9 . \times 12.7^{d}\end{array}$ \\
\hline${ }^{1} \mathrm{H}$ & $\mathrm{CH}_{2}$ & -- & 0.0105 & $10 . \times 20$ \\
\hline
\end{tabular}

a Configuration $a$ and $c$ of $F 1 g$. II-5.

b Configuration $c$ (top) of Fig. II -5 .

c Top of configuration b of Fig. II-5.

d Bottom of configuration b of $\mathrm{FIg}$. II -5 , 

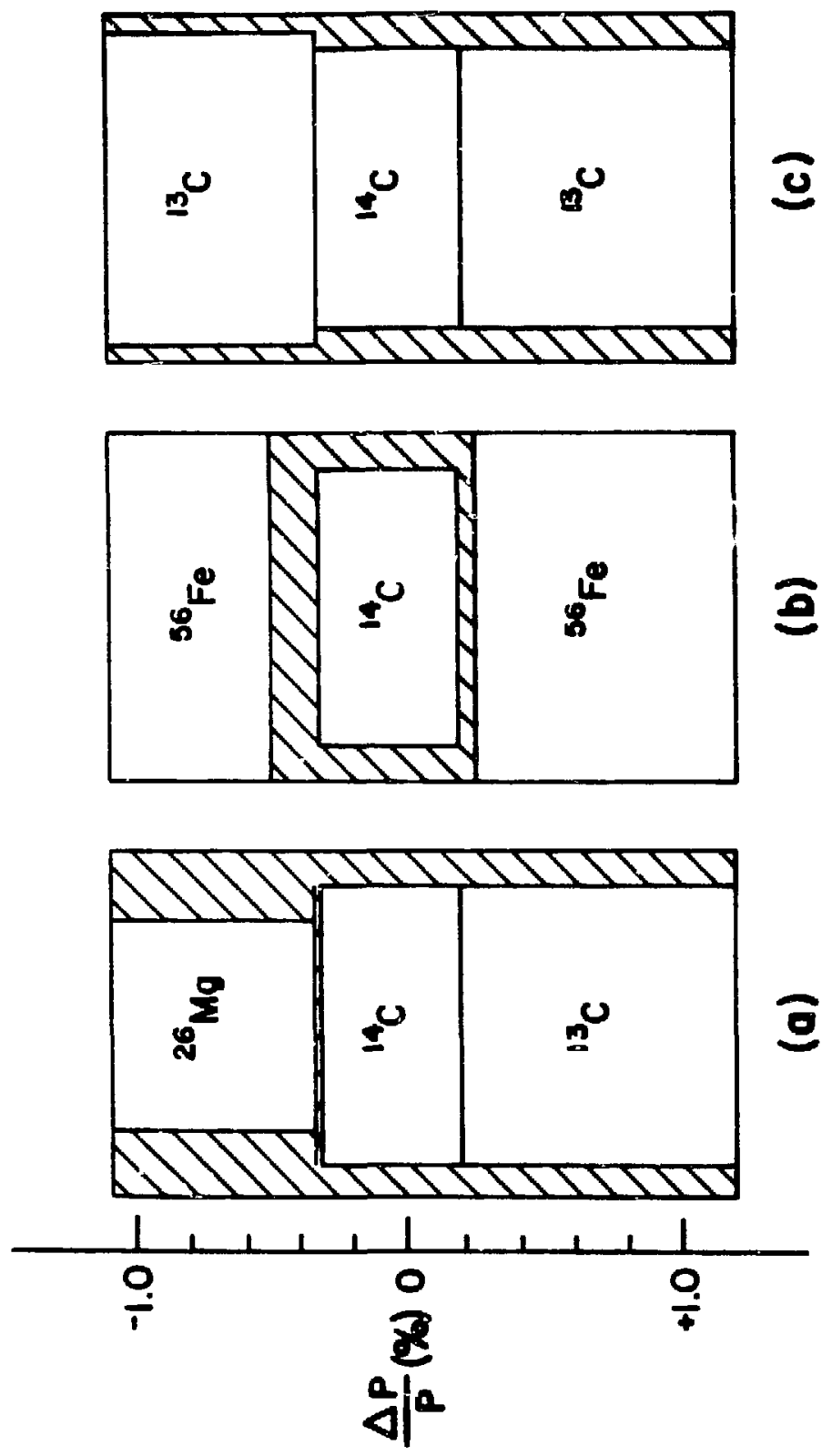

F1g. II-5. Schematic of the target arrangement in the EPICS momentum dispersed pion beam. 
III. DATA REDUCTION

Gates on the data words $x_{t g t}$, $y_{t g t}$, $\phi_{t g}$, and $\theta_{t g t}$, the target coordinates, provide some of the background refection. An $x_{\text {tgt }}$ histogram is shown In FIg. III-1, where background electrons have not been refected from the histogram, and make up $-80 \%$ of the counts. Due to the differing $Z$ and areal densities of the ${ }^{13} \mathrm{C},{ }^{14} \mathrm{C}$ (including nickel cells), and ${ }^{26} \mathrm{Mg}$ cargets, the edges of the targets are well deflned. Gates were placed on each of the three targets, and thelr corresponding missing mass spectra were separately histogrammed.

In order to eliminate events that scattered from the spectroneter beam pipe, gates were placed on calculated radil at two potnts between the spectrometer entrance and the front chambers. These "flange cuts" refected less than 27 of the events.

Muons passing through the focal plane arise from elther inflight decay of plons in the spectrometer or elastic scattering of Incldent beam muons. Most muon events corresponding to plon decays between the front and rear chambers are vetoed by gating the data words $\theta_{\mathrm{ch}}$ and $\phi_{\mathrm{ch}} \cdot{ }^{\theta}{ }_{\mathrm{ch}}\left(\phi_{\mathrm{ch}}\right)$ is calculated from an empirically determined polynomlal [Bo-79] with dependent varlables $x_{f}, \theta_{f}$, and $\delta_{s p}$ $\left(y_{f}, \phi_{f}\right.$, and $\left.\delta_{s p}\right)$. The polynomial represents the difference between th: rear angle $\theta_{r}\left(\phi_{r}\right)$ and a calculated rear angle based on $\theta_{f}$ and $x_{f}$ $\left(\phi_{f}\right.$ and $y_{f}$ ) front chamber measurements. Good plon events have $\theta_{c h}$ and 


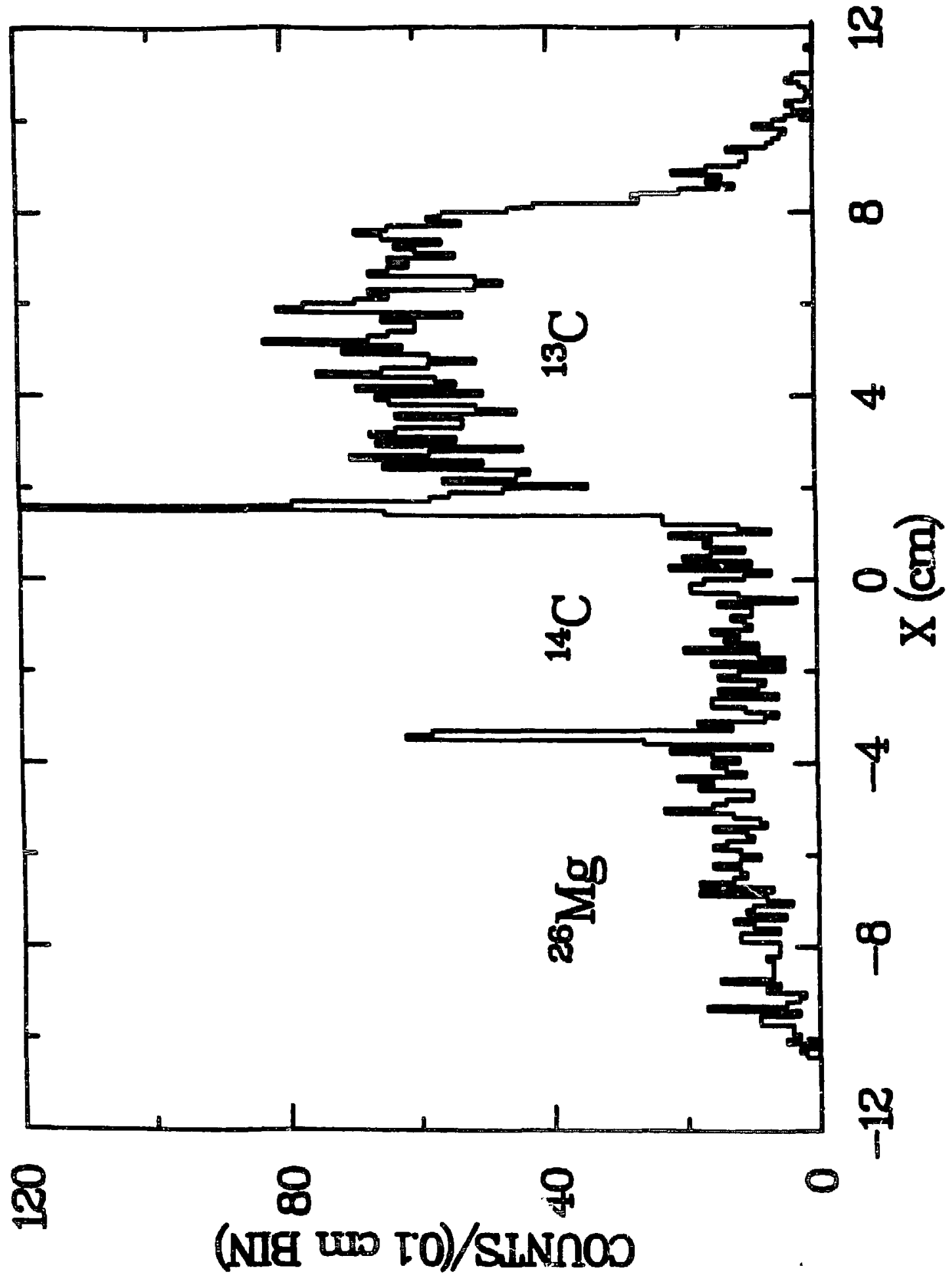

F1g. III-1: Histogram of $x_{\mathrm{tg}} \cdot{ }^{26} \mathrm{Mg},{ }^{14} \mathrm{C}$, and ${ }^{13} \mathrm{C}$ are the targets, from left to right. 
\$ch distributions no wlder than $20 \mathrm{mrad}$, whlle the $\pi+u+v$ decay cone has an opening angle of $-550 \mathrm{mrad}$ at $T_{\pi}=120 \mathrm{MeV}$ and $-230 \mathrm{mrad}$ at $T_{\pi}=292 \mathrm{MeV}$. Thus, events falling outslde the 20 mrad gate are assumed to be muon eventa, and at least $95 \%$ of muon events are rejected in this fashion.

The $9 \mathrm{~m}$ flight path between $\mathrm{Sl}$ and (S2.S3) provides a complimentary method to the muon rejector for rejecting scattered beam muons. Fig, III-2 shows that muons are wel! separated in time from plons at lower energles. The fact that they are less well resolved at higher energles is compensated for by thelr relatively lower fraction of scattered beam composition [Se-81].

Inttial particle 1dentification (PID) was obtained from the $S 2$ ro S3 time of flight and the geometrical mean of the S2 and $\mathrm{S} 3$ pulse helghts. EVENTS were required to pass gates on both worda simultaneously (BOX test). If a trigger did not pass the PID test the analyzer was interrupted and proceeded to process the next event. Th1s BoX test, shown in F1g. III-3, was unable to distingulsh background electrons and muons from plons. Much remaining background was rejected by placing a BOX test on the data words: "Corrected S1 Time of Flight" (CTOF) and "Cherenkov Pulse Helght Sum" (CPH). CTOF 1s the s1 to (S..S3) time of flight, corrected for path length differences of different particle trajectorles. A dot plot of these two data words is shown in F1g. III-4. Electrons with non-zero CPH are distinguished from the much more massive plons and muons aiong the vertical axis. Some muons with shorter Sl times of flight than plons 


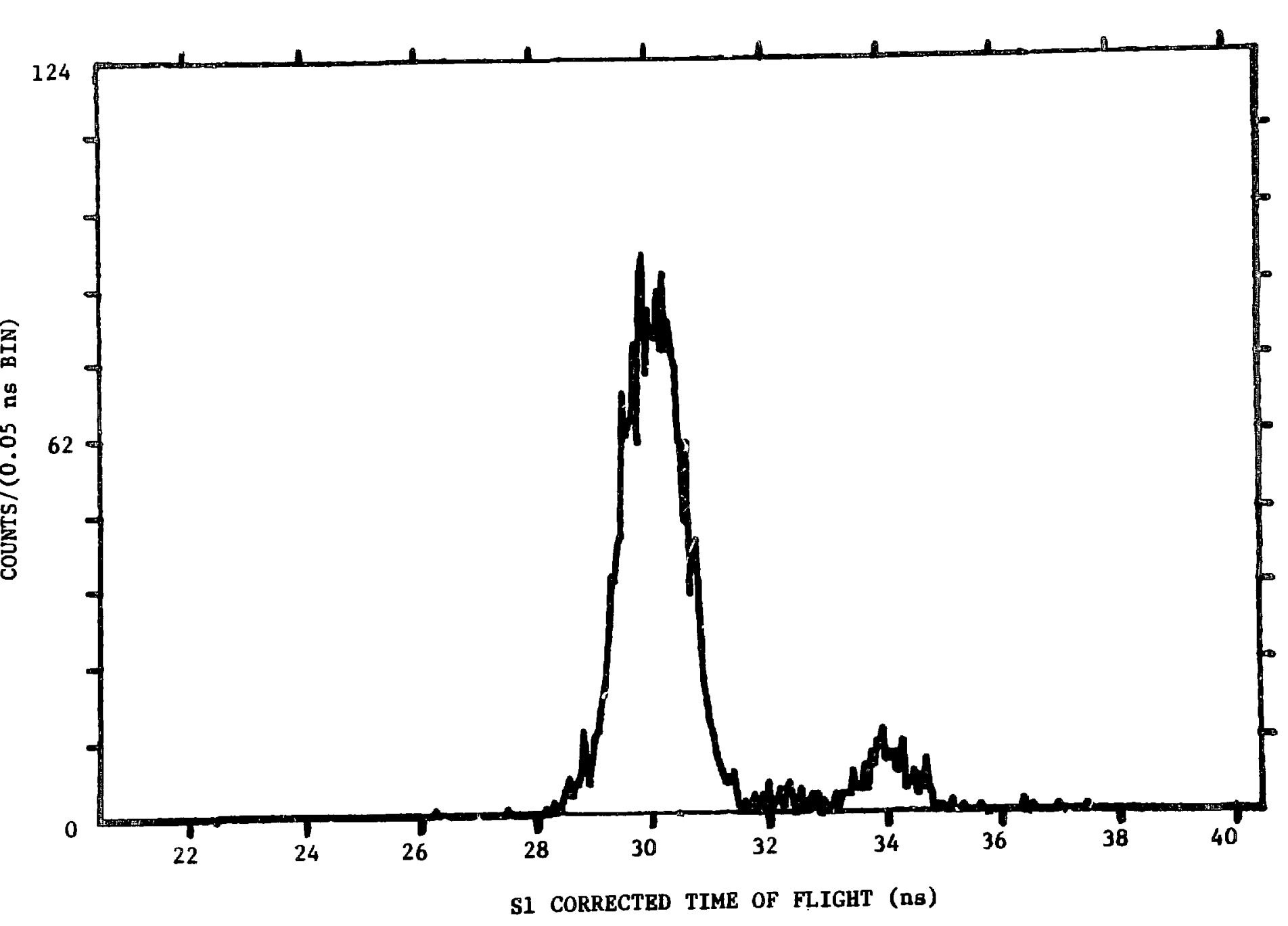




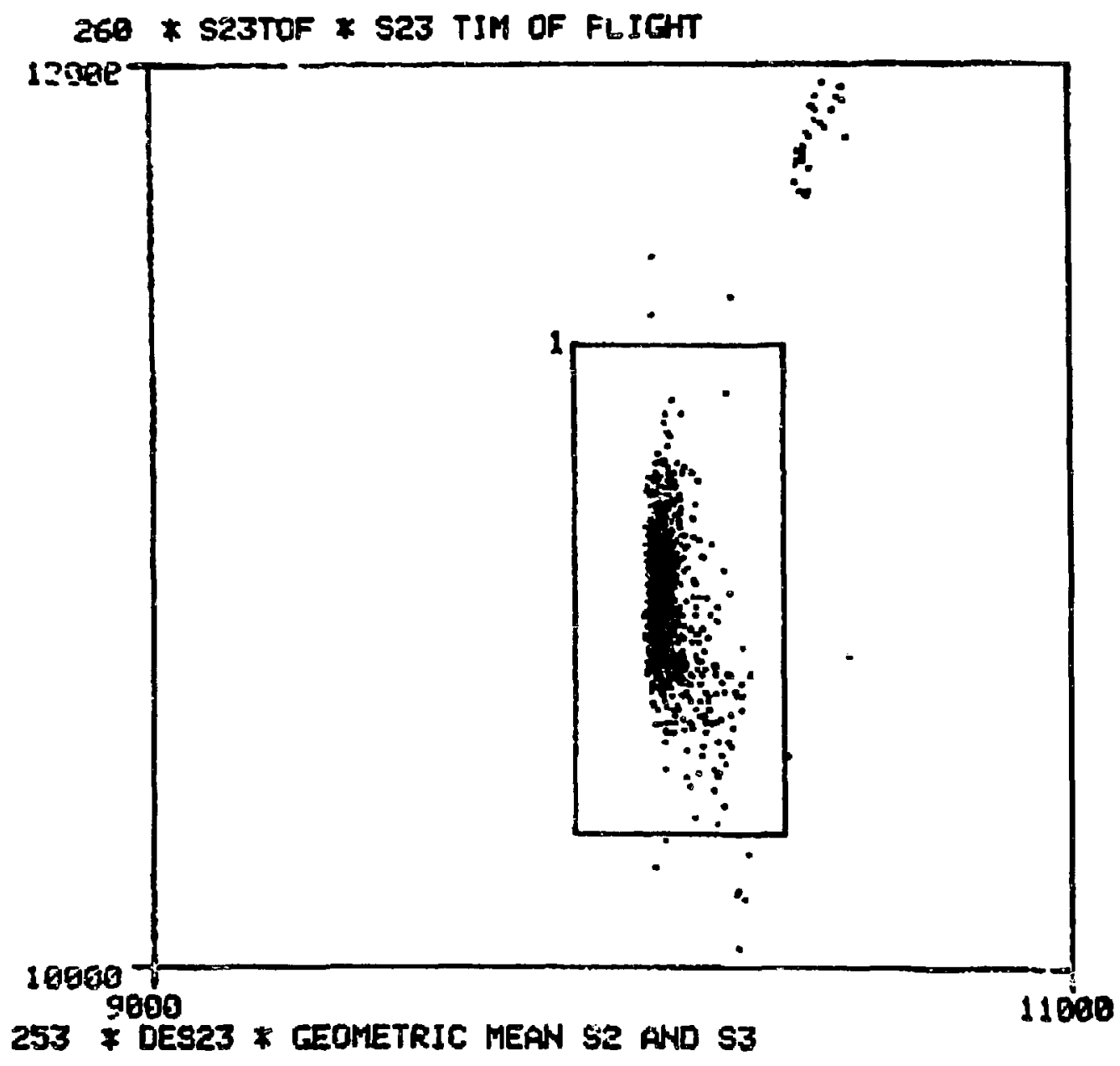

F18. III-3: 52 to S3 time of flight vergus the geometrlc mean of the 52 and 53 pulse heights for $1_{H}\left(\pi^{+}, T^{+}\right)$at $T_{\pi}=292 \mathrm{MeV}$. 


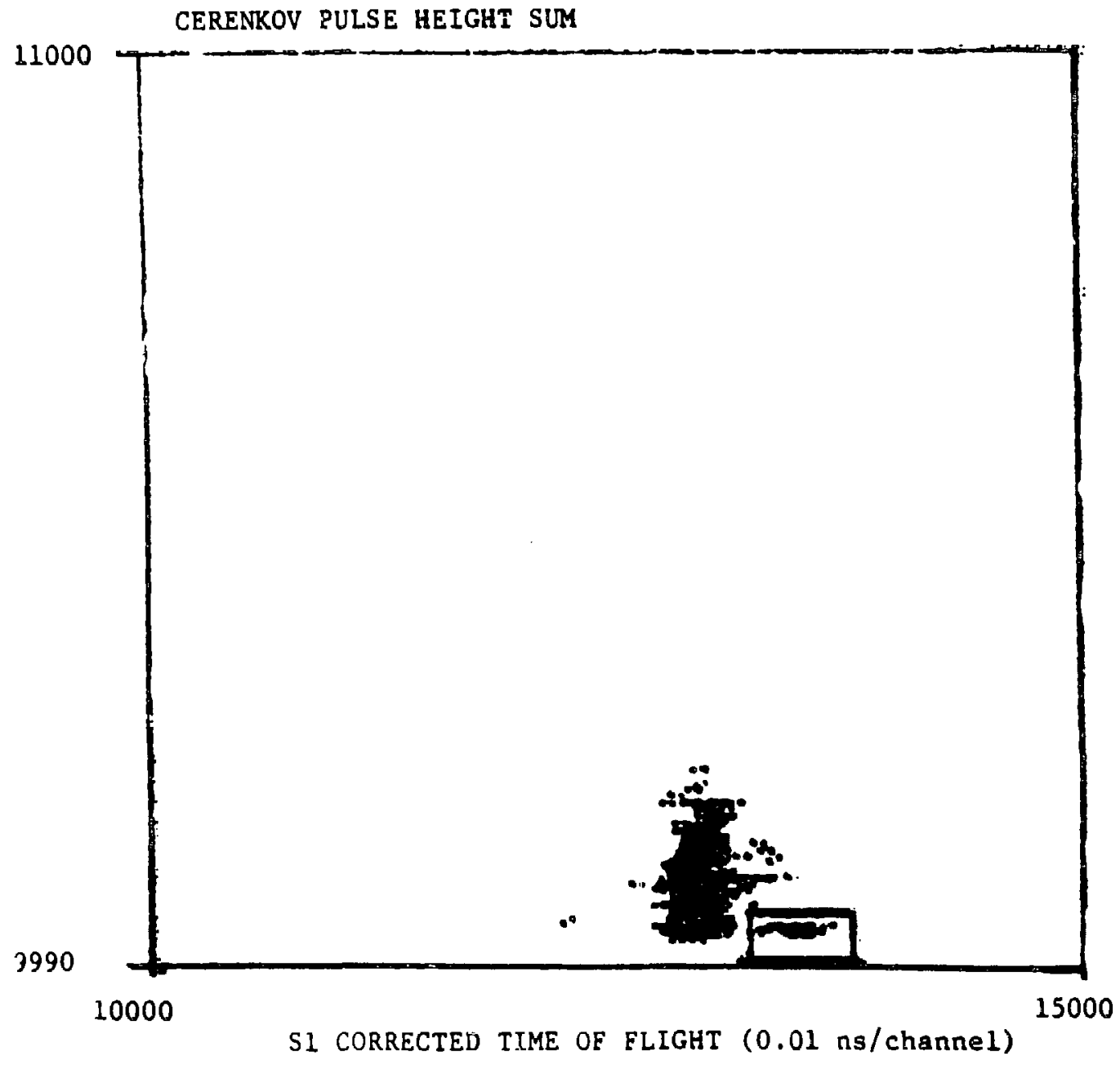

F1g. III-4: Cherenkov Pulse Helght Sum versug S1 Corrected Time of Flight. Electrons with large pulse helght sums were hardware refected. 
were Included in the BOX, but were refected by a gate in the CTOF spectrum (F1g. III-2).

The fractional deviation of plon momentum from the momentum of the central trafectory through the spectrometer $1 \mathrm{~s}$ denoted $\delta_{8 p}$ "

$$
\delta_{s p}=\frac{p_{\pi}-P_{s p}}{P_{s p}} .
$$

The varying spectrometer acceptance as a function of scattered particle momentum is measured by the yield as a function of $\delta_{s p}$. This Is done by varying the spectrometer magnet settings, and effectively moving the peak of $: \because\left(\pi^{+}, \pi^{+}\right)^{l} \mathrm{H}$ across the focal plane of the spectrometer. The resulting acceptance scans are shown in Fig. III-5. Because strip target configurations were used, and the acceptance of the spectrometer varies as a function of $x_{\text {tgt }}$, the acceptance had to be determined for each of the three different DCX target positione. Target configurations in the incident beam are shown in Fig. II-5.

Missing mass spectra for ${ }^{13} \mathrm{C},{ }^{14} \mathrm{C},{ }^{26} \mathrm{Mg}$ are shown in Fig. III-6. The peaks for the DIAS are well separated in energy from the other low-lying states of the residual nucle1. An Indication of the efficlency of background rejection is evidenced by the near absence of counts between the $14 \mathrm{O}(\mathrm{gs})$ and the first exclted state at $5.17 \mathrm{MeV}$ $\left(\mathrm{J}^{\pi}=\mathrm{1}^{-}\right)$. The background in this region is on the order of 30 $\mathrm{nb} / \mathrm{sr} / \mathrm{MeV}$, while the cross section for the transition to the ground state $1 \mathrm{~s} \sim 1 \mu \mathrm{b} / \mathrm{sr}$. The energies of the excited $0^{+}, 3^{-}$, and $2^{+}$states of 140 are $5.92 \mathrm{MeV}, 6.27 \mathrm{MeV}$, and $6.59 \mathrm{MeV}$ respectively (see F1g. 


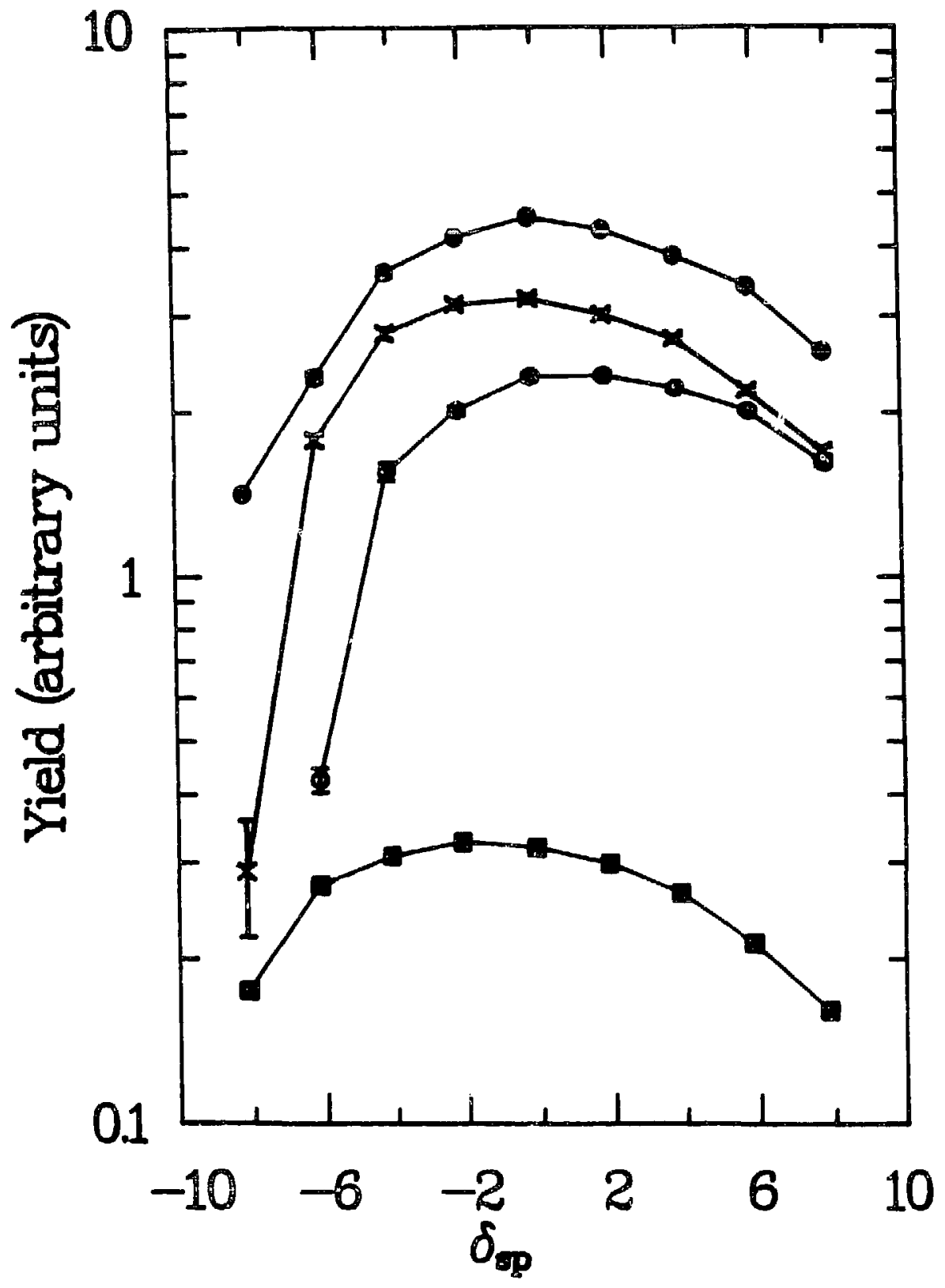

F1g. III-5: Spectrometer acceptance for $56 \mathrm{Fe}$ (solid circles), ${ }^{14 \mathrm{C}}$ (crosses), ${ }^{26} \mathrm{Mg}$ (open c1rcles), and ${ }^{13} \mathrm{C}$ (squeres). Ylelds were measured for ${ }^{1} \mathrm{H}\left(\pi^{+}, \pi^{+}\right)^{1} \mathrm{H}$ at $\theta=40^{\circ}$ and $\mathrm{T}_{\pi}=164 \mathrm{MeV}$ with a $\mathrm{CH}_{2}$ target of areal density $152 \mathrm{mg} / \mathrm{cm}^{2}$. 


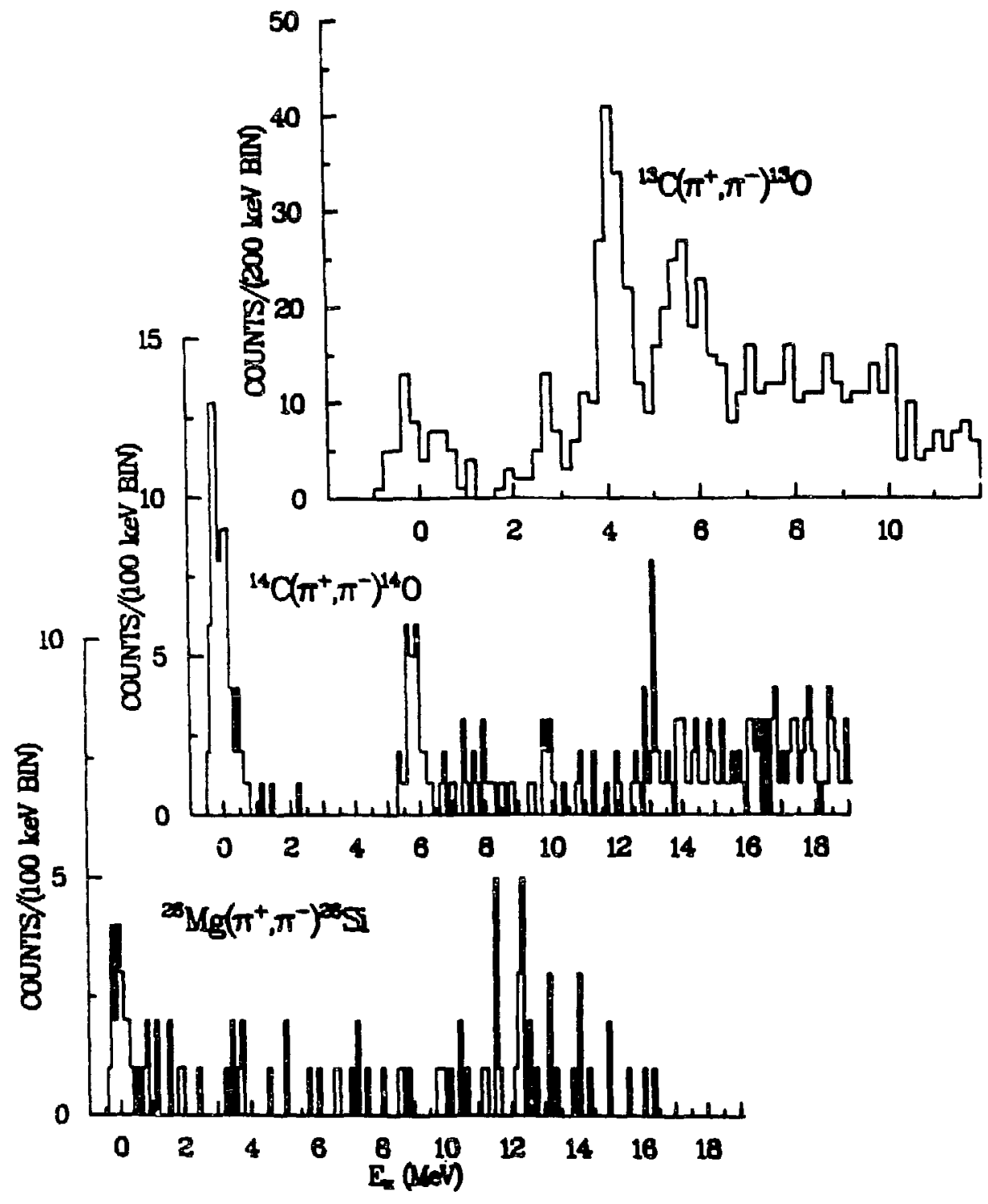

F1g. III- 6: Missing mass spectra for $\left.{ }^{13} \mathrm{C},{ }^{14} \mathrm{C},{ }^{26} \mathrm{Mg}\left(\pi^{+}, \pi^{-}\right)\right)^{13} 0,1^{14} 0,{ }^{26} \mathrm{SI}$ at $\mathrm{T}_{\pi}=164 \mathrm{MeV}, \theta=5^{\circ}$. 
III-8). The FWHM energy resolution for the spectrum $1 \mathrm{~s} 400-500 \mathrm{keV}$, making reliable extraction of cross sections difflcult for these states. The regions to the left of the ground states of ${ }^{56} \mathrm{N1},{ }^{26} \mathrm{St}$, and ${ }^{13} 0$ show $11 t$ te or no evidence of DCX counts originating from targets of more positive $Q$ value, lending credence to the ability to resolve target boundaries well in the $\pi_{\text {tgt }}$ epectra.

The number of counts in the peaks were determined by using the PEKFIT rout1ne $[S 1-76]$. For the transitions to the ground states of $130,{ }^{14} \mathrm{O},{ }^{26} \mathrm{Mg}$, and ${ }^{56} \mathrm{N1}$ the determination of the peaik areas was stralghtforward: Based on the peak-free reglons to the left and right of the ground states, the number of background counts was egtimated and was subtracted from the total number of counts in the peak region. The same method was employed for the $\left.{ }^{14} \mathrm{O}_{\left(0_{2}^{+}\right.}, 5.92 \mathrm{MeV}\right)$ state, but the fits were hampered by the unresolved $6.27 \mathrm{MeV}, 3^{-}$state. For the fits to the ${ }^{56} \mathrm{NI}(\mathrm{T}=2,9.6 \mathrm{MeV})$ state, (spectra are shown in F1g. III-7), a region of exctitation energy was fit with a constant background. The position and width ( $0.56 \mathrm{MeV}$ FWHM) of the peak were determined from a sum of the excitation function data.

The differential cross section is related to the peak area by:

$$
\begin{aligned}
& \frac{d \sigma}{d \Omega}=\frac{\text { peak area } \times A}{\rho t \times N_{0} \times(I \Delta \Omega)} \times \frac{1}{E F F} \times \frac{1}{\cos \theta t g t} . \\
& A=\text { mass number of target nucleus. } \\
& \rho t=\text { areal dens1ty of target. } \\
& N_{0}=6.02 \times 10^{23} \text { nucleons } / g r a m .
\end{aligned}
$$




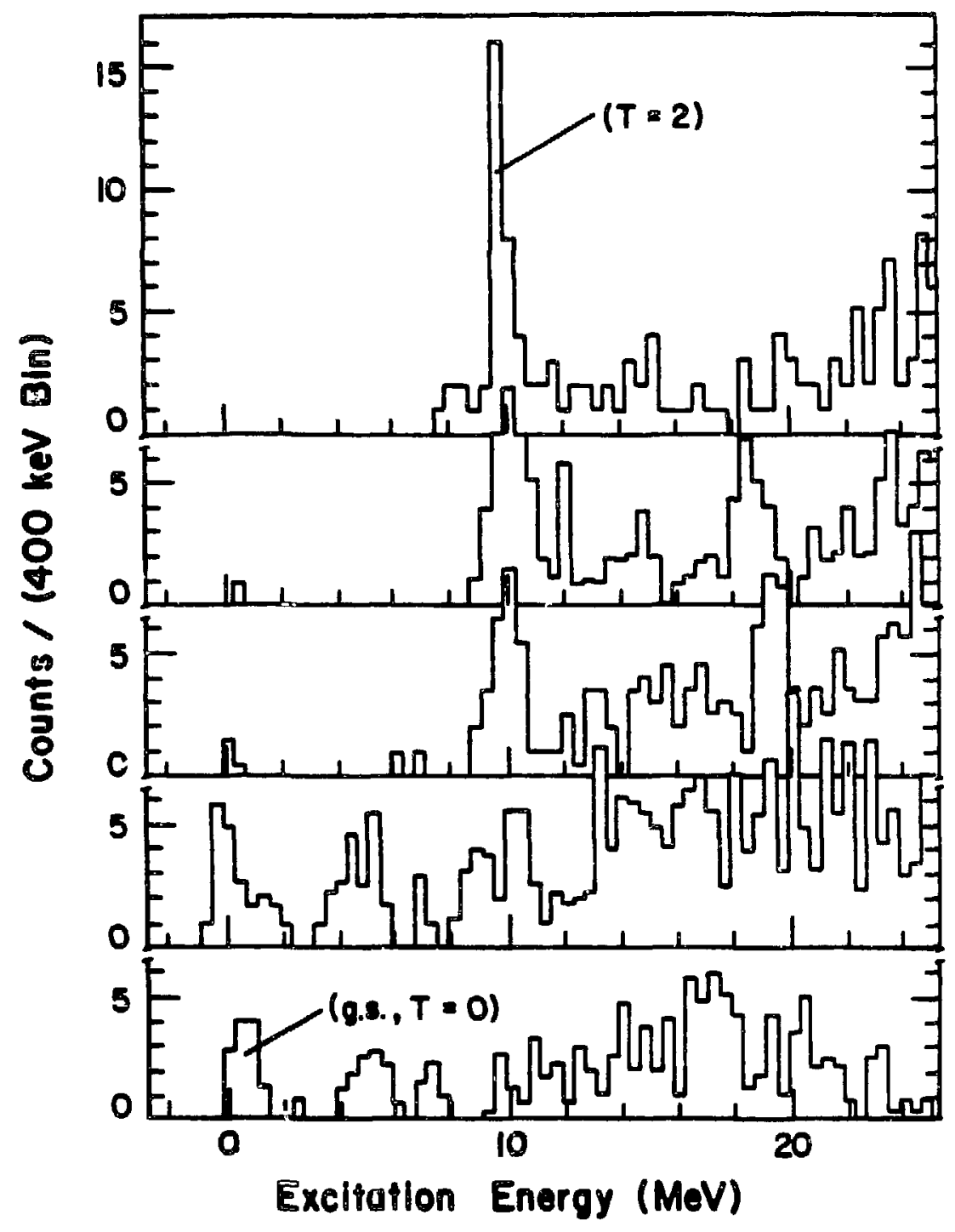

F1g. III-7: Comparison of spectra for the ${ }^{56} \mathrm{Fe}\left(\pi^{+}, \pi^{-}\right)^{56} \mathrm{N1}$ reaction at $T_{\pi}=140,164,220,260,292 \mathrm{MeV}$ (from bottom to top). 

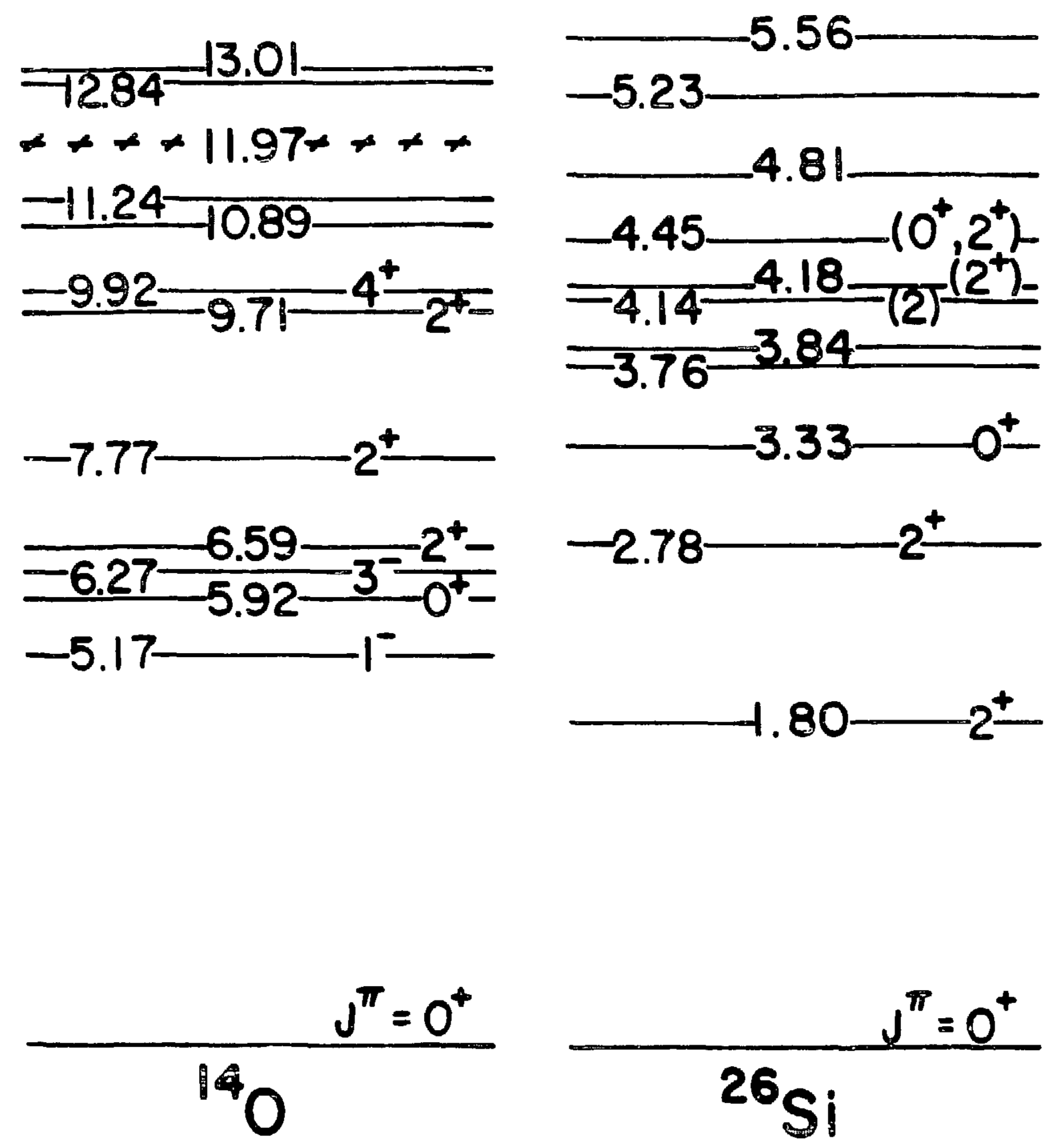


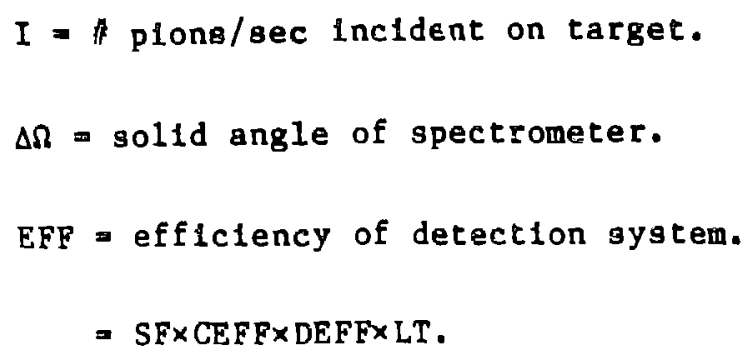

I is proportional to lAC:O2 (and BOT), and $\Delta \Omega$ ( $\approx 10 \mathrm{mgr}$ ) is not absolutely known. Thus, norialization runs were done to callbrate

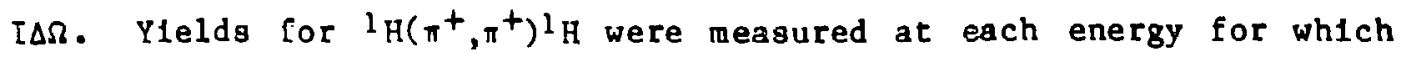
data were taken $\left(\theta=50^{\circ}\right)$ with a full sized $(10 \mathrm{~cm} \times 20 \mathrm{~cm}) \mathrm{CH}_{2}$ target of areal density $73.5 \mathrm{mg} / \mathrm{cm}^{2}$. Ttgt gates consigtent with those placed on the DCX targets were used to determine the $\pi-p$ ylelds for each of the target postions in the incldent beam.

For the ${ }^{14} \mathrm{C}, 26 \mathrm{Mg}, 56 \mathrm{Fe}\left(\pi^{+}, \pi^{-}\right)$data absolute norralization Factors were determined by comparing these ylelds to cross sectloris calculated from the $\pi-p$ phase-shift fits of Rowe, Salomon and Landau (RSL) [Ro-78, Bu-n.d.]. Normallzation factors for the ${ }^{13} \mathrm{C}\left(\pi^{+}, \pi^{-}\right)$ contaln $\pi-p$ cross sections calculated from the phase shift analysis of Carter, Bugg, and Carter (CBC) [Ca-73, Wa-79], wh1ch differed from RSL cross sections by $41 \%$, except for $T_{\pi}=120 \mathrm{MeV}$, where $\sigma_{H}$ calculated from RSL was $4 \%$ higher than that calculated from CBC. The cross section is then expressed as:

$$
\frac{d \sigma}{d \Omega}=\frac{2}{14} \times \frac{y 1 e l d(D C X) \times A(D C X)}{\rho t(D C X)} \times \frac{\sigma_{H} \times \rho t\left(C H_{2}\right)}{y 1 e l d(K)} \times G
$$




$$
\text { yield }=\frac{\text { peak areax } \cos \theta \mathrm{tg} t}{\text { BFPX IACH02 } 2 \times 0 \text { DEGA }}
$$

DOMEGA is the relative yleld as a function of $8 \mathrm{sp}$, and ts obtainet from the acceptance scans (FIg. III-5). $\theta_{\text {tgt }}$, the angle subtended by the Incident beam and a line norwal to the target; $1930^{\circ}$ less than

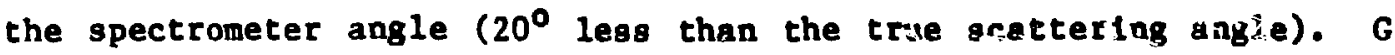
Is the lab to center-of-mass frame jacoblan. All of the new and previously measured cross sections in this work are in the center-ofmass frame. The errors quoted for the cross sections (tabulated in Appendix A) Include only the statiatical uncertainty of the DCX sind ${ }^{1} \mathrm{H}\left(\pi^{+}, \pi^{+}\right)$peak a reas.

The survival fraction, SF, corrects for flons that decay between the target and the focal plane of the spectrometer. Th1s is given by:

$$
\begin{array}{ll}
S F=\exp \left(-\mathrm{m}_{\pi} \mathrm{D} / \mathrm{p}_{\pi} c \tau_{0}\right), & \text { where } \\
c \tau_{0}=7.804 \text { meters } & \mathrm{p}_{\pi}=\mathrm{plon} \text { momentum } \\
\mathrm{w}_{\pi}=\text { plon rest mass } & \mathrm{D}=12.28-0.035 \delta_{\mathrm{sp}} \text { meters (f11ght path). }
\end{array}
$$

The chamber efficiency is a product of the efficiencles of the elght anode and elght cathode wire planes:

$$
\text { CEFF }=\prod_{1=1}^{N} \frac{\text { All. OR }}{\text { AlI but } 1 \text { DR }} \approx 0.95
$$


The drift efficlency, DEFF $(\approx 0.8)$, is the ratio of events which do not pass drift time differences tests between adjacent palred planes (1.e., calculated trajectories are required to agree with all of the chamber positions to within $1.6 \mathrm{ma}$ ), but register good signals $1 \mathrm{n}$ all wire planes. The computer IIve-tIme, LT (s 1.0 in DCX experiments),

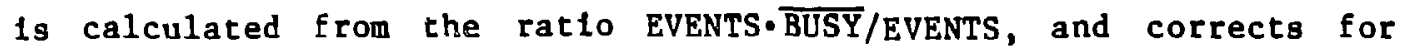
trigger events occurring while the $11 / 45$ was reading from CAMAC and wrlting to tape a previous event.

There are systematic uncertalnties associated with the extraction of these cross sections. DCX target thlcknesses (Including Impuritles), $\rho t(D C X)$, are known to within $2 \%$, whlle the $\mathrm{CH}_{2}$ target thickness $1 \mathrm{~s}$ known to $0.6 \%$. The 1sotoplc purfty for each of the ${ }^{13} \mathrm{C}$, ${ }^{26} \mathrm{Mg}$, and ${ }^{56} \mathrm{Fe}$ targets is known to w1th1n $1 \%$, while the ${ }^{14} \mathrm{C}$ target lsotoplc purity has an uncertainty of $6 \%$ [Ha-84]. The uncertalnty in the calculation of the $\pi-p$ cross sections from the programs CRoss [Bu-n.d.] or SCATPI [Wa-79] 1s 3\%. CEFF, beam monitoring, DOMEGA, and SF have respective uncertaintles of $3 \%, 3 \%, 2 \%$, and $3 \%$. The uncertainty in the placement of target gates in the $x_{\text {tgt }}$ spectza for DCX and $1 \mathrm{H}\left(\pi^{+}, \pi^{-}\right)$is $\pm 4 \%$. The sum of all of these effects in quadrature gives an overall systematic uncertalnty in the data of $4 \pm 10 \%$.

A weld between the sweep magnet and the scattering chamber, which helps malntain the alignment between the scartering chamber, sweep magnet and spectrometer, was discovered broken at the end of the experiment. This resulted $1 \mathrm{n}$ a $-1 \mathrm{~cm}$ scatterlng chamber misalignment Iri the horlzontal plane. Comparisons of $\pi^{+}-p$ yleljs measured at 
different times during the experiment indicate that this could have had a $\pm 5 \%$ effect on the DCX cross sections. However, the time at which the weld broke 18 not known, and could not be Inferred from any of the histogrammed coordinates. Therefore, no corrections have been made to any subset of the data to account for the posstble 108 of flux arlsing from the misalignment.

In addition to the $\theta=5^{\circ}$ overlap polnt, $26 \mathrm{Mg}\left(\pi^{+}, \pi^{-}\right)^{26} \mathrm{SI}$ (DIAS) at $T_{\pi}=120 \mathrm{MeV}$, which agrees well with the result of Greene [Gr-81] (see F1g. IV-1), another normalization check was measured by G1lman et al. In September 1983 [G1-83]. Thelr determination of the ${ }^{14} \mathrm{C}\left(\pi^{+}, \pi^{-}\right)^{14} \mathrm{O}$ (DIAS), $\mathrm{T}_{\pi}=292 \mathrm{MeV}$ cross section of $\mathrm{d} \sigma / \mathrm{d} \Omega=4.62 \pm 0.54$ $\mu b / s r$ is in good agreement with with the cross section reported here, $\mathrm{d} \sigma / \mathrm{d} \Omega=4.51 \pm 0.59 \mu \mathrm{b} / \mathrm{sr}$. Good agreement was found for the ${ }^{13} \mathrm{C}\left(\pi^{+}, \pi^{-}\right)^{13} \mathrm{O}(\mathrm{gs})$ measurement at $\mathrm{T}_{\pi}=180 \mathrm{MeV}$ : the new measurement is $\mathrm{d} \sigma / \mathrm{d} \Omega\left(5^{\circ}\right)=83 \pm 19 \mathrm{nb} / \mathrm{sr}$, compared to $\mathrm{d} \sigma / \mathrm{d} \Omega\left(5^{\circ}\right)=94 \pm 28 \mathrm{nb} / \mathrm{sr}$. 


\section{A. Transitions to the DIAS}

\section{Excltation functions}

The new data are shown in FIg. IV-1. The new datum for $26 \mathrm{Mg}\left(\pi^{+}, \pi^{-}\right)^{26} \mathrm{SI}(\mathrm{gs})$ at $\mathrm{T}_{\pi}=120 \mathrm{MeV}$ agrees with the previous measurement [Gr-82a], and the new data at 164 and $180 \mathrm{MeV}$ make clear the simflarity of the excitation functions for 180 and ${ }^{26} \mathrm{Mg}$. Both are peaked at $T_{\pi} \simeq 140 \mathrm{MeV}$, have a minlmum near $T_{\pi}=170 \mathrm{MeV}$ and 1 ncrease towards the maxtmum measured energy of $292 \mathrm{MeV}$. In F1g. IV-2, the new excltation functions are compared to analog DCX for five other target nucle1. The energy dependence of ${ }^{42} \mathrm{Ca}\left(\pi^{+}, \pi^{-}\right)^{42} \mathrm{TI}(\mathrm{gs}) \quad[\mathrm{Ka}-83]$ is consistent with the above description for that of 180 and ${ }^{26} \mathrm{Mg}$.

On the other hand, the excltation functions for ${ }^{14} \mathrm{C}\left(\pi^{+}, \pi^{-}\right)^{14} \mathrm{O}(\mathrm{gs})$ and $56 \mathrm{Fe}\left(\pi^{+}, \pi^{-}\right)^{56} \mathrm{NI}$ (DIAS, $9.6 \mathrm{MeV}$ ) Increase monotonically over the energy range measured, The $48 \mathrm{TI}\left(\pi^{+}, \pi^{-}\right.$)(DIAS, 8.75 HeV) excltation-function data [Ka-83] strongly resembles the ${ }^{56} \mathrm{Fe}$ data, and 1 t 1 s Interesting to speculate that the ${ }^{14} \mathrm{C},{ }^{48} \mathrm{~T} 1$, and $56 \mathrm{Fe}$ reactions might possess local maxima for $T_{\pi}<140 \mathrm{MeV}$, analogous to those observed in the ${ }^{18} 0$ and $26 \mathrm{Mg}$ data at $T_{\pi}=140 \mathrm{MeV}$. It is difficult to say whether the ${ }^{48} \mathrm{Ca}\left(\pi^{+}, \pi^{-}\right)^{48} \mathrm{TI}$ (DIAS, $17.38 \mathrm{MeV}$ ) data [Ka-83] 


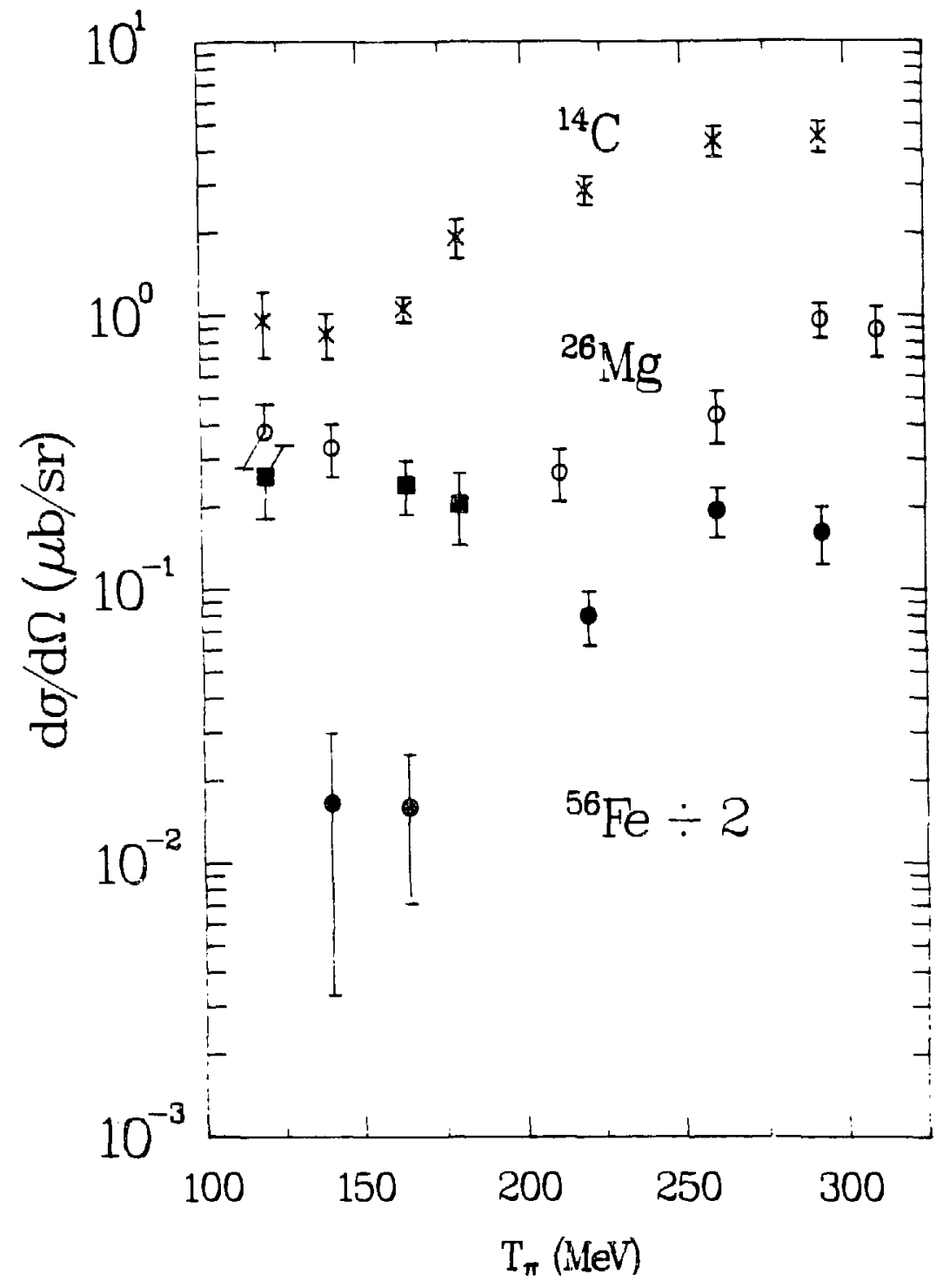

F1g. IV-1: New DIAS excitation function data for ${ }^{14} \mathrm{C}\left(\pi^{+}, \pi^{-}\right)^{140}$ (crosses) and ${ }^{26} \mathrm{Mg}\left(\pi^{+}, \pi^{-}\right)^{26} \mathrm{SI}$ (squares for tl:1s work and open c1rcles from $[\mathrm{Gr}-82 \mathrm{a}])$. The closed clrcles are (do/d $\Omega) / 2$ for $56 \mathrm{Fe}\left(\pi^{+}, \pi^{-}\right)^{56} \mathrm{N1}$ (DIAS, $9.6 \mathrm{MeV}$ ). 


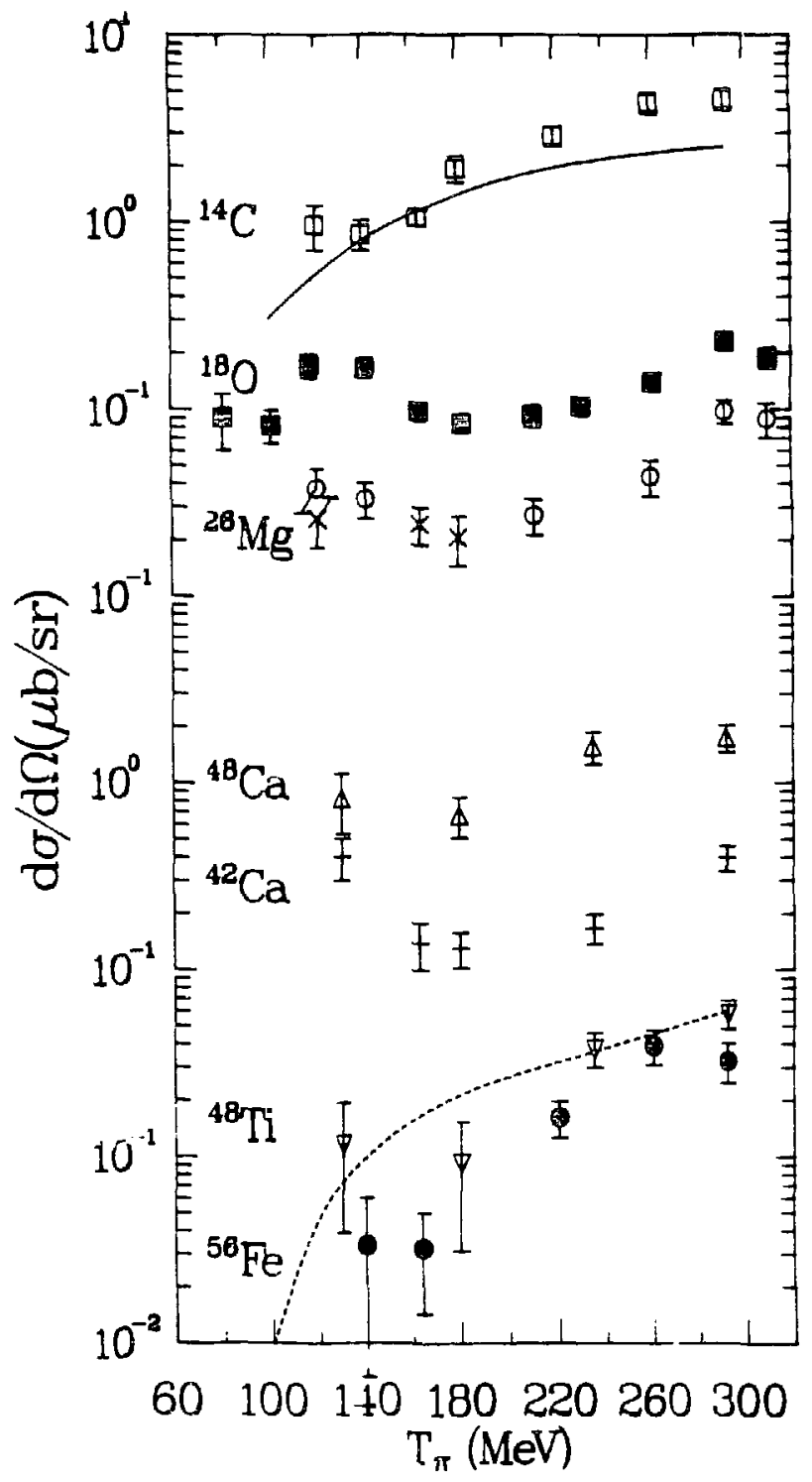

F1g. IV-2: Excltation functions for $A\left(\pi^{+}, \pi^{-}\right) A^{\prime}$ (DIAS). The ${ }^{26} \mathrm{Mg}$ data represented by c1rcles and the 180 data are from [Gr-92:- ]. The data for ${ }^{42} \mathrm{Ca},{ }^{48} \mathrm{Ca}$, and $48 \mathrm{TI}$ are from [Ra-83]. The sol1d and dashed curves are lowest-order PIESDEX [Jo-83b] calculations for ${ }^{14} \mathrm{C}\left(\pi^{+}, \pi^{-}\right)^{14} \mathrm{O}(\mathrm{g8})$ and $56 \mathrm{Fe}\left(\pi^{+}, \pi^{-}\right)^{56} \mathrm{NI}$ (DIAS, $\left.9.6 \mathrm{MeV}\right)$, respectively. 
most resembles the 180 and $26 \mathrm{Mg}$ excitation functicns, or the monotonic shape of the ${ }^{14} \mathrm{C},{ }^{48} \mathrm{TI}$ and $56 \mathrm{Fe}$ excitation functions. Across the $\Delta_{33}$ resonance, and for a wide range of target nuclel, a monotonlcally increasing DIAS excitation function is a common feature of DCX calculations that treat tire process as sequential charge exchange through the free $\pi$-nucleon amplitude. Optical-potential calculations have been performed with the computer program PIESDEX for some of the 1sospin conserving reactions discusscd. (See [Jo-83b], and Chapter v. No second-order 1soscalar $\left(\rho^{2}\right)$, lsovector $(\rho \Delta \rho)$, or 1sotensor $\left(\Delta \rho^{2}\right)$ terms have been included in the calculations presented in this chapter.) The shapes of the exc1tation functions for ${ }^{14} \mathrm{C}$ and $56 \mathrm{Fe}$ are In rough agreement with these lowest-order optical potentlal calculations. For $T_{\pi} \leqslant 200 \mathrm{MeV}$, the ${ }^{18} 0\left(\pi^{+}, \pi^{-}\right)^{18} \mathrm{Ne}(\mathrm{gs})$ exc1ta:1en function has been shown to be in strong disagreement with a similar (sequential charge exchange through the 1sobartc analog state in 18 F) calculation [M1-81]. These results suggest that in the case of ${ }^{14} \mathrm{C}$ and $56 \mathrm{Fe}$, for $T_{\pi}>140 \mathrm{MeV}$, charge exchange through the Intermediate analog state dominates the reaction amplitude, while for 180 , more interesting physics must be invoked to explain the data. 


\section{Angular distributions}

The new angular distributions for ${ }^{14} \mathrm{C},{ }^{26} \mathrm{Mg}\left(\pi^{+}, \pi^{-}\right){ }^{14} 0,{ }^{26} \mathrm{SI}(\mathrm{gs})$ at $T_{\pi}=164 \mathrm{MeV}$ are compared with that for $18 \mathrm{n} 1 \mathrm{n} \mathrm{F} 1 \mathrm{~g}$. IV-3. At $T_{\pi}=164 \mathrm{MeV}$ the 180 and $26 \mathrm{Mg}$ angular distributions have first minima occurring at small momentum transfers. The ${ }^{14} \mathrm{C}\left(\pi^{+}, \pi^{-}\right)^{14} \mathrm{O}(\mathrm{gs})$ angular distribution does not possess a well deflned minlmum, perhaps due to nuclear structure effects pecullar to ${ }^{14} \mathrm{C}$. However, the decrease in cross section between $0^{\circ}$ and $20^{\circ}$ is consistent with a shallow minimum near $\theta=20^{\circ}$. The ratios of the first maximum to the second maximum in the three angular distributions are a smooth function of A: $5.1 \pm 1.7, \quad 4.0 \pm 0.9, \quad$ and $\quad 1.5 \pm 0.5$ for ${ }^{14} \mathrm{C},{ }^{18} \mathrm{O},{ }^{26} \mathrm{Mg}\left(\pi^{+}, \pi^{-}\right){ }^{14} \mathrm{O},{ }^{18} \mathrm{Ne},{ }^{26} \mathrm{S1}(\mathrm{gs})$, respectively.

The three angular distributions at $\mathrm{T}_{\pi}=292 \mathrm{MeV}$ (F1g. IV-3) are similar in that they exhibit deap minima at momentum transfers conslstent with sequential charge excharige calculations. Data are lacking in the region of the second maximum, making a comparison of the cross sections at the first and second maxima Impossible at this energe.

PIESDEX [Jo-83a] calculations are compared with the angulardistributio.. data in Fig. IV-3. The fallure of the angular-distribution calculations at $\tau_{\pi}=164 \mathrm{MeV}$ and the partial success of the calculations at $T_{\pi}=292 \mathrm{MeV}$ indicate the complexity of the DCX reaction mechandsm near the $\Delta_{33}$ resonance energy and suggests the need for a second amplitude in the reaction. 


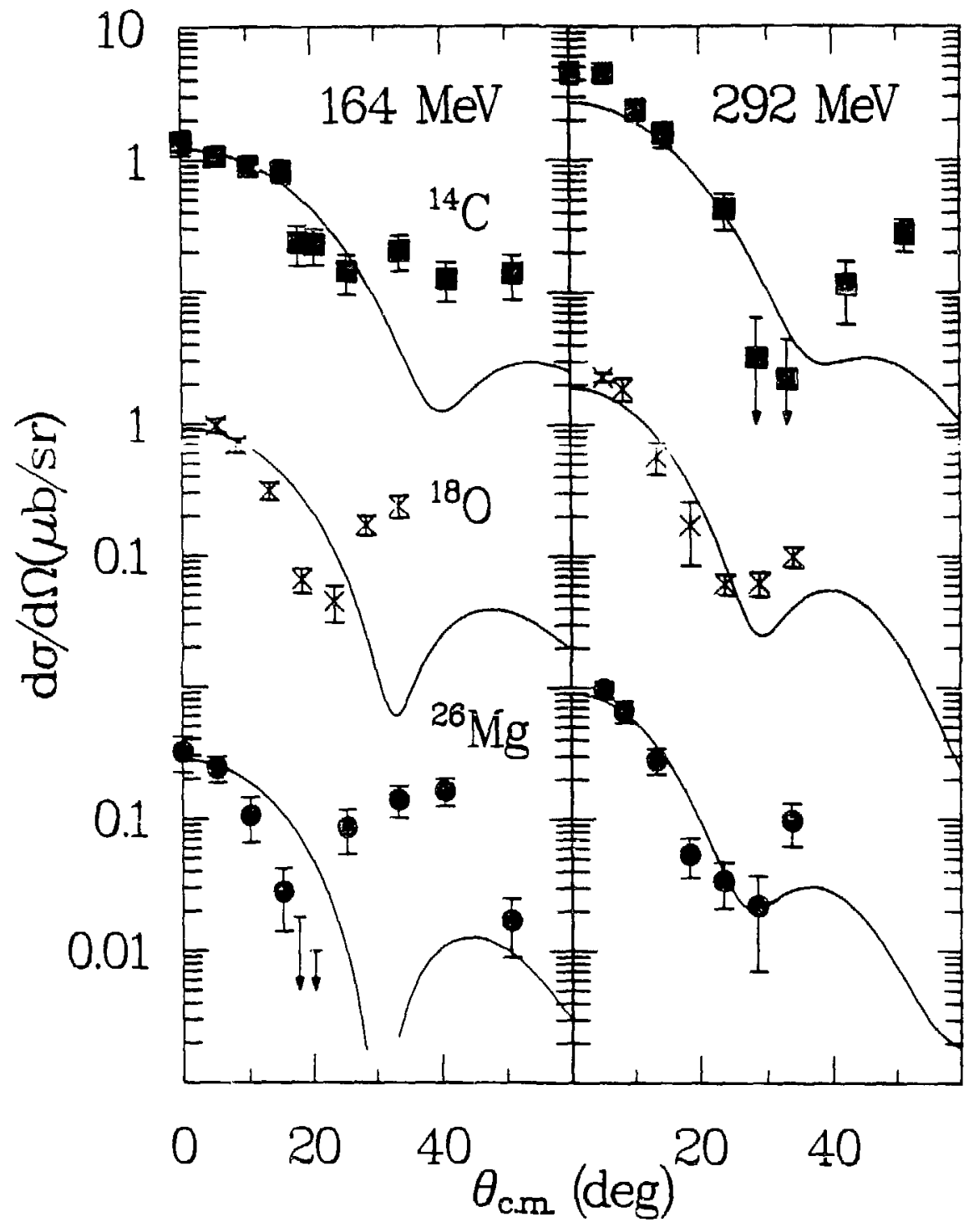

F1g. IV-3: Angular distributions at $T_{2}=164$ and $292 \mathrm{MeV}$ for the reactions: ${ }^{14} \mathrm{C}\left(\pi^{+}, \pi^{-}\right)^{14} \mathrm{O}(\mathrm{gs}),\left(\right.$ gquares) ${ }^{1} 1 \mathrm{O}_{\mathrm{O}}\left(\pi^{+}, \pi^{-}\right)^{18} \mathrm{Ne}$ (gs) (crosses, from $[\mathrm{Gr}-82 \mathrm{a}]$ ), and ${ }^{26} \mathrm{Mg}\left(\pi^{+}, \pi^{-}\right)^{26} \mathrm{Sl}$ (gs) (clrcles). The data for the latter at $T_{\pi}=292 \mathrm{MeV}$ are from [Gr-82a]. The curves are lowest order optical potential calculations from the theory of [Jo-83b]. 
The $s 1 \bar{x}$ angular distributions are plotted as a function of $q R$ In Fig. IV-4, where $q$ is the momentum transfer and $R$ is a sultable strong absorption radius for the target nuclel. Values of $R$ for ${ }^{14} \mathrm{C}$, 180 and $26 \mathrm{Mg}$ are $3.18,3.46$ and $3.91 \mathrm{fm}$, reapectively, calculated from $R=1.32 \mathrm{~A}^{1 / 3}$. These rad11 correspond to $\rho(R) / \rho(0) \approx 0.2$ for the Hartree-Fock (Skyrme-III effective Interaction [Be-75]) nuclear densities that were used for the PIESDEX calculations. At $T_{\pi}=164$ MeV, the angular distributions exhibit minima at $q R=1.7$, whereas at $T_{\pi}=292 \mathrm{MeV}$ the minima appear at $q R \cong 2.5$.

3. A dependence

Forward angle cross sections for transitions to double Isobarlc analog states as a function of target mass are shown $1 \mathrm{n}$ Fig. IV-5, with straight 11 nes corresponding to an $(\mathrm{N}-\mathrm{Z})(\mathrm{N}-\mathrm{Z}-1) \mathrm{A}^{-7 / 3}$ mass dependence, and $(\mathrm{N}-\mathrm{Z})(\mathrm{N}-\mathrm{Z}-1) \mathrm{A}^{-10 / 3}$ for comparison. The $\mathrm{A}^{-7 / 3}$ expression better describes the data for $T=1$ target nuclel at both energles and the agreement with the curve is better at $292 \mathrm{MeV}$ than at $164 \mathrm{MeV}$. There $1 \mathrm{~s}$ no known fundamental significance of this observed mass dependence; however, Johnson and Siclliano have shown that the geometr1c $(\mathrm{N}-\mathrm{Z})(\mathrm{N}-\mathrm{Z}-1) \mathrm{A}^{-10 / 3}$ dependence ts vlolated when an Isotensor term is included in the pion-nucleus optical potential [Jo-83b]. The addition of $\rho^{2}$ dependent terms to the pion-nucleus optical potential can describe much existing $164 \mathrm{MeV}$ SCX and $T>1$ DCX data for transitions to 1sobarlc analog states (see Chapter V). It should be 


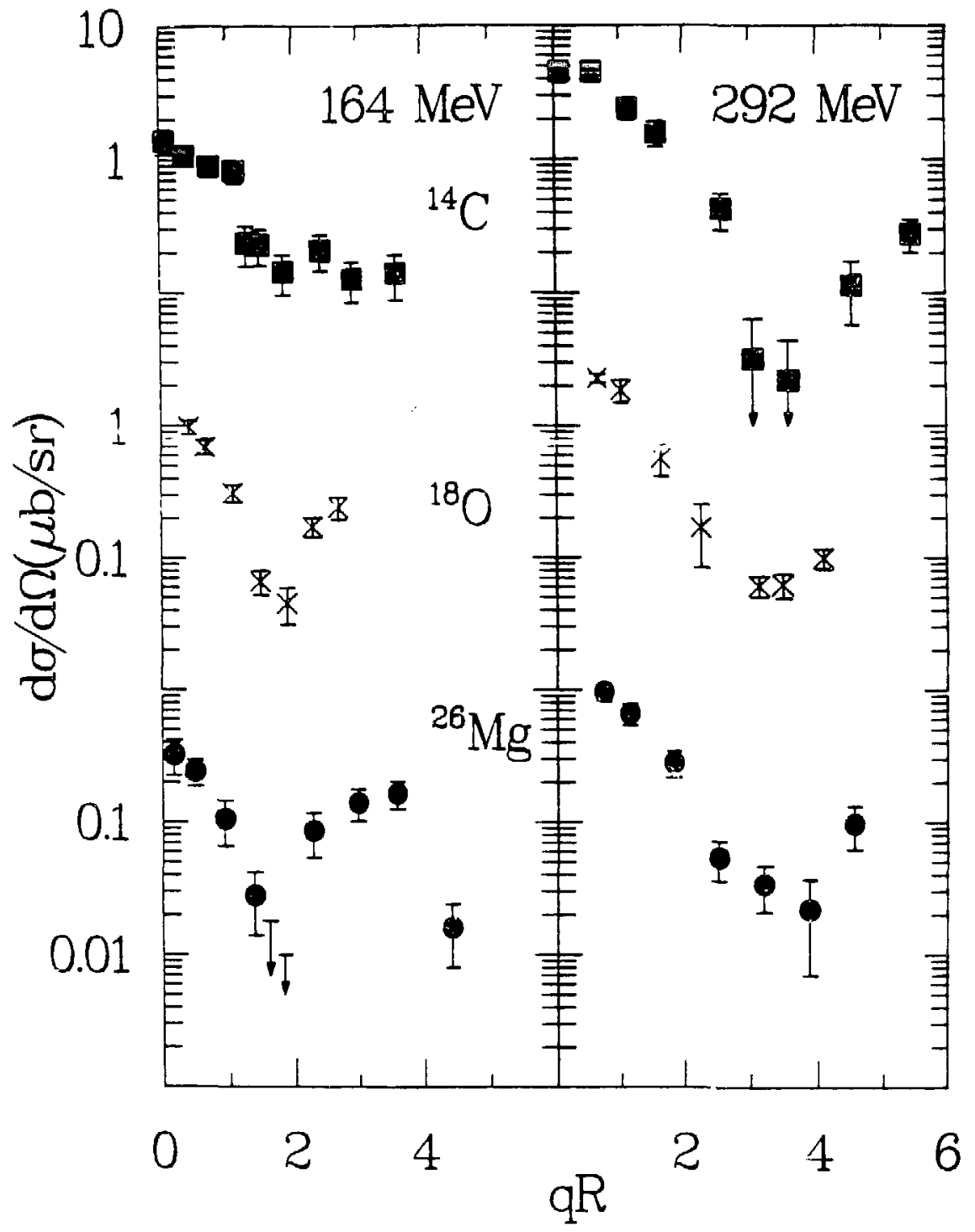

FIg. IV-4: The same daca as In Fig. IV-3 plotted versus $q R$. 


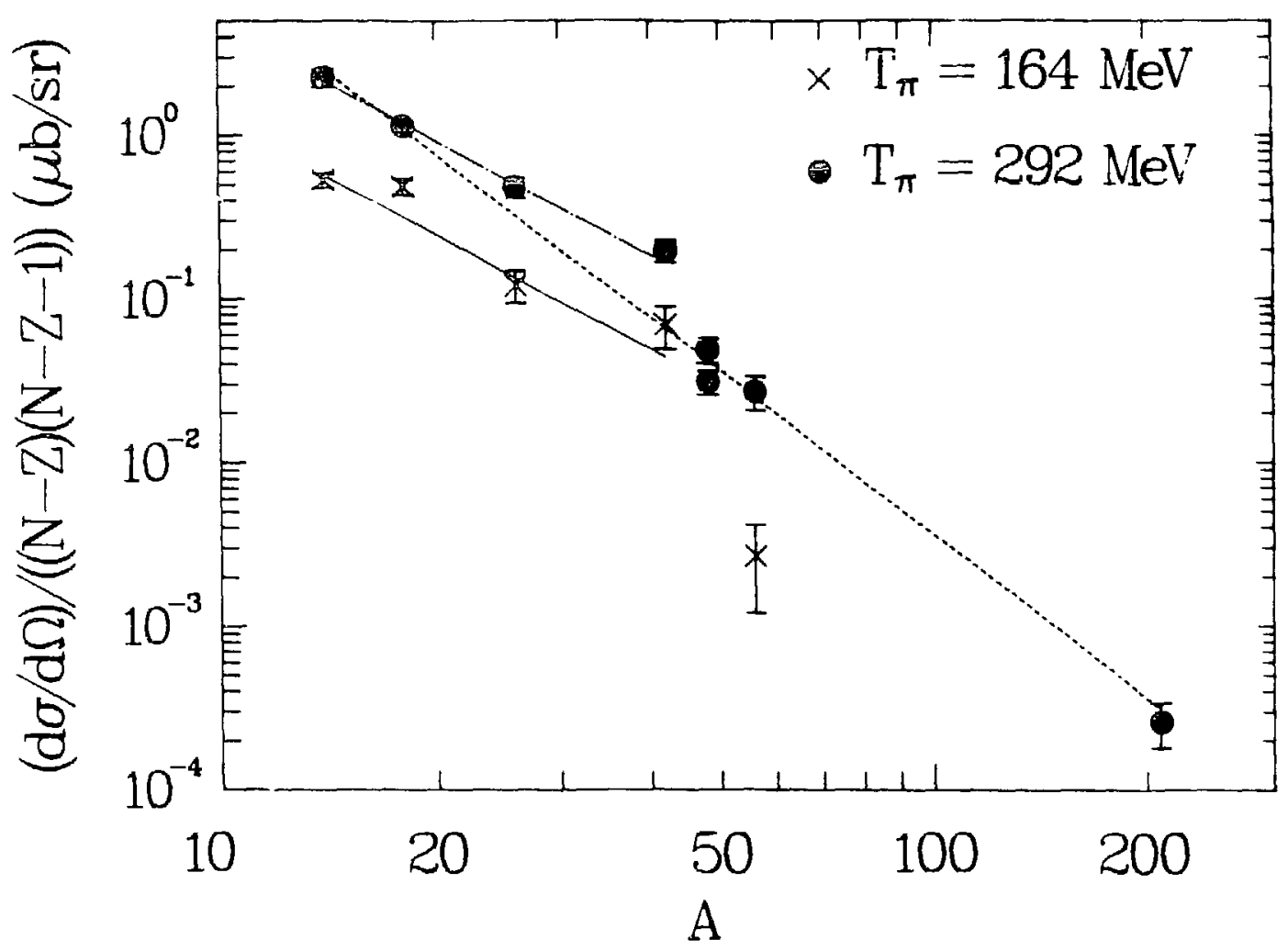

Fig. IV-5: Forward angle cross sections as a function of target mass for $T_{T}=164 \mathrm{MeV}$ and $292 \mathrm{MeV} .18_{0}$ was measured by Greene et a1. $[G r-82 \mathrm{a}]$. $26 \mathrm{Mg}$ at $292 \mathrm{l} \mathrm{cV}$ was measured by Greene et alo, and $42 \mathrm{Ca} 1 \mathrm{~s}$ from [Ka-83]. The dot-dash and solid 11 nes are an $\mathrm{A}^{-7 / 3}$ mass dependence at 292 and $164 \mathrm{MeV}$, respectively. The dashed 11 ne $1 \mathrm{~s}$ an $A^{-10 / 3}$ mass dependence. 
noted that when $T>1$ data are 1ricluded, the forward angle DCX data are fit better by $(N-Z)(N-Z-1) A^{-10 / 3}$.

The transition to a smoother $(N-Z)(N-Z-1) A^{-10 i 3}$ dependence is shown in FIg. IV-6, where the ${ }^{14} \mathrm{C}$ and ${ }^{26} \mathrm{Mg}$ data have been multiplied by ratios of $A^{10 / 3}$, and emphasize that the transition to an Irregular mass dependence occurs for $\mathrm{T}_{\pi} \leqslant 200 \mathrm{MeV}$.

A varying A dependence as a function of energy for the analog $\left(\pi^{+}, \pi^{\circ}\right) 0^{\circ}$ differential cross section has been noted by Sennhauser et al. [Sen-83]. Based on fits to SCX data for $7 \leqslant A \leqslant 208$, the mass dependence changes from about $A^{-1.4}$ at $T_{\pi}=100 \mathrm{MeV}$ to $A^{-1.1}$ at $\mathrm{T}_{\pi}=295 \mathrm{MeV}$. There is no subset of analog DCX data for whtch a similar trend is observed.

B. Nonanalog transitions

1. $0^{+} \rightarrow 0^{+}$transtetons

The transition to the ${ }^{56} \mathrm{Ni}$ (gs) does not suffer from the the same identification problem as the DIAS since it is weil separated from the first excited state of ${ }^{56} \mathrm{~N} 1$. The spectra comparison of Fig. III-7 exhibits the difference of the energy dependence of the nonanalog transition (to the ${ }^{56} \mathrm{NI}(\mathrm{gs})$ ) and the transition to the DIAS at $E_{X}=9.6 \mathrm{MeV}$. At lower energles, the excitation of the ${ }^{56} \mathrm{NI}(\mathrm{gg}) 18$ clearly seen, whereas there are no ground state events at $T_{\pi}=292$ MeV. The spectrum at $292 \mathrm{MeV}$ is dominated by the DIAS whereas at $\mathrm{T}_{\pi}=140 \mathrm{MeV}$ no clear signal appears for this state. 


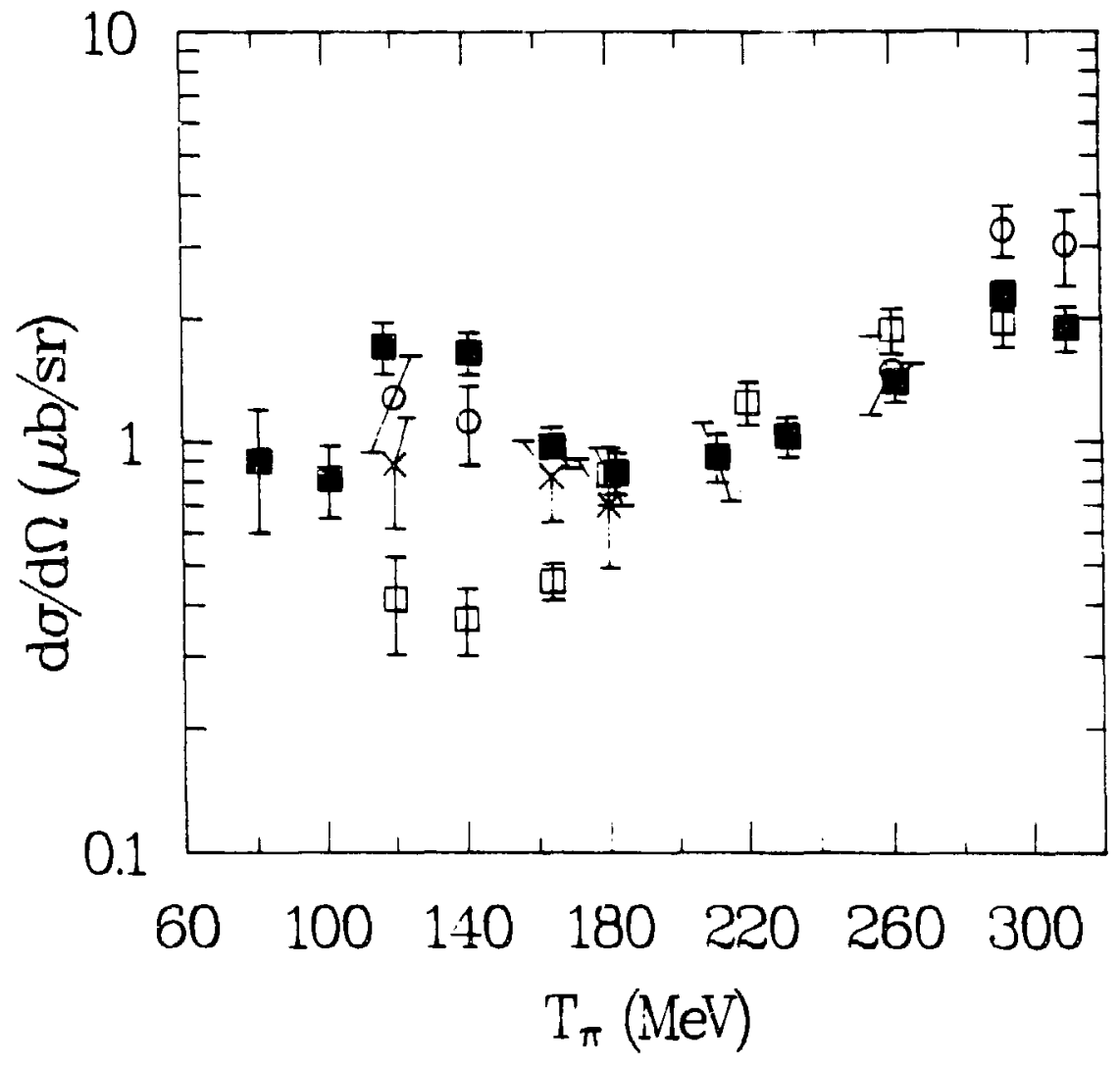

F1g: IV-6: DIAS exc1tation functions of $\left.{ }^{14} \mathrm{C}^{+} \pi^{+}, \pi^{-}\right)^{14} \mathrm{O}$ (open gquares), $180\left(\pi^{+}, \pi^{-}\right)^{18} \mathrm{Ne}$ (sol1d squares, from [Gr-82a]) and $26 \mathrm{Mg}\left(\pi^{+}, \pi^{-}\right)^{26} \mathrm{Si}$ (crosses are new data, open, c1rcles are from [Gr-82a]). By multiplying by ratios of $\mathrm{A}^{-10 / 3}$, the data for $14 \mathrm{C}$ and $26 \mathrm{Mg}$ are displayed on the scale of the ${ }^{18} 0$ data. 
The excitation function for a region $0.5 \mathrm{MeV}$ wide centered about the position of the $\left.{ }^{14} \mathrm{O}^{+}, 5.92 \mathrm{MeV}\right)$ state 28 shown in F18. IV-T, along with that for the ${ }^{56} \mathrm{Fe}\left(\pi^{+}, \pi^{-}\right)^{56} \mathrm{NI}(\mathrm{g.8.})$ reaction. Both desrease with Increasing pion kinetic energy, a reature also seen in other $A J=0$ nori-analog DCX reactions $[B 1-83]$, The data are compared ath curves obtained from a Brelt-W1gner expression for the cross section,

$$
\sigma_{B W}\left(T_{\pi}\right)=\frac{N \Gamma^{2}}{4 k^{2}\left(\left(T_{\pi}-T_{I e 8}\right)^{2}+\Gamma^{2 / 4}\right)}
$$

plus a backgrouna proportional to the PIESDEX cross sections (F18. IV-7) to account for the less dominant analcg reaction mechanism. In [B1-83], Brelt-WignE $\bar{i}$ expressions were used to extract peak posttions and widhs for the excttation functions on $\mathrm{T}=0$ target nuclel. For the non-analog transitions shown in FIg. IV-7 the widths have been fixed to be $70 \mathrm{MeV}$ (an average value from $[\mathrm{Bl}-\mathrm{B3}]$ ) and the data have been flt to obtain peak positioris of $148 \mathrm{MeV}$ and $149 \mathrm{MeV}$ for ${ }^{14} \mathrm{C}\left(\pi^{+}, \pi^{-}\right)^{14} \mathrm{O}\left(0^{+}, 5.92 \mathrm{Me}+1\right.$ and $56 \mathrm{Fe}\left(\bar{\pi}^{+}, \pi^{-}\right)^{56} \mathrm{N1}(\mathrm{g.s.})$, respectively. These peak pnsitions are 10 to $20 \mathrm{MeV}$ lower than those reported for the reactions studied in $[B 1-83]$.

The angular distribution for ${ }^{14} \mathrm{C}\left(\pi^{+}, \pi^{*}\right)^{14} \mathrm{O}\left(\mathrm{O}^{+}, 5.92 \mathrm{MeV}\right)$ is shown In Fig. IV-8. Poor stwisicics prevent raking meaningful comparisons with the known characteristics of non-analog DCX reactions, but the data are consistent with the presencs of a minimum near $30^{\circ}$. 


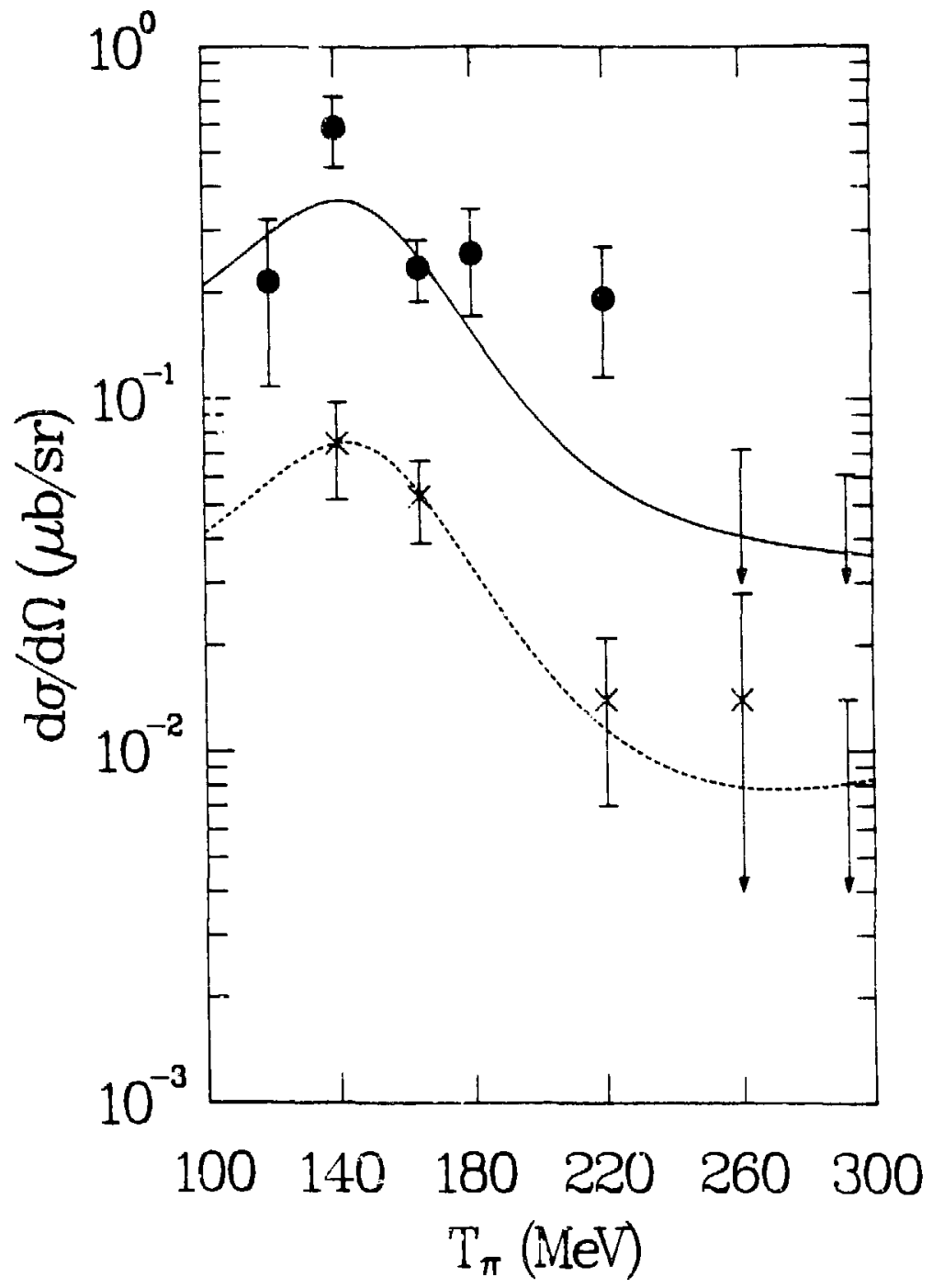

F1g. IV-7: Exc1tation functions for ${ }^{14} \mathrm{C}\left(\pi^{+}, \pi^{-}\right)^{14} \mathrm{O}\left(\mathrm{O}^{+}, 5.92 \mathrm{MeV}\right)$ (cfrcles) and $56 \mathrm{Fe}\left(\pi^{+}, \pi^{-}\right)^{56} \mathrm{N1}\left(\mathrm{g}_{\mathrm{s} .}\right)$ (crosses). The curves are obrained fron a Breit-W1gner expression, plun a background term. 


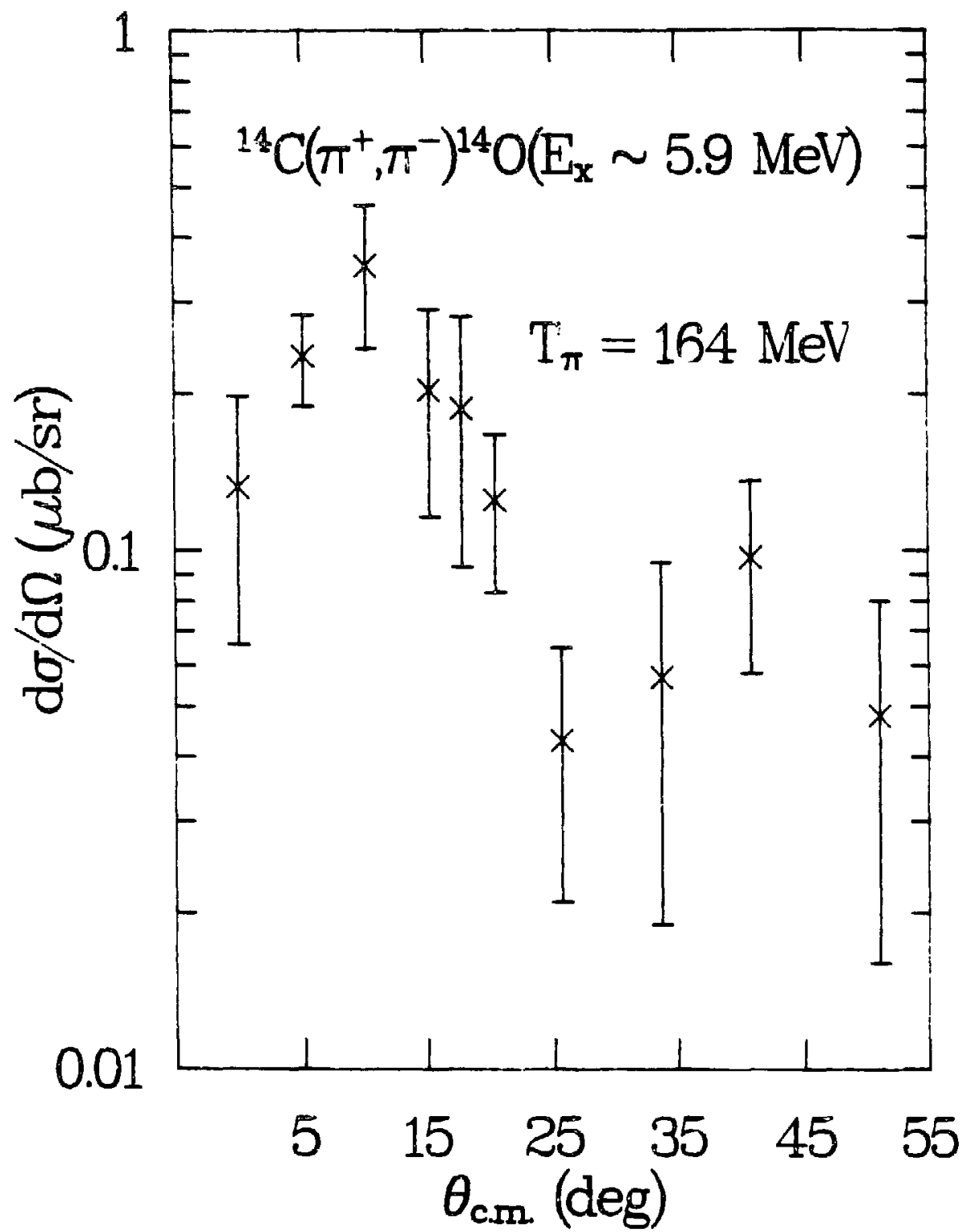

Fig. IV-8: Angular distribution for a $0.5-\mathrm{MeV}$ region centered about the ${ }^{14} \mathrm{O}\left(0^{+}, 5.92 \mathrm{MeV}\right)$ state. 
2. ${ }^{14} \mathrm{C}\left(\pi^{+}, \pi^{-}\right){ }^{14} \mathrm{O}\left(2^{+}, 7.77 \mathrm{MeV}\right)$

The ${ }^{14} \mathrm{C}\left(\pi^{+}, \pi^{-}\right)^{14} \mathrm{O}\left(2^{+}, 7.77 \mathrm{MeV}\right)$ excitation function is compared to that for the ${ }^{18} \mathrm{O}\left(\pi^{+}, \pi^{-}\right)^{18} \mathrm{Ne}\left(2^{+}, 1.89 \mathrm{MeV}\right)$ reactius $\ln \mathrm{F} 1 \mathrm{~g}$. IV-9. ?oth reactions exhibit a minimum near $T_{\pi}=150 \mathrm{MeV}$, and are otherwise constant over the energy range measured. The angular distribution at $T_{\pi}=292 \mathrm{MeV}$ (see Fig. IV-10) is flat, and consistent with the expectation that the shape shou'd be determined by a IInear combination of $\mathrm{J}_{0}(\mathrm{qR})$ and $\mathrm{J}_{2}(\mathrm{qR})$. The suppression of the cross section near $150 \mathrm{MeV}$ may be connected to the dynamics that create the anomalous $164 \mathrm{MeV}$ angular distributions for the DIAS transitions (see Fig. IV-3), as well as the peaking of nonanalog $0^{+} \rightarrow 0^{+}$xyoss sections In that energy region. Unfortunately, the statistical uncertainty of the ${ }^{14} \mathrm{C}\left(\pi^{+}, \pi^{-}\right)^{14} \mathrm{O}\left(2^{+}\right), \quad 164-\mathrm{MeV}$ angular-d1stribution data prevent the determination of a forward angle mintmum.

3. ${ }^{13} \mathrm{C}\left(\pi^{+}, \pi^{-} ;\right)^{13} 0$

Two spectra, containing ali daca collected with the thick target at $\mathrm{T}_{\pi}=164$ and $292 \mathrm{MeV}$, are shown In F1g. IV-1L. The onset of particle Instability -- ${ }^{12} \mathrm{~N}+i$, and ${ }^{11} \mathrm{C}+2 \mathrm{p}$ above $\mathrm{E}_{\mathbf{x}}=1.53$ and $2.12 \mathrm{MeV}$, respectively -- $1 \mathrm{~s}$ evident in the spectra. Little else is known about the nuclear structure of ${ }^{13} \mathrm{O}$. The $\mathrm{T}_{\pi}=164 \mathrm{MeV}$ spectrum shows evidence for an exclted state at $E_{X}=2.75 \pm 0.04 \mathrm{MeV}$, In agreement with the ${ }^{13} 0$ spectrum measured with the ${ }^{12} \mathrm{C}\left(\mathrm{p}, \pi^{-}\right)^{13} \mathrm{O}$ reaction [Co-78], where a state has been observed at $2.82 \pm 0 . \angle 4 \mathrm{MeV}$. 


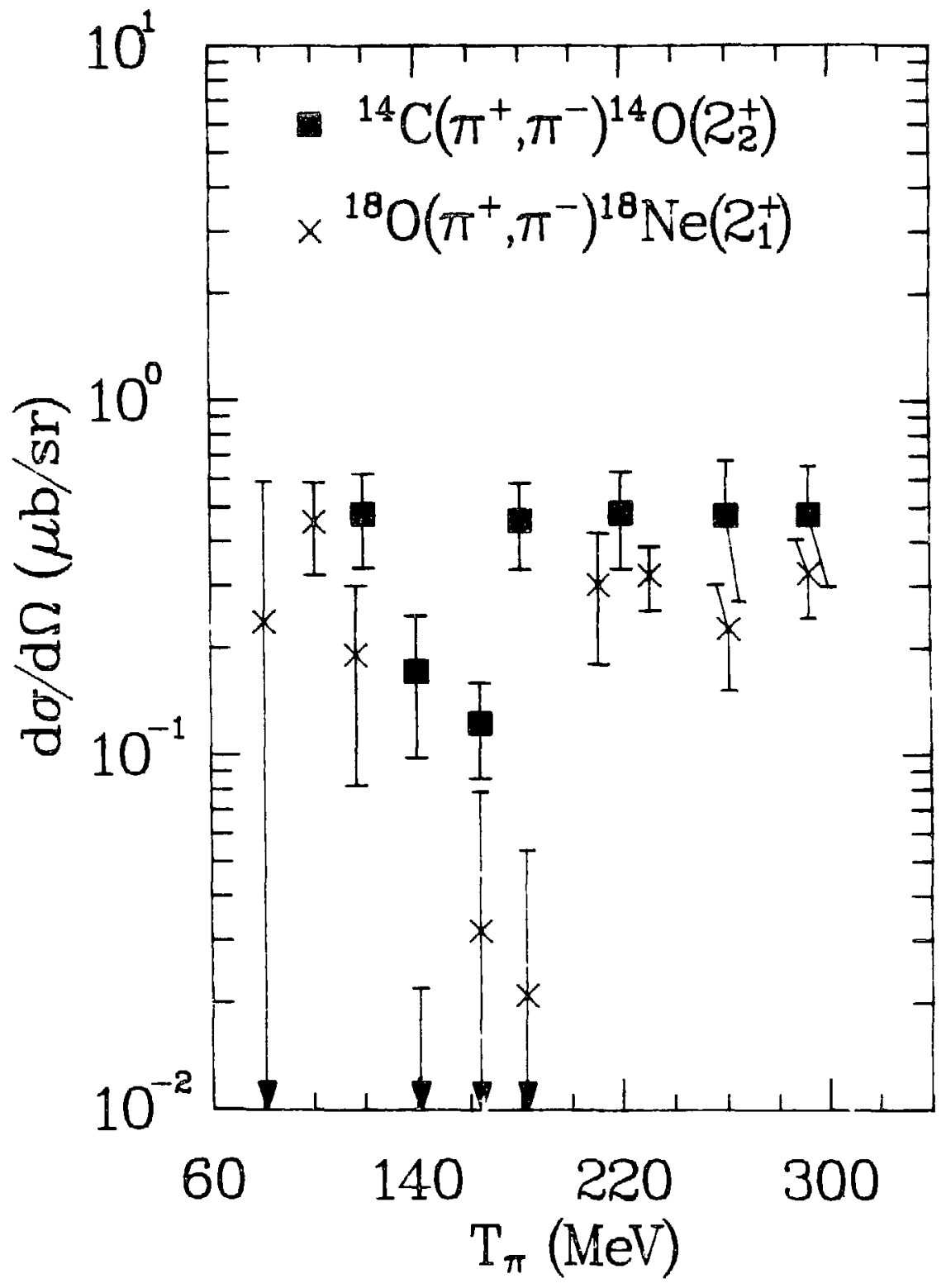

F1g. IV-9: Excltation function for $\left.14 \mathrm{C}_{\left(\pi^{+}, \pi^{-}\right.}\right)^{14} \mathrm{O}\left(2^{+}, 7.77 \mathrm{MeV}\right)$ is compared to that for the $180\left(\pi^{+}, \pi^{-}\right) 18 \mathrm{Ne}\left(2^{+}, 1.89 \mathrm{MeV}\right)$ reaction $[\mathrm{Gr}-82 \mathrm{a}]$. 


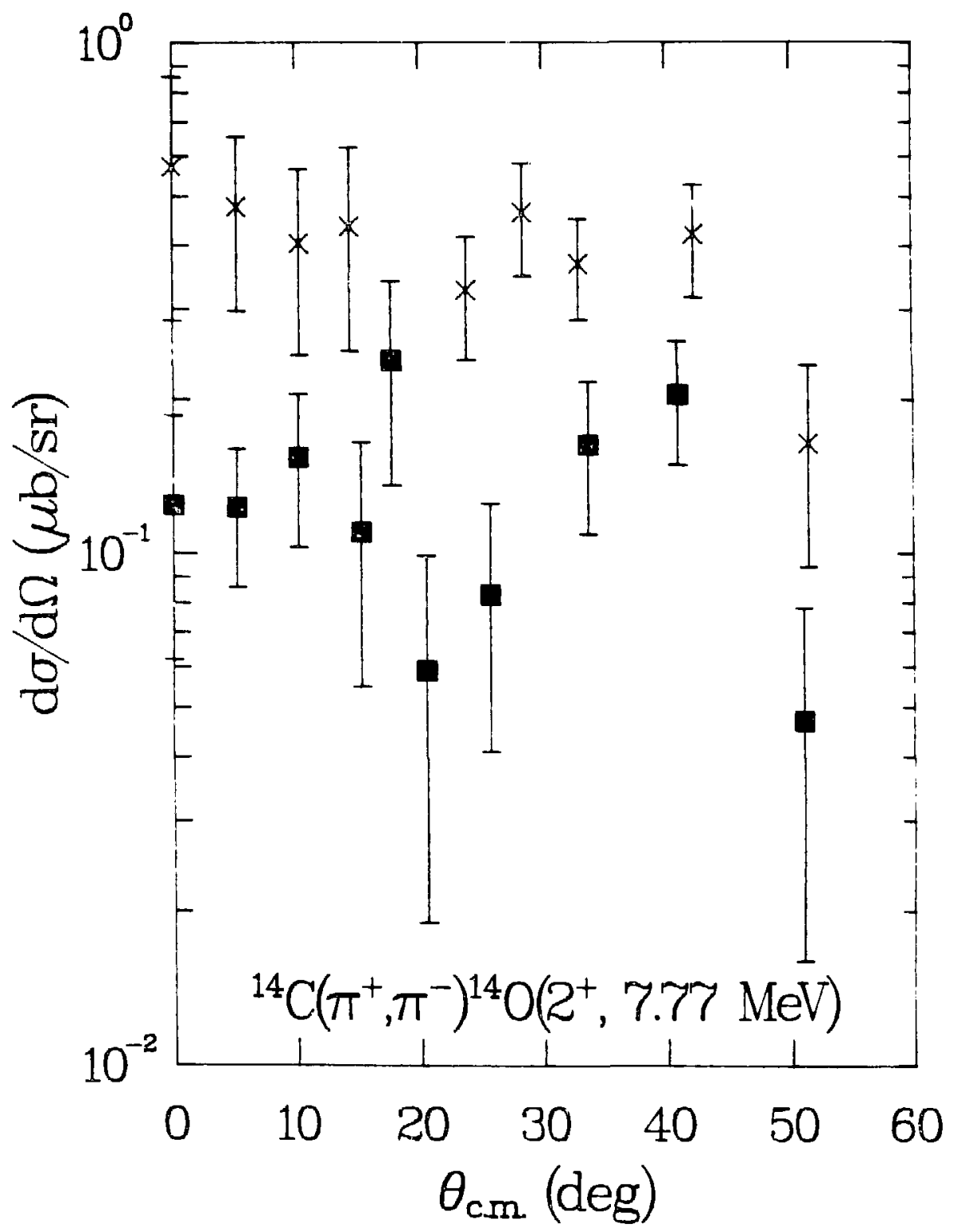

F1g. IV-10: Angular distribution for $\left.14 \mathrm{C}^{+} \pi^{+}, \pi^{-}\right)^{14} \mathrm{O}\left(2^{+}, 7.77 \mathrm{MeV}\right)$ at $\mathrm{T}_{\pi}=292 \mathrm{MeV}$ (crosses) and $164 \mathrm{MeV}$ (squares). 


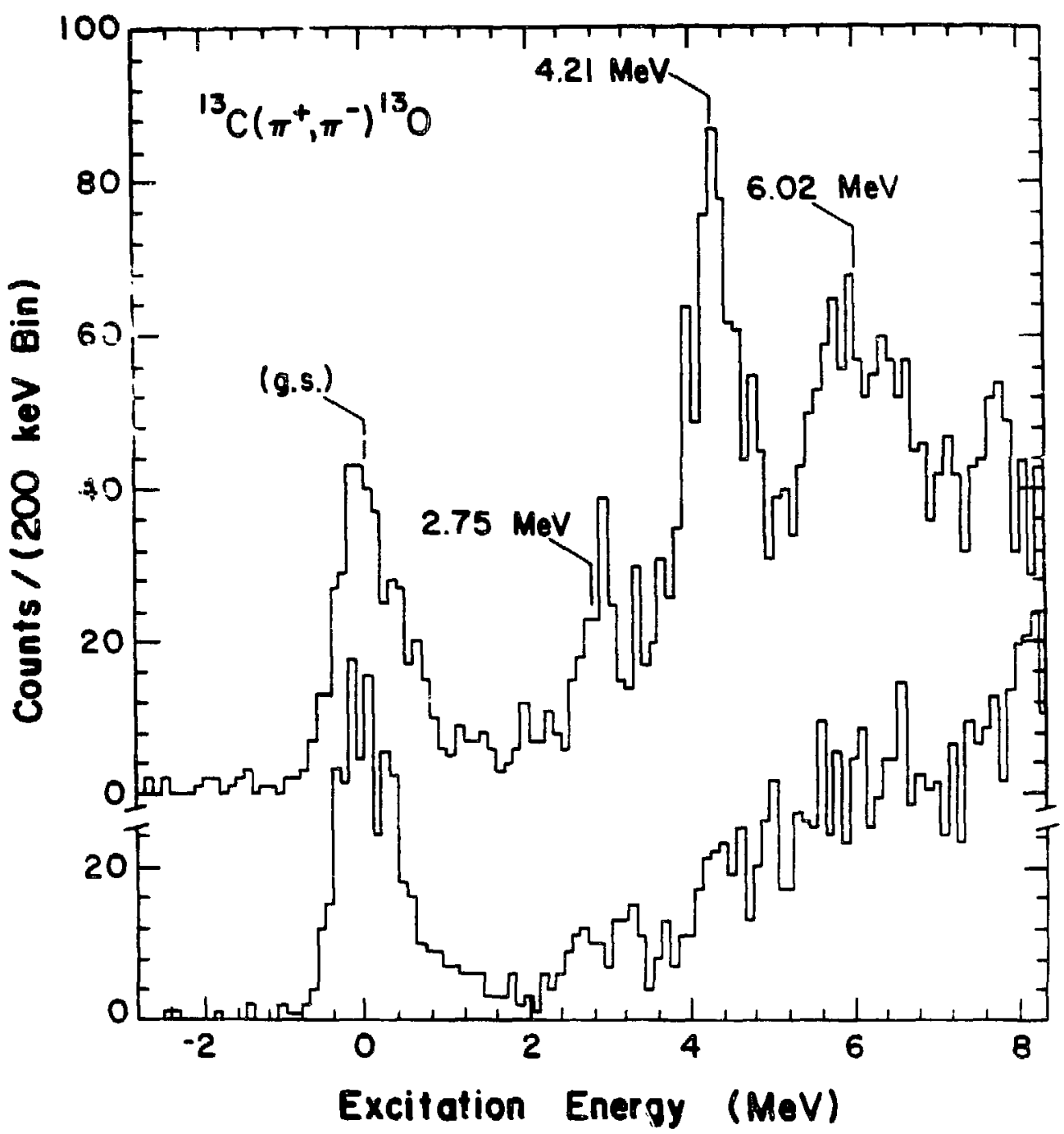

F1g. IV-11: Missing mass spectra for ${ }^{13} \mathrm{C}\left(\pi^{+}, \pi^{-}\right)^{13} \mathrm{O}$ at $\mathrm{T}_{\pi}=164 \mathrm{MeV}$ (top) and $292 \mathrm{MeV}$ (bottom), measured with the target of areal density $1489 \mathrm{mg} / \mathrm{cm}^{2}$. The spectra are the raw number of counts summed over all angles for which data were taken and are not corrected for spectrometer acceptance as a function of outgoing pion momentum. 
The $\left(\pi^{+}, \pi^{-}\right) 164 \mathrm{ieV}$ spectrum shows an enhancement at $6.02 \pm 0.08 \mathrm{MeV}$, with a FWHM of $1.2 \mathrm{MeV}$ and may be due to the excitation of more than one state. A state at $4.21 \pm 0.05 \mathrm{MeV}$ is the only one to hava a large enough cross section and a sufficlently narrow width to facilitate the extraction of an angular distribution -- the existence of the continum background prevents a reliable determination of peak areas for the more weakly excited states. There is no evidence for any of these excited states in the $292 \mathrm{MeV}$ spectrum.

The excitation functions for ${ }^{13} \mathrm{C}\left(\pi^{+}, \pi^{-}\right)^{13} 0(\mathrm{gs})$, and ${ }^{13} \mathrm{C}\left(\pi^{+}, \pi^{-}\right)^{13} \mathrm{O}(4.21 \mathrm{MeV})$ are shown in F1g. IV-12. The $13 \mathrm{O}(\mathrm{g} \cdot \mathrm{B}$. excitation function decreases by a factor of 2.5 between 119 and $180 \mathrm{MeV}$ and the new datum at $180 \mathrm{MeV}$ agrees well with the previous measurement of $[\mathrm{Bu}-80]$. The cross sections at $T_{\pi}=164$ and $292 \mathrm{MeV}$ are roughly equal, in contrast to the excitation function for the only other nonanalog DCX measurement on a $T=1 / 2$ target [Bu-80, Se-80], ${ }^{9} \mathrm{Be}\left(\pi^{+}, \pi^{-}\right)^{9} \mathrm{C}\left(\mathrm{g} \cdot \mathrm{s}_{\mathrm{*}}\right)$, which monotonically decreases by a factor of 8 between $T_{\pi}=140$ and $295 \mathrm{MeV}$. In a slmple shell model, the ${ }^{9} \mathrm{Be}\left(\pi^{+}, \pi^{-}\right)^{9} \mathrm{C}(\mathrm{g} \cdot \mathrm{s} \cdot)$ reaction can proceed via $v\left(\mathrm{p}_{3} / 2\right)^{3} \pi\left(\mathrm{p}_{3} / 2\right)^{2} \rightarrow$ $v\left(p_{3} / 2\right)^{1} \pi\left(p_{3 / 2}\right)^{4}$, while the ${ }^{13} \mathrm{C}\left(\pi^{+}, \pi^{-}\right)^{13} 0(\mathrm{~g} \cdot \mathrm{s} \cdot)$ reaction must necessartly change the orbits of nucleons. In the latter reaction the relatively large cross section at $T_{\pi}=292 \mathrm{MeV}$ is a feature common to the nonanalog $\triangle J=2 D C X$ excitation functions discussed above, while the ${ }^{9} \mathrm{Be}\left(\pi^{+}, \pi^{-}\right)^{9} \mathrm{C}\left(\mathrm{g} \cdot \mathrm{s}_{\mathrm{H}}\right)$ excitation function resembles those for (ground state) to (ground state), $\Delta \mathrm{J}=0$, nonanalog $\mathrm{DCX}$ on $\mathrm{T}=0$ targets. These fearures of the data are Indicative of interesting nuclear structure or momentum dependence effects. 


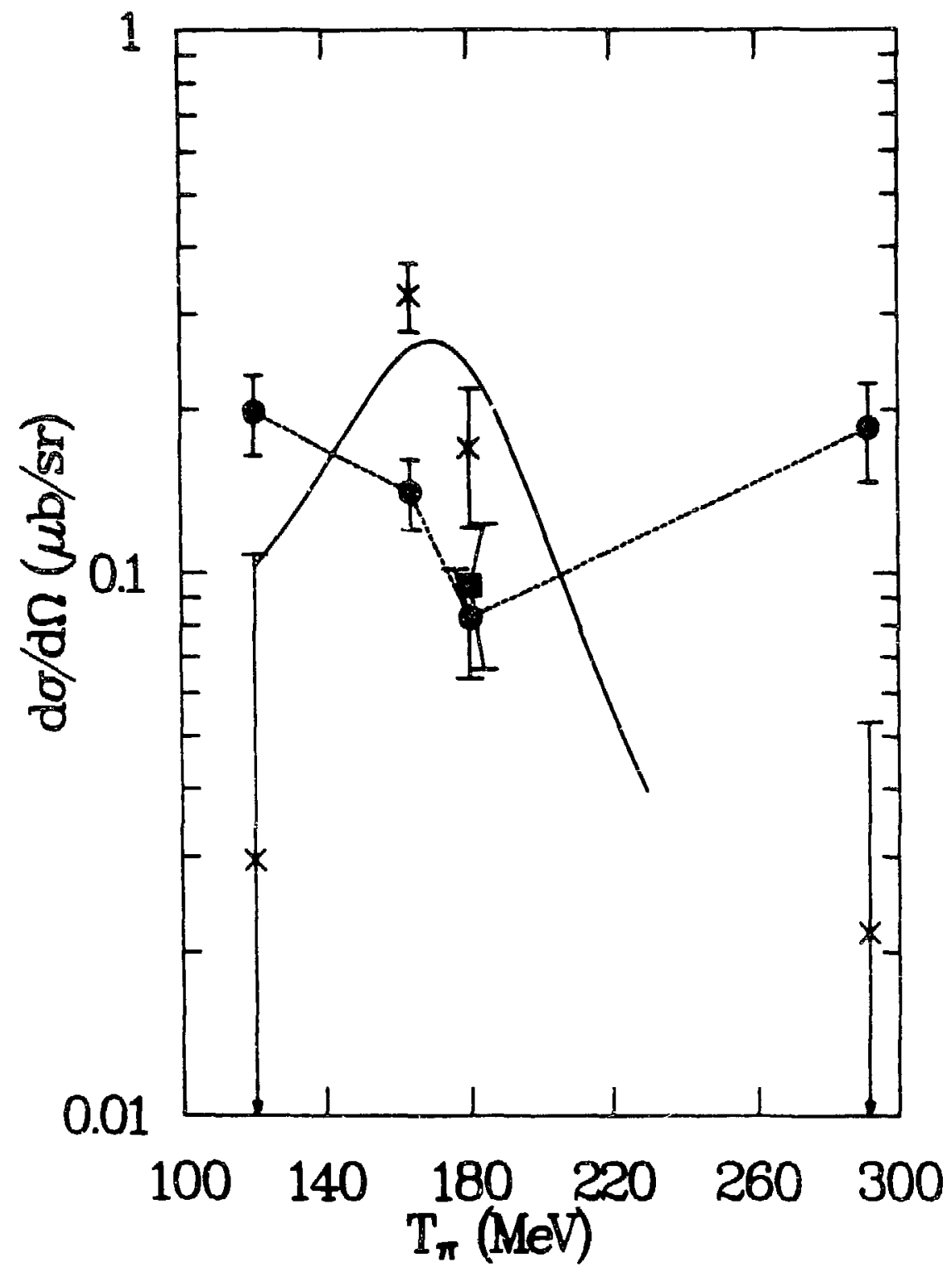

F1g. IV-12: Excttation function for ${ }^{13} \mathrm{C}\left(\pi^{+}, \pi^{-}\right)^{13} \mathrm{O}(\mathrm{gs})$ for which the square is from [Bu-80] and circles are from this work. The dashed Iine serves to guide the eye. The crosses are for ${ }^{3} \mathrm{C}\left(\pi^{+}, \pi^{-}\right)^{13} \mathrm{O}(4.21 \mathrm{MeV})$. The solld 11ne is a Brelt-W1gner parameterization of the ${ }^{12} \mathrm{C}\left(\pi^{+}, \pi^{-}\right)^{12} \mathrm{O}(\mathrm{gs})$ exc1cation function [B1-83], with a width and peak position of $60 \mathrm{MeV}$ and $178 \mathrm{MeV}$, respectively. The curve has been scaled down to the ${ }^{13} \mathrm{C}\left(\pi^{+}, \pi^{-}\right)^{13} \mathrm{O}(4.21 \mathrm{MeV})$ excltation function. 
The excltation function for the $E_{\pi}=4.21 \mathrm{MeV}$ state gives only upper limits for the cross sectlons at 119 and $292 \mathrm{MeV}$ and at $164 \mathrm{MeV}$ exhibits cross sections about twice as large as that of the transition to the ground state. The energy dependence is similar to that measured for $12 \mathrm{C}\left(\pi^{+}, \pi^{-}\right)^{12} 0(8.9$.$) [B1-83] as shown in F1g. IV-12, and$ ${ }^{14} \mathrm{C}\left(\pi^{+}, \pi^{-}\right)^{14} \mathrm{O}\left(0^{+}, 5.92 \mathrm{MeV}\right)(\mathrm{F} 1 \mathrm{~g} . \mathrm{IV}-7)$

The $4.21 \mathrm{MeV}$ state cross sestion at $T_{\pi}=164 \mathrm{MeV}$ does not agree wth the experimental $A^{-4 / 3}$ mass dependence of nonanalog DCX on self conjugate targets: $\sigma\left(5^{\circ}\right)$ for the ${ }^{13} 0(4.21 \mathrm{MeV})$ is $0.50 \pm 0.07$ times lower than the best fit $A^{-4 / 3}$ parameterization of the data in [B1-83]. Fig. IV-13 shows the angular distributions for ${ }^{13} \mathrm{C}\left(\pi^{+}, \pi^{-}\right)^{13} \mathrm{O}(\mathrm{g.9.})$. At $164 \mathrm{MeV}$, the $0^{\circ}$ and $50^{\circ}$ cross section are roughly a factor of two lower than cross sections for $5^{\circ}<\otimes<40^{\circ}$. Other than this feature there is no strong angular dependence. At $292 \mathrm{MeV}$, do/d $1 \mathrm{~s}$ roughly constant for $0^{\circ}<\theta<41^{\circ}$, and is decreased at $50^{\circ}$. We note that for the (ground state) to (ground state) transition, $J_{i}^{\pi}=1 / 2^{-}$and $J_{i}^{\pi}=3 / 2^{-}$, which allows for the contribution of $\Delta J=1$ and 2 processes in this transition. More than one multipole can also contribute to the ${ }^{9} \mathrm{Pe}\left(\pi^{+}, \pi^{-}\right)^{9} \mathrm{C}\left(\mathrm{g} \cdot \mathrm{s}_{.}\right)$reaction $[5 \varepsilon-80]$, for which the angular distribution at $T_{\pi}=162 \mathrm{MeV}$ is slowly varying for $5^{\circ}<\theta<36^{\circ}$, and has a shallow minimum near $22^{\circ}$. Since the ground state angular distributions for both ${ }^{9} \mathrm{Be}$ and ${ }^{13} \mathrm{C}$ are not forward peaked, and the excitation functions differ, comparison to $0^{+}$to $0^{+}$ nonanalog DCX reactions is difficult. Comparisons should be made through angle-integrated cross sections, but existing nonanalog data are limited to $0^{\circ}<\theta<50^{\circ}$. 


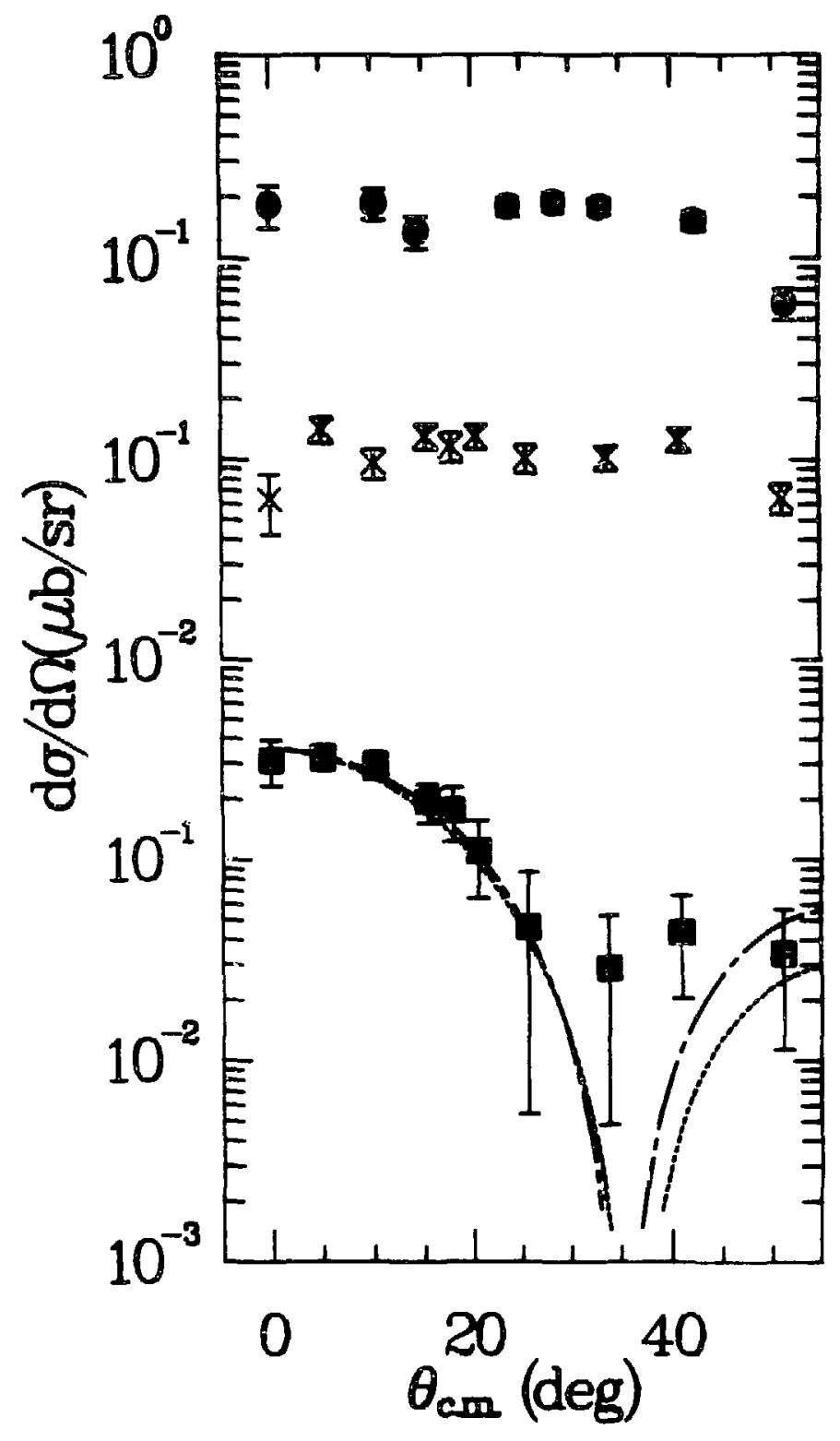

F1g. IV-13: Angular distributions for ${ }^{13} \mathrm{C}\left(\pi^{+}, \pi^{-}\right)^{13} \mathrm{O}(\mathrm{gs})$ are glmllar in shape and magnitude at both 164 (crosses) and $292 \mathrm{MeV}$ (circlea). The curves are $\sigma(\theta)=\mathrm{NJ}^{2}(q R) \mathrm{e}^{-q \mathrm{~d}}$, fit to the ${ }^{13} \mathrm{C}\left(\pi^{+}{ }_{3} \pi^{-}\right)^{13} 0(4.21 \mathrm{MeV})$ data (squares). The long dashed curve 19 a best fit to the data: $R=3.0 \pm 0.8 \mathrm{fm}, d=0.1 \pm 1.1 \mathrm{fm}, x^{2}=0.77$, and $N=0.39 \mu b / s r$. The short dashed curve has $R=2.95 \mathrm{fm}, d=0.61 \mathrm{fm}$, calculated Ẽ rom the two thirds density polnt of a harmonic oscillator electron scattering parameterization [de-74] of the charge distribution. 
The angular distribution (see F1g. IV-13) for the $E_{x}=4.21 \mathrm{MeV}$ state 18 clearly forward peaked. The decrease $1 \mathrm{~d} \mathrm{~d} \sigma / \mathrm{d} \Omega$ between $0^{\circ}$ and $30^{\circ}$ is simflar to that obgerved for the ${ }^{12} \mathrm{C}\left(\pi^{+}, \pi^{-}\right) 120(\mathrm{g.s.})$ reaction $[\mathrm{B1}-83]$ at $164 \mathrm{MeV}$. The data can be represented by the elkonal form $\left\{A m-80\right.$ ] $J_{0}^{2}(q R) e^{-q d}$, where $q$ is the momentum transfer, $R$ is a strong absorption radius, and $d$ is the nuclear surface diffuseness. F18. IV-13 shows curves of damped Bessel functions, one with $R$ and $d$ chosen to best fit the data, the other with $R$ and $d\left(A=\rho / \rho^{\circ}\right)$ evaluated at the $2 / 10$ denelty point of the ${ }^{13} \mathrm{C}$ charge density, calculated from an electron scattering parameterization [de-74]. A11 nonanalog DCX transitions on $T=0$ target nuclel have the transition to the ground state being the strongest transition in the spectrum at forward angles. In the case of ${ }^{13} \mathrm{C}\left(\pi^{+}, \pi^{-}\right)^{13} 0$ at $164 \mathrm{MeV}$, the transition to the $4.21 \mathrm{MeV}$ state dominates at forward angles -- In angular and energy (but not mass) dependence it fits in with nonanalog DCX on self-conjugate target nuclei. The similarities of the $12 \mathrm{C}\left(\pi^{+}, \pi^{-}\right)^{12} \mathrm{O}(\mathrm{g.s.})$, $\left.{ }^{13} \mathrm{C}\left(\pi^{+}, \pi^{-}\right)\right)^{13} \mathrm{O}(4.21 \mathrm{MeV})$, and ${ }^{14} \mathrm{C}\left(\pi^{+}, \pi^{-}\right)^{14} \mathrm{O}(5.9 \mathrm{MeV})$ reactions cause us to speculate that the ${ }^{13} 0(4.21 \mathrm{MeV})$ state has $\mathrm{J}^{\pi}=1 / 2^{-}$, thus allowing the reaction to proceed $v i a$ a $\Delta J=0$ process. Shell model calculations [Ra-83] using a Cuhen-Kurath p-shell effective Interaction [Co-65] predict the existence of a $1 / 2^{-}$state at $E_{x}=4.0$ $\mathrm{MeV}$. 


\section{ANALYSIS OF THE DIAS TRANSITIONS}

A. Secouc Order Optical Potential Phenomenology

This section describes the application of the Isobarlc-1nvarlant plon-nucleus optical model of Johnson and Siclliano [Jo-83a,b] to $T_{\pi}=164 \mathrm{MeV}$ DCX data, and $165 \mathrm{MeV}$ SCX data. other detalls of an analysis of elastic, single-, and double-charge-exchange scattering may be found in $[G r-84]$.

The general form for the $\pi-A$ optical potentlal for scattering from $T>1$ nuclet is

$$
\mathrm{U}=\mathrm{U}_{0}+\mathrm{U}_{1}(\vec{\phi} \cdot \overrightarrow{\mathrm{T}}) \prec \mathrm{U}_{2}(\overrightarrow{\dot{\phi}} \cdot \overrightarrow{\mathrm{T}})^{2},
$$

where $\downarrow$ is the 1sospin operzior of the plon and + is the 1sospin operator of the nucleus. $U_{0}, I_{1}$ and $U_{2}$ are known as the isoscalar, 1sovector, and 1sotensor parts of the optical potentlal, respectively. The s- and p-wave parts of the interaction may be separated by writing

$$
\mathrm{U}=-\vec{\nabla} \cdot \boldsymbol{\xi}(\vec{r}) \vec{\nabla}+k^{2} \overrightarrow{E_{*}}(\vec{r})
$$

where the barred and unbarred quantities, $\bar{\xi}$ and $\xi$, refer to 8 - and p-waves, respectively. 


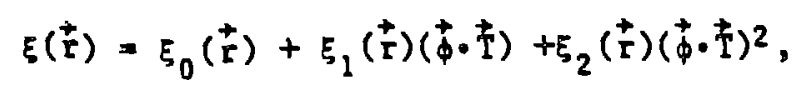

and simflarly for s-waves. By defining

$$
\xi^{(\jmath)} \equiv\left\langle\pi^{\jmath} ; T, T_{z}=-T|\xi| \pi j ; T, T_{z}=-T\right\rangle
$$

where $T$ is the nuclear 1sospin and ( $f$ ) is the charge state of the pion $(+, 0,-)$, the 1sospln dependence of the lowest order optical potential may be derlved. The 1sovector and 1sotensor operators can be expressed in terms of lsospin raising and lowering operators:

$$
\begin{aligned}
& (\vec{\phi} \cdot \vec{T})=\frac{1}{2}\left(\phi_{+} T_{-}+\phi_{-} T_{+}+2 \phi_{z} T_{z}\right) \\
& \left(\vec{\phi} \cdot+\frac{T}{T}\right)^{\prime}=\frac{1}{4}\left(\phi_{+} T_{-}+\phi_{-} T_{+}+2 \phi_{z} T_{z}\right)^{2} \\
& \phi_{+} \phi_{-}\left|\pi^{-}\right\rangle=0, \quad \phi_{+} \phi_{-}\left|\pi^{0}\right\rangle=2\left|\pi^{0}\right\rangle \\
& \phi_{+} \phi_{-}\left|\pi^{+}\right\rangle=2\left|\pi^{+}\right\rangle
\end{aligned}
$$

For $(\dot{\phi} \cdot \vec{T})$ only $\phi_{z} \Gamma_{z}$ gives non-zero $\xi^{(\jmath)}$, and for $(\vec{\phi} \cdot \vec{T})^{2}$ only $\left(\phi_{z} T_{z}\right)^{2}$ and $\left(\phi_{+} T_{-} \phi_{-.} T_{+}\right)$contribute. Thus one odtains:

$$
\begin{aligned}
& \xi^{(+)}=\xi_{0}-\xi_{1} T+\xi_{2}\left(T^{2}+T\right) \\
& \xi^{(0)}=\xi_{0}+\xi_{2} T \\
& \xi^{(-)}=\xi_{0}+\xi_{1} T+\xi_{2} T^{2} .
\end{aligned}
$$




$$
\begin{aligned}
& \xi_{2}=\frac{1}{T(2 T-1)}\left(\xi^{(+)}+\xi^{(-)}-2 \xi^{(0)}\right) \\
& \xi_{0}=\xi^{(0)}-\xi_{2} T \\
& \xi_{1}=\frac{1}{T}\left(\xi^{(0)}-\xi^{(+)}\right)+\xi_{2} T
\end{aligned}
$$

The pot iclal terms way be writren in a general way in terms of the neutron and proton densities:

$$
\xi^{(1)}=a_{n}^{(1)} \rho_{n}(r)+a_{p}^{(1)} \rho_{p}(r) .
$$

$\rho_{n}$ and $\rho_{p}$ are normallzed to $N$ and $z$. Nea: $T_{n}=280 \mathrm{MeV}$, where the $\Delta_{33}$ resonance doninates the $\pi-N$ scstering amplitigh, $\pi-N$ cross sections are related in a simpie way by 1sospin:

$$
\frac{d \sigma}{d \Omega}\left(\pi^{+} p+\pi^{+} p\right)=\frac{d \sigma}{d \Omega}\left(\pi^{-} p+\pi^{-} p\right)=4 \frac{d \sigma}{d \Omega}\left(\pi^{0} n+\pi^{0} n\right)=\frac{d \sigma}{d \Omega}\left(\pi^{-} n+\pi-n\right) .
$$

which Implies that $a_{n}^{(+)}=a_{p}^{(-)}$and $a_{n}^{(-)}=a_{p}^{(+)}$. Also, since pion scattering froz a $T=0$ nuciecs must be independent of the nuclear 1sospln:

$$
\begin{aligned}
& a_{n}^{(-)}+a_{p}^{(-)}=a_{n}^{(+)}+a_{p}^{(+)}=a_{n}^{(0)}+a_{p}^{(0)}, \\
& \text { so that } a_{n}^{(0)}=a_{p}^{(0)} \equiv \lambda_{0}^{(1)} .
\end{aligned}
$$




$$
\begin{aligned}
& \xi_{2}=\frac{1}{T(T-1)}\left(a_{n}^{(+)} \rho_{n}+a_{p}^{(+)} \rho_{p}+a_{p}^{(-)} \rho_{p}\right. \\
& \left.-2\left(a_{n}^{(0)} \rho_{n}+a_{p}^{(0)} \rho_{p}\right)\right)=0
\end{aligned}
$$

Using Fq. V-8, the Isoscalar and 1sovector p-wave terms become:

$$
\begin{aligned}
& \xi_{0}=\lambda_{0}^{(l)} \rho(r), \quad p(r) \equiv \rho_{n}(r)+o_{p}(r), \\
& \xi_{1}=\frac{1}{2 T} \lambda_{1}^{(1)} \Delta \rho, \quad \Delta p(r) \equiv \rho_{n}(r)-\rho_{p}(r) .
\end{aligned}
$$

So that in lowest order:

$$
\xi(r)=\xi_{0}+\xi_{1}(\vec{\phi} \cdot \vec{T})
$$

$\left.\lambda_{0}^{(}\right)$and $\left.\lambda_{1}^{(}\right)$are expressed in terms of the free $\pi-N$ scattering amplitudes, $a_{2 \mathrm{~T}, 2 \mathrm{~J}^{2}}^{2}$

$$
\begin{aligned}
& \lambda_{0}^{(1)}=\frac{4 \pi}{3 k^{3} p_{1}}\left(4 a_{33}^{1}+2 \alpha_{31}^{1}+2 a_{13}^{1}+a_{11}^{1}\right) \\
& \lambda_{1}^{(1)}=\frac{8 \pi}{3 k^{3} p_{1}}\left(2 a_{33}^{1}+a_{31}^{1}-2 \alpha_{13}^{1}-a_{11}^{1}\right) .
\end{aligned}
$$

The results for the s-wave part of the lowest order optlcal potential are: 


$$
\begin{aligned}
& \bar{\lambda}_{0}^{(1)}=\frac{4 \pi}{3 k k^{2}} p_{1}\left(a_{31}^{0}+a_{11}^{0}\right) \\
& \bar{\lambda}_{1}^{(1)}=\frac{8 \pi}{3 k k^{2}} p_{1}\left(a_{31}^{0}-\alpha_{11}^{0}\right) . \\
& \bar{\xi}_{2}(r)=0
\end{aligned}
$$

$k$ is the relative $\pi-N$ center-of-mass momentum, and $k$ is the relative $\pi-A$ center-of-mass momentum. The $\pi-N$ amp11tudes, $a_{2 \mathrm{~T}, 2 \mathrm{~J}}^{\ell}$ are evaluated at the center of mags energy equal to the center-of-mass $\pi-A$ energy. Thus, s- and p-wave parts have the same form, 1e: $\vec{\xi}_{0} \vec{\xi}_{0}+$ $\bar{\xi}_{1}(\vec{\phi} \cdot \vec{T})$. $P_{1}$ is a kinematic factor arising from the transformation from the $\pi-N$ center-of-mass frame to the $\pi-A$ center-of-mass frame, glven by

$$
\begin{aligned}
& p_{1}=\frac{1+\varepsilon}{1+\varepsilon / A}, \quad \sigma=\omega / M \\
& \omega=\left(k^{2}+m_{\pi}^{2}\right)^{1 / 2}
\end{aligned}
$$

and $M$ is the nucleon mass.

In order to accommodate an energy shift in the $\Delta_{33}$ channel $a_{33}^{i}$ Is replaced by $\Omega a_{33}$, where

$$
\begin{aligned}
& \Omega=\frac{\omega-\omega_{r}+1 \Gamma}{\omega-\left(\omega_{r}+\Delta E_{1}\right)+1\left(\Gamma+\Delta E_{2}\right)} \\
& \omega_{r}=1232 \mathrm{MeV}-\left(k^{2}+M^{2}\right)^{1 / 2}
\end{aligned}
$$




$$
r=\frac{4}{3} \frac{0.08 x^{3} w}{m_{\pi}^{2}\left(k^{2}+m_{\pi}^{2}\right)^{1 / 2}}
$$

$\Delta E_{1}$ and $\Delta E_{2}$ are emplrically determined real and lmaginary energy shifts obtalned by fitting elastlc scattering data.

Johnson and Slctllano have derlved a forn for the 1sospin and density dependence of the $\pi-A$ optical potentlal to second order in density [Jo-83a]. Thelr result, quadratic in $\Delta \rho$ and $\rho$, is characterized by five complex parameters that contain the reaction dynamics Information of the second order terms. The 1sospin dependence of the second order terms resembles that of the first order terms. The full optical potential is:

$$
\begin{aligned}
& U=-\vec{\nabla} \cdot(\xi(r)+\Delta \xi(r)) \vec{\nabla}-k^{2}(\bar{\xi}(r)+\Delta \bar{\xi}(r)) \\
& -\frac{1}{2}\left(p_{1}-1\right) \nabla^{2} \xi(r)-\frac{1}{2}\left(p_{2}-1\right) \nabla^{2} \Delta \xi(r)
\end{aligned}
$$

$\Delta \xi(r)(\Delta \bar{\xi}(r))$ are the second order cerws s $P_{2}$ is a frame transformation factor:

$$
P_{2}=\frac{1+\varepsilon / 2}{1+\varepsilon / A}
$$

It is aggumed that in the region of $T_{\pi}=164 \mathrm{MeV}$ s-wave contributions to the second order potentlal are negligible, and thus have been Ignored in this analygls. For p-waves the second order terms are: 


$$
\begin{aligned}
& \Delta \xi_{0}=\lambda_{0}^{(2)} \frac{\rho^{2}(r)}{\rho_{0}}-\frac{1}{2 T-1} \lambda_{2}^{(2)} \frac{\Delta \rho^{2}(r)}{\rho_{0}} \\
& \Delta \xi_{1}=\frac{\lambda_{1}^{(2)} \rho(r) \Delta \rho(r)}{2 T}+\frac{\lambda_{2}^{(2)}}{2 T(2 T-1) \frac{\Delta \rho^{2}(r)}{\rho_{0}}} \\
& \Delta \xi_{2}=\frac{\lambda_{2}^{(2)}}{T(2 T-1) \frac{\Delta \rho^{2}(r)}{\rho_{0}}+\frac{\lambda_{4}^{(2)}}{T^{2}} \frac{\Delta \rho^{2}(r)}{\rho_{0}}}
\end{aligned}
$$

A simflar expression holds for s-waves. $p_{0}=0.16 \mathrm{fm}^{-3} 1 \mathrm{tg}$ present so that the first and eecond order parameters have the same ( $\mathrm{fm}^{3}$ ) units. In $[J o-83 a]$ it is shown that the $\lambda_{1}^{(2)}$ are weakly dependent on $N, Z$, and $A$. However, they are expected to have a strong energy dependence. Fnr the fits to elastic, single and double charge exchange it was assumed that the $\lambda_{1}^{(2)}$ were independent of $N, Z$, and A. Since total Isospin ( $\left.\dagger=+\frac{T}{T}+\phi\right)$ is conserved to a high degree in the strong interaction, the elastic and charge exchange cross sections may be expressed in terms of the scattering amplitudes in the channels $T=T+1, T=T$, and $T=T-1$. In this scheme the Kleln-Gordon equations describing elastic and charge exchange scattering become uncoupled:

$$
\begin{aligned}
& \left(-\nabla^{2}+\mathrm{U}_{\mathrm{T}-1}\right){ }_{\mathrm{T}-1} \Rightarrow \mathrm{k}^{2} \mathrm{~T}_{\mathrm{T}-1} \\
& \left(-\nabla^{2}+\mathrm{U}_{\mathrm{T}}\right) \Psi_{\mathrm{T}}=\mathrm{k}^{2} \mathrm{~T}_{\mathrm{T}} \\
& \left(-\nabla^{2}+\mathrm{U}_{\mathrm{T}+1}\right){ }_{\mathrm{T}+1}=\mathrm{k}^{2} \Psi_{\mathrm{T}+1} \cdot
\end{aligned}
$$


The $U_{T}$ are calculated from

$$
\begin{aligned}
& (\vec{\phi} \cdot \vec{T})=\frac{1}{2}(T(T+1)-T(T+1)-2) \\
& \text { so for } T=T \quad \vec{\phi} \cdot \vec{T}=-1, \\
& \text { and for } T=T+1 \quad \vec{\phi} \cdot \vec{T}=T, \\
& \text { and for } T=T-1 \quad \vec{\phi} \cdot \vec{T}=-(T+1) .
\end{aligned}
$$

By evaluating $U$ in eq. $V-1$ between states of total isospin, $T$, the optical potential in the three 1sospin channels becomes:

$$
\begin{aligned}
& \mathrm{U}_{\mathrm{T}}=\mathrm{U}_{0}-\mathrm{U}_{1}+\mathrm{U}_{2}, \\
& \mathrm{U}_{\mathrm{T}+1}=\mathrm{U}_{0}+\mathrm{TU} \mathrm{U}_{1}+\mathrm{T}^{2} \mathrm{U}_{2}, \\
& \mathrm{U}_{\mathrm{T}-1}=\mathrm{U}_{0}-(\mathrm{T}+1) \mathrm{U}_{1}+(\mathrm{T}+1)^{2} \mathrm{U}_{2} .
\end{aligned}
$$

The computer code PIESDEX [Jo-83b] is a modification of the elastlc scattering code PIRK [E1-74]. Elast1c scattering amplitudes In channels of $\mathrm{T}$ are calculated, and Ilnear comblnations of these are used to form the $\left(\pi^{ \pm}, \pi^{ \pm}\right),\left(\pi^{+}, \pi^{-}\right)$, and $\left(\pi^{+}, \pi^{0}\right)$ cross sections. The coulomb interaction is not included in the calculation of the charge exchange amplitudes, but is included for the $\pi^{ \pm}-A$ elastic amplitudes. PIESDEX 13 linked to the MINUIT $\chi^{2}$ optimlzing program [Ja-75], which allows the best $f_{1 t} \lambda_{1}(2)$, and $\Delta E=\Delta E_{1}+1 \Delta E_{2}$ values to be found. 
In Eq. V-13c the dynemics of the second order lsotensor part of the optical potential is described by two parameters, $\lambda_{2}^{(2)}$ and $\lambda_{4}^{(2)} . \quad \lambda_{2}^{(2)}$ contalns the sequentlal scattering of the pton by two correlated nucleons through all non-analog intermediate states and the single analog intersedlate state. The latter, however, is already included in the iteration of the lowest order optical potential (Eq. $v-9 d)$. To prevent double counting of two sequentlal charge exchanges through the intermediate single analog state, the $\lambda_{4}^{(2)}$ term subtracts this channel from the $\lambda_{2}^{(2)}$ term. $\lambda_{4}^{(2)}$ is calculated theoretically for a given energy shift $\Delta E$ from Eq. 5.37 of [Jo-83a].

The fltting $p r$ dure was as follows: $\rho$ and $\Delta \rho$ (the valence neutron density) are Hartree-Fock densitles of the Skyrme III effective interaction [Be-75], and contain the nuclear structure Information. The energy shift and second order 1soscalar parameter $\lambda_{0}^{(2)}$ were obtained by fitting elastic scattering data for 160 [In-78], ${ }^{28} \mathrm{SI}[01-80]$, and ${ }^{40} \mathrm{Ca}[\mathrm{In}-78]$. The results of fitting the elastlc scatterling data are:

$$
\begin{aligned}
& \Delta E=35.0+0.31 \mathrm{MeV} \\
& \lambda_{0}^{(2)}=0.75+3.671 \mathrm{fm}^{3} .
\end{aligned}
$$

The total reduced $x^{2}=20$. The calculated value of $\lambda_{4}^{(2)}$ is

$$
\lambda_{4}^{(2)}=2.89-1.131 \mathrm{fm}^{3}
$$


The energy shift rals=s the resonance by $35 \mathrm{MeV}$ and broadens $1 t$ slightly.

$\lambda_{1}^{(2)}$ and $\lambda_{2}^{(2)}$ were determined by glmultaneously fitting the $0^{\circ}$ SCX and $5^{\circ}$ DCX data in Table V-1. The results of fitting this forward angle data with the values of $\Delta E, \lambda_{0}^{(2)}$, and $\lambda_{4}^{(2)}$ above are

$$
\begin{aligned}
& \lambda_{1}^{(2)}=7.71( \pm 1.96)+15.51( \pm 0.89) \mathrm{fm}^{3}, \\
& \lambda_{2}^{(2)}=1.66( \pm 2.12)+10.8( \pm 0.5) \mathrm{fm}^{3},
\end{aligned}
$$

Table V-1: DCX and SCX [Sen-83] center-of-mass cross sections Input to the PIESNEX fits.

$\begin{array}{lll}\left(\pi^{+}, \pi^{-}\right), & \tau_{\mathrm{d}}=164 \mathrm{MeV} / \mathrm{d} \Omega\left(5^{\circ}\right) \\ (\mu \mathrm{b} / \mathrm{sr}) & \left(\pi^{+}, \pi^{\circ}\right), \mathrm{T}_{\pi}=165 \mathrm{MeV} \\ & \text { Target } & \begin{array}{l}\mathrm{do} / \mathrm{d} \Omega\left(0^{\circ}\right) \\ (\mathrm{mb} / \mathbf{s r})\end{array}\end{array}$

\begin{tabular}{llll}
\hline${ }^{14} \mathrm{C}$ & $1.00 \pm 0.10^{\mathrm{a}}$ & ${ }^{7} \mathrm{~L} 1$ & $4.03 \pm 0.60$ \\
$18 \mathrm{O}$ & $0.976 \pm 0.112^{\mathrm{b}}$ & $1{ }^{3} \mathrm{C}$ & $1.80 \pm 0.33$ \\
$26 \mathrm{Mg}$ & $0.242 \pm 0.097$ & $14 \mathrm{C}$ & $2.37 \pm 0.36$ \\
${ }^{42} \mathrm{Ca}$ & $0.138 \pm 0.039 \mathrm{c}$ & $15 \mathrm{~N}$ & $1.20 \pm 0.40$ \\
${ }^{48} \mathrm{Ca}$ & $0.635 \pm 0.182^{\mathrm{d}}$ & $18 \mathrm{O}$ & $1.91 \pm 0.42$ \\
${ }^{56} \mathrm{Fe}$ & $0.032 \pm 0.018$ & $60 \mathrm{N1}$ & $0.87 \pm 0.09$ \\
& & $90 \mathrm{Zr}$ & $0.89 \pm 0.09$ \\
& & $120 \mathrm{Sn}$ & $1.87 \pm 0.14$ \\
& & $140 \mathrm{Ce}$ & $1.33 \pm 0.15$ \\
& & $208 \mathrm{~Pb}$ & $1.80 \pm 0.48$
\end{tabular}

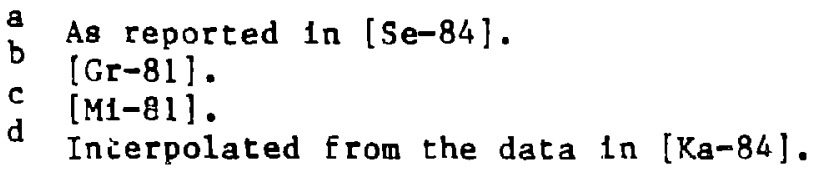


with reduced $x^{2}=3.3$. The errors correspond to an Increase of the total $x^{2}$ of one. For the purposes of comparing to the phenomenologically determined second second order parameters, the first order parameters are

$$
\begin{aligned}
& \lambda_{0}^{(1)}=4.64+5.431 \mathrm{fm}^{3}, \\
& \lambda_{1}^{(1)}=5.12+5.411 \mathrm{fm}^{3},
\end{aligned}
$$

for 180 at $T_{\pi}=164 \mathrm{MeV}$. Note that $\lambda_{0}^{(2)}, \lambda_{1}^{(2)}$, and $\lambda_{2}^{(2)}$ are roughly the same size as the single scattering terms and thus significantly alter the SCX and DCX amplitudes from the lowest order results.

To show how the $\lambda_{1}(2)$ contribute to the scattering amplitude, the lowest order scattering amplttude $F(\theta)\left(\lambda_{1}(2)=0, \Delta E=0\right)$, $1 \mathrm{~s}$ shown in Fig. V-la for ${ }^{26} \mathrm{Mg}\left(\pi^{+}, \pi^{-}\right)^{26} \mathrm{SI}$ (DIAS), and the contributions, $\mathbb{F}^{(2)}(\theta)$, made to the scátéting amplitude by the $\lambda(2)$ are shown in F1g. ". .b. The task presented to the second order order theory 1s that the forward angle DCX data are described falrly well by the lowest order calculations, but the forward angle SCX data are underestimated by a factor of two to four in lowest order calculations. SCX cross sections are most sensitive to $\lambda_{1}(2)$, while DCX cross sections are sensitlve to both $\lambda_{1}^{(2)}$ and $\lambda_{2}^{(2)}$. The effect of $\lambda_{1}^{(2)}$ is to add coherently to the lowest order amplitude for SCX and thus reproduces the trend of the A-dependence $1 \mathrm{n} \mathrm{F1g.} \mathrm{V-2.} \mathrm{In} \mathrm{the}$ case of DCX at forward angles, the effect of $\lambda_{1}^{(2)}$ and $\lambda_{2}^{(2)}$ cancel each other, and the forward angle data are well reproduced in Fig. V-3. Angular distributions calculated with the phenomenologicaily 


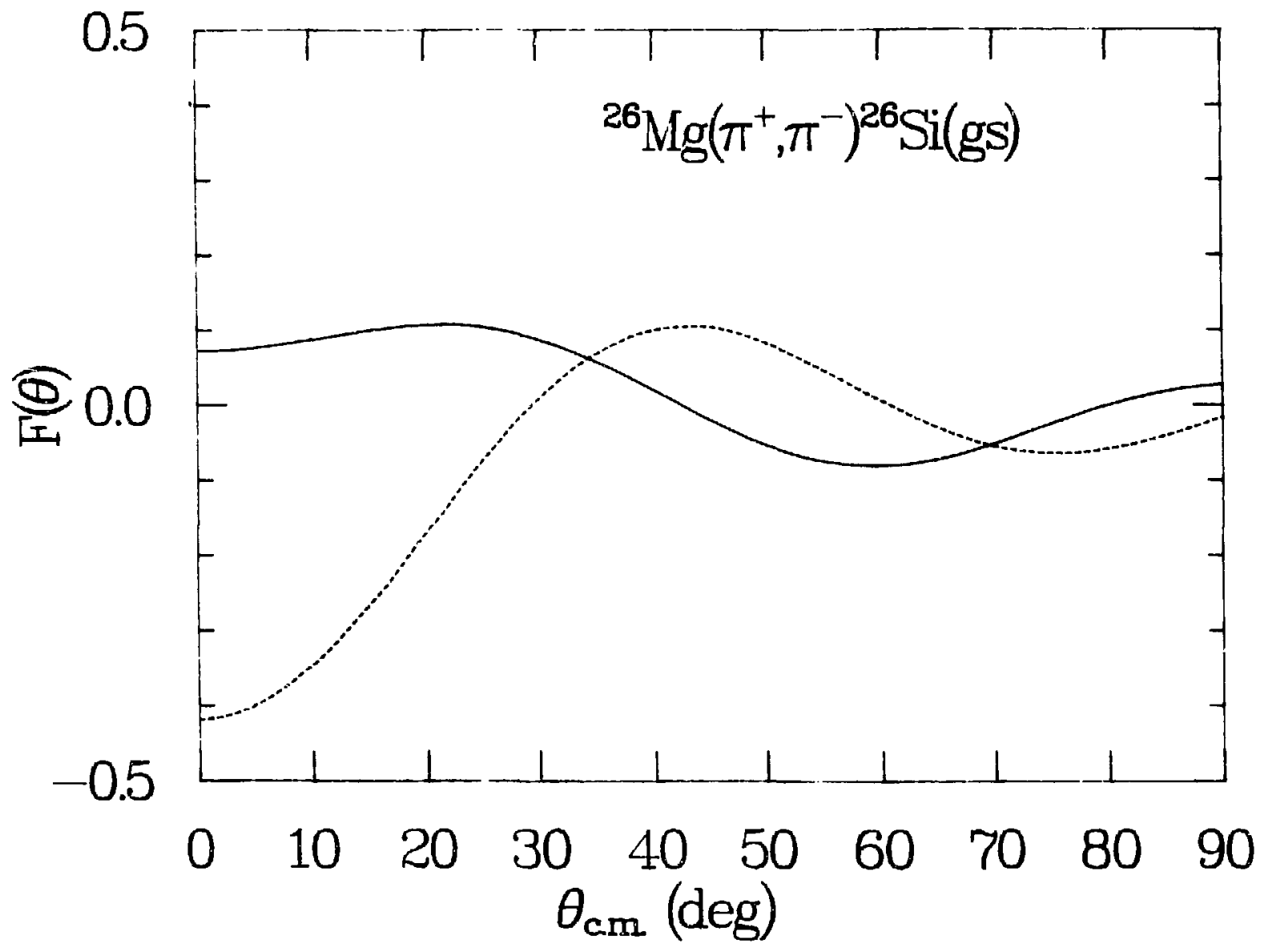

Fig. V-:a: Real (solid line) and lmaginary (dashed 1ine) parts of the lowest order $(\lambda\} 2)=0, \Delta E=35.0+0.3 \mathrm{MeV})$ scat :ering amplitude for $26 \mathrm{Mg}\left(\pi^{+}, \pi^{-}\right)^{26}$ SitDIAS), in $\sqrt{\mu \mathrm{b} / \mathrm{sr}}$. 

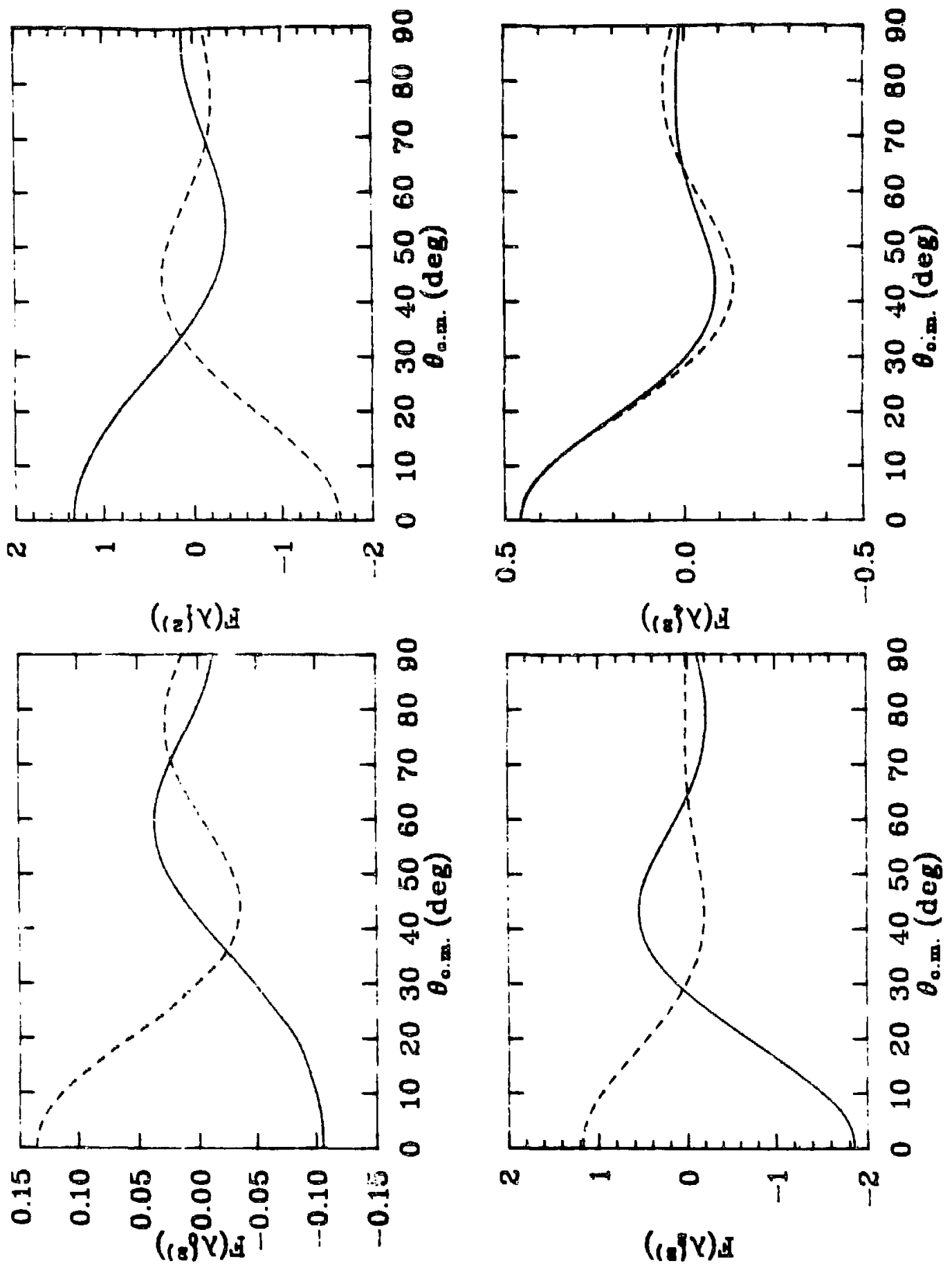

FIg. V-lb: Real (sol1d 11nes) and Imaglnary (dashed 11nes) contributions to the scattering amplitude from the $\lambda\left\{_{2}\right.$ terms of Eq.
$V-17,18,19$, in $\sqrt{p b / s r}$. 


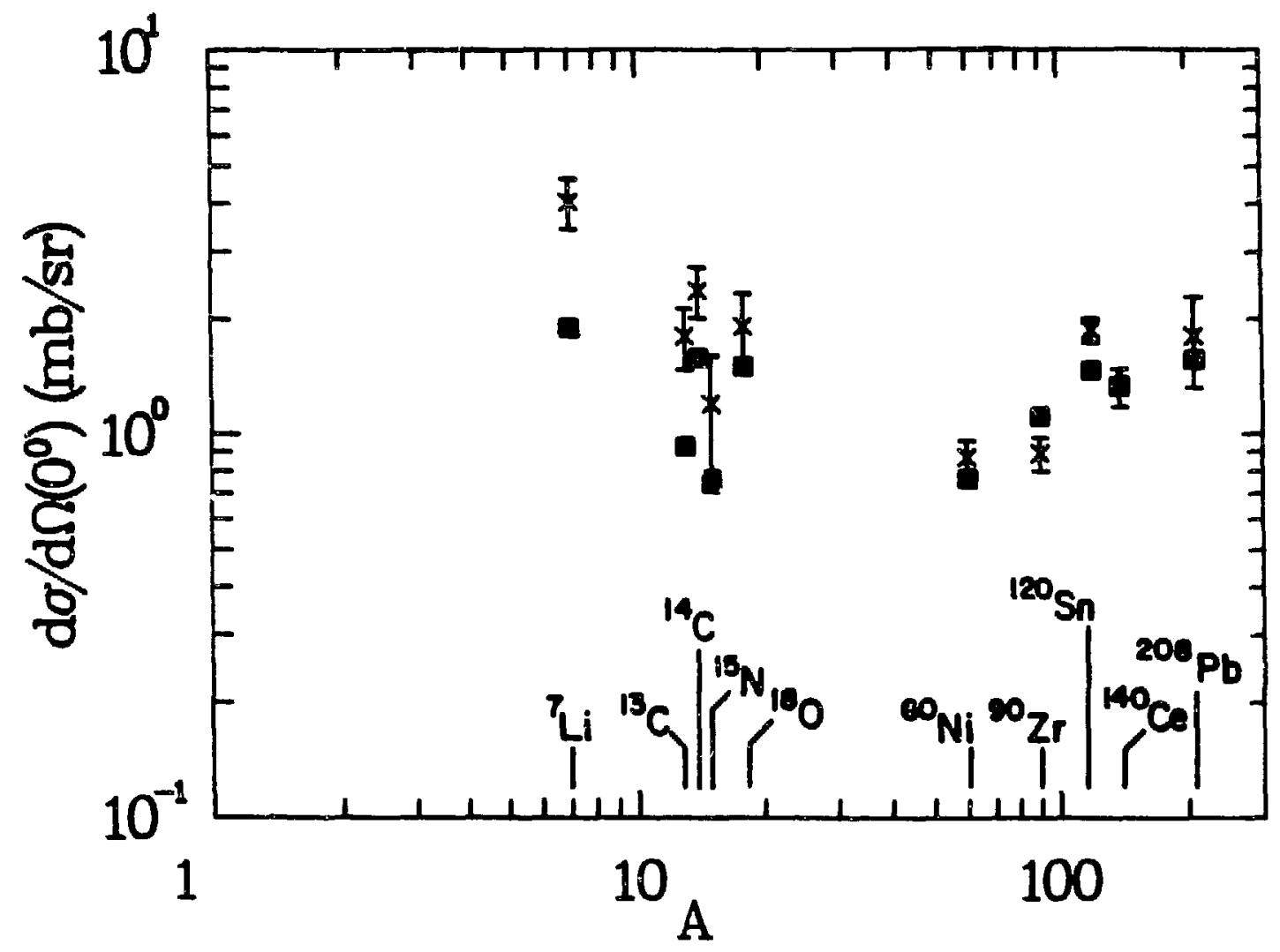

Fig. V-2: Comparison of forward angle SCX differential cross sections (crosses) to the PIESDEX resilts (squares). 


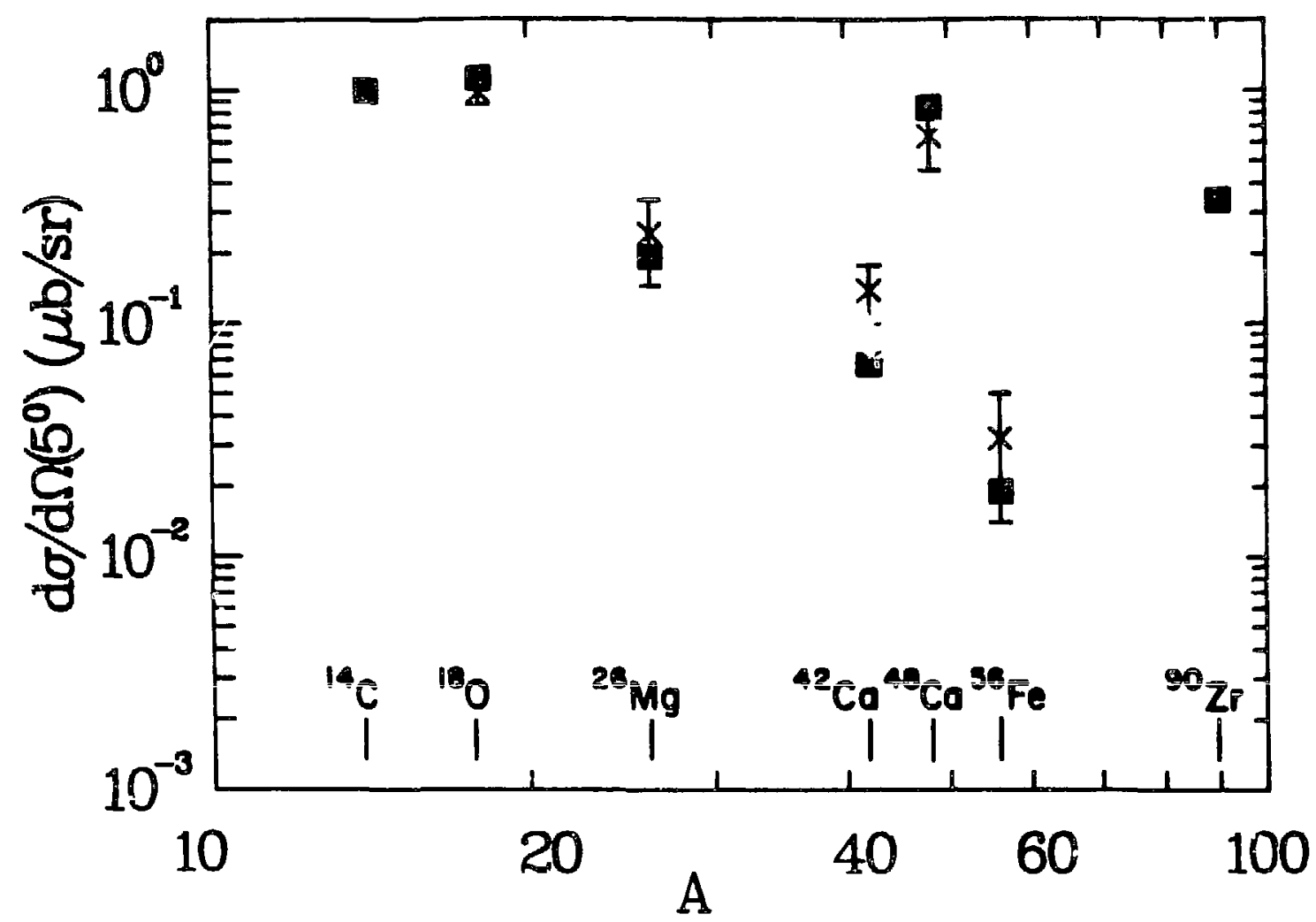

Flg, V-3: Comparison of forward angle DCX differential cross sections (crosses) to the PIESDEX results (squares). The $90 \mathrm{Zr}$ point is a prediction. 


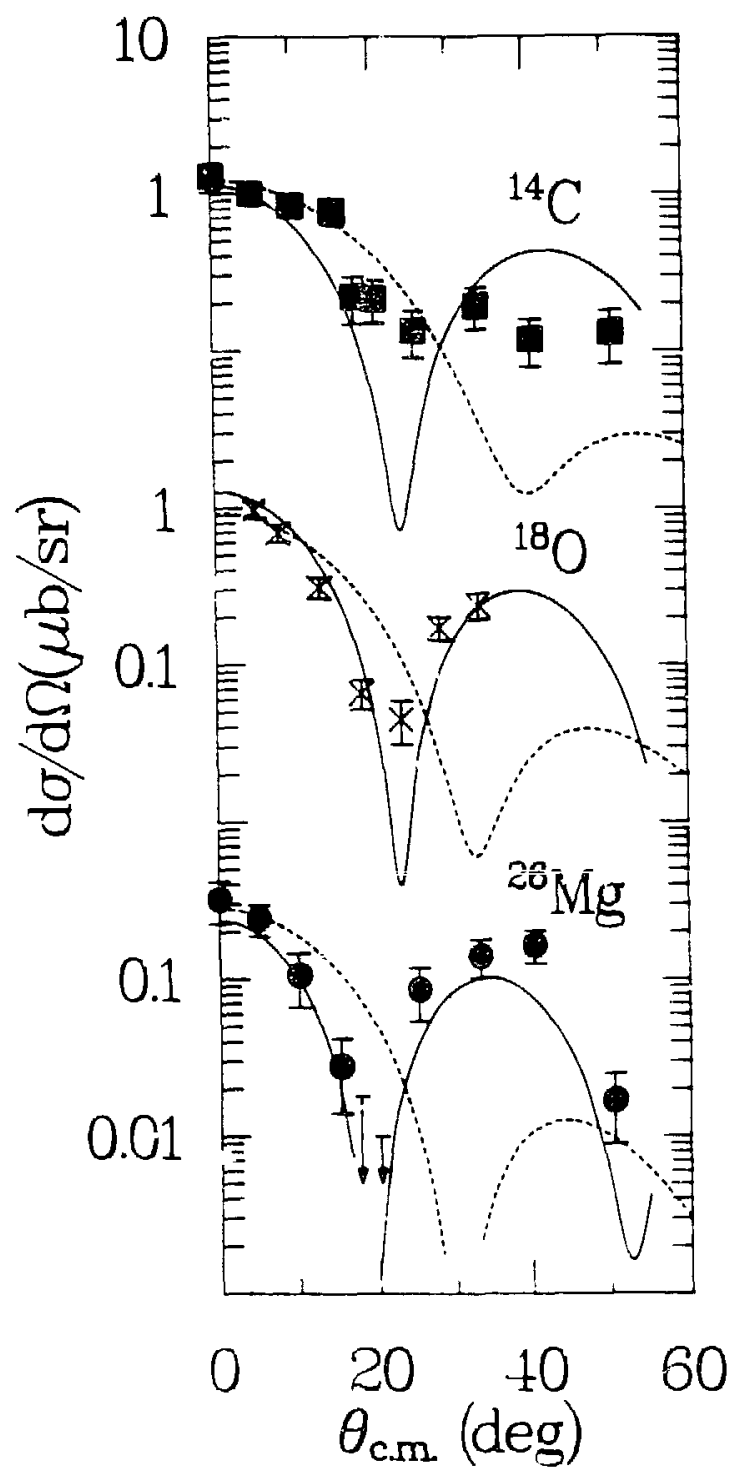

F1g. V-4: Comparison of DCX data at $T_{\pi}=164 \mathrm{MeV}$ to the 1sobaric invariant model PFESDEX calculations. The dashed curve $1 \mathrm{~s}$ the lowest order result $(A\{2)=0, \Delta E=0)$. The solld curve is the result of fitting only forward angle SCX, DCX data and elastic scattering angular distributions for $160,28 \mathrm{~s} 1$, and $40 \mathrm{ca}$. 
determined parameters for the second order potentlal are shown in Fig. V-4. For the DCX angular distributions the effect of $\lambda_{2}^{(2)}$ is to move the minimum predicted in the lowest order calculation from $Q R=2.7$ tc $q R=1.7 \mathrm{fm}^{-1}, 1 \mathrm{n}$ agreement with the ${ }^{18} 0$ and ${ }^{26} \mathrm{Mg}$ data. In the case of ${ }^{14} \mathrm{C}$, the shallow minimum at $164 \mathrm{MeV}$ remalns enigmatic.

The dependence of the charge exchange angular distributions on tive particular form of the densities used is shown In Fig. V-5 for ${ }^{13} \mathrm{C}$ ard $15 \mathrm{~N}$ SCX data at $165 \mathrm{MeV}[\mathrm{Do}-82]$, and for DCX on ${ }^{14} \mathrm{C}$ In P1g. V-6. The fact that the valence neutron density at the $\sim 0.1$ density point $1 \mathrm{~s}$ larger for DME denslties than for Skyrme III denalties is reflectad In a proportional increase in the cross sections at forward angles, since SCX cross sections are roughly proportional to $(\Delta p / p)^{2}$, while $D C X$ cross sections are proportional to $(\Delta \rho / \rho)^{4}$. This strong densicy dependence shows the need to correctiy describe the nuclear atrueture In $\rho$ and $\Delta p$, in ordier to successfully separate it irom the reaction dynamics information contained in the $\lambda(2)$. it is strossed that the success of this rests on the aesumptioa that Skycme-III Hartree-Fock densities adequately describe nuclear structure for the purposes of $\left(\pi^{+}, \pi^{-}\right)$and $\left(\pi^{+}, \pi^{0}\right)$ calculations.

The effect of $\pi-\Delta_{33}$ and $p-\Delta_{33}$ interactions on the $130\left(\pi^{+}, \pi^{-}\right)^{18} \mathrm{Ne}(\mathrm{DIAS})$ excitation function have been Investigated in [Jo-84]. In that work, the authors found large contributions to the cross sections for the sequence of processes: $\pi^{+} n+\Delta^{+}, \theta^{+} n+\Delta^{C}$, $\Delta^{0}+\pi^{-}$p. The calculated DCX cross section, however, is generally too large and reproduces the excltation function only for $T_{\pi} \leq 100 \mathrm{MeV}$. 


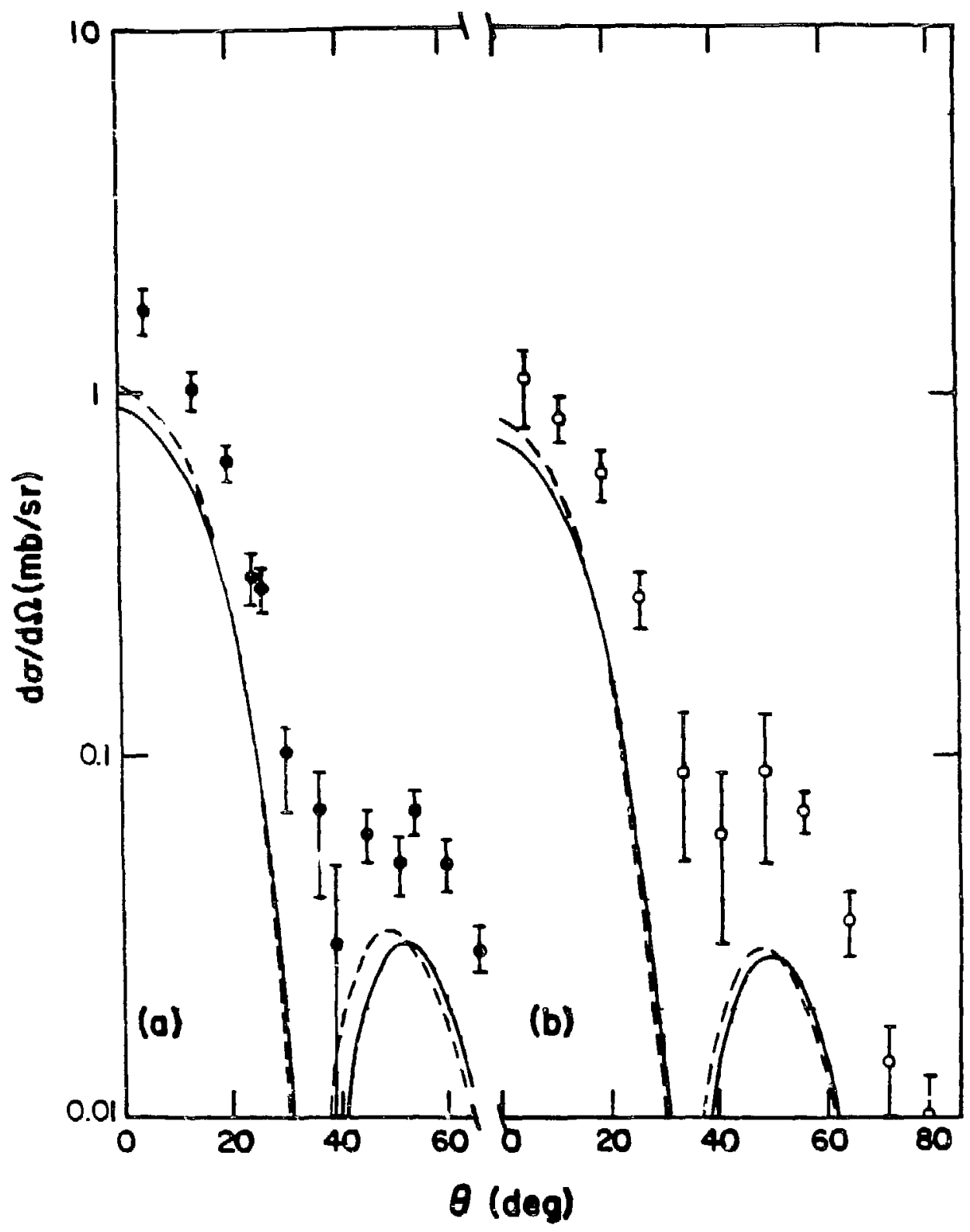

F1g. V-5: Cafculations for (a): ${ }^{13} \mathrm{C}\left(\pi^{+}, \pi^{0}\right)^{13} \mathrm{~N}$, and (b): ${ }^{15} \mathrm{~N}\left(\pi^{+}, \pi^{0}\right)^{15} \mathrm{C}$ data with $\lambda\{2\}$ and $\Delta E$ from $E q . V-17,18,19$. The dashed 11 nes are for Skyrme-III Hartree-Fock densities and the solid lines are for Negele-Vauthertn DME densities [Ne-72]. 


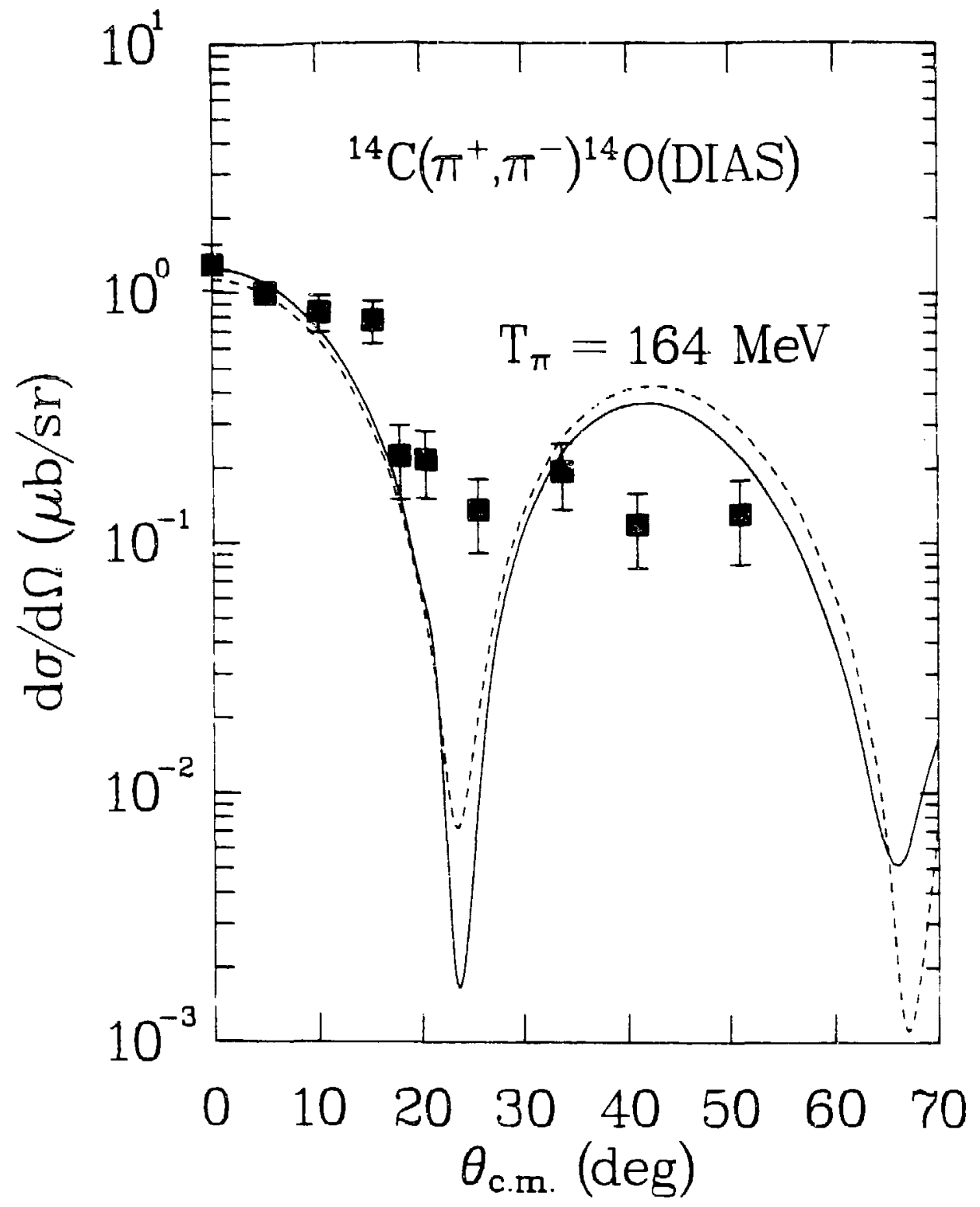

F1g. V-6: Calculations for ${ }^{14} \mathrm{C}\left(\pi^{+}, \pi^{-}\right)^{14} \mathrm{O}$ (DIAS) wth $\lambda\{2)$ and $\Delta E$ from Fq. V-17, 18, 19. The dashed IIne is for a skyrme-IIt Hartree-Fock density and the solid IIne is for a Negele-Vautherin DEE density [Ne-72] . 
Contributions from this and other exotic $\Delta$-nuclear effects may be contributing to the rather large second order terms obtained from the phenomenological fits discussed here. The energy dependence of these $\lambda(2)$ can be determined by fitting elastic and charge exchange data at several energles. Such an effort could gulde theoretical efforts to microscopically describe second order coneributions to the $\pi$-A Interaction.

B. Second order Optical Potential and Core Excitation

A coupled channels approach to DCX has been applied by Liu to the ${ }^{18} \cap\left(\pi^{+}, \pi^{-}\right)^{18} \mathrm{Ne}$ (DIAS) [L1-83] and ${ }^{42} \mathrm{Ca},{ }^{48} \mathrm{Ca}\left(\pi^{+}, \pi^{-}\right)^{42} \mathrm{T1},{ }^{48} \mathrm{TI}$ (DIAS) reactions [Set-84, Ka-83]. The detalls of this theory are described In [L1-83], where the ${ }^{18} 0\left(\pi^{+}, \pi^{-}\right)^{18} \mathrm{Ne}$ (DIAS) excltation function data and angular distribution data at $T_{\pi}=164$ and $292 \mathrm{MeV}$ are well reproduced by a pion-nucleus interaction that includes the effect of plon absorption. Core-excltation wave functions were used to describe the structure of $18^{0}$. In this section the application of this theory to the ${ }^{14} \mathrm{C}\left(\pi^{+}, \pi^{-}\right)^{14} \mathrm{O}$ (DIAS) data is described $[L 1-84 \mathrm{~b}]$.

Through 1sospin coupling, the charge exchunge matrix elements are Iinearly related to the 1soscalar, 1sovector, and 1sotensor parts of the r-A strong interaction,

$$
\mathrm{U}_{\mathrm{g}}=\mathrm{U}_{0}+\mathrm{U}_{1}(\dot{\phi} \cdot \overrightarrow{\mathrm{T}})+\mathrm{U}_{2}(\dot{\phi} \cdot \overrightarrow{\mathrm{T}})^{2}
$$

$\mathrm{U}_{0}, \mathrm{U}_{1}$ and $\mathrm{I}_{2}$ are also expressed in terms of optical potentials for 
${ }^{14} \mathrm{C}(\pi, \pi)^{14} \mathrm{C}$ elastic scattering. Thus, the $\pi^{(1)}-14 \mathrm{C}(1=+, 0,-)$ optical potential and the ${ }^{14} \mathrm{C}$ wave functions are tine necessary 1 nput to the DCX calculations.

The first order optical potentials, $U_{0 p t, 1}^{(1)}$ are proportional to $t_{\pi N}(E) \rho(r)$, where $t_{\pi N}(E)$ is the free $\pi-N$ t-matrix, and $\rho(r)$ is the nuclear density. Blnding energles for core and valence nucleons are taken into account in the determination of the energy $E$ at which $t_{\pi N}$ is evaluated.

The second order terms are more complicated and are determined for a specific second order reaction mechanism, namely the absorpiton and emission of a plon by a palr of nucleons. The strength of these terms is calculated from a study of $\pi^{-12} \mathrm{C}$ elastic scattering data, and an "lsospin scaling model" is used to obtain the $U_{\text {opt }}^{(2)}$ for $\pi^{-14} \mathrm{C}$ scattering from that of the 12 G-system. In principle, the second order terms could be obtalned directly from $\pi^{-14} \mathrm{C}$ elastic scattering data, however, such data is limlted, existing only for $T_{\pi}=i 62 \mathrm{MeV}$. This procedure of obtalning the second order potential terms from neighborling nuclel provided good fits to $180(\pi, \pi)^{150}$ elastic scattering data in $[21-83]$. It $1 \mathrm{~s}$ because the ${ }^{14} \mathrm{C},{ }^{14} \mathrm{~N}(\mathrm{IAS})$, and ${ }^{14}$ (DIAS) wave functions have Identical space-spin parts that only the nuclear structure of ${ }^{14} \mathrm{C}(\mathrm{gg})$ need be known. A p-shell configuration mixed wave function was used $[\mathrm{Co}-65]$ :

$$
\begin{aligned}
& \left|{ }^{14} \mathrm{C}\right\rangle=|160\rangle \otimes|2 \mathrm{~h}\rangle \\
& \text { where }|2 \mathrm{~h}\rangle=-0.4053\left|\left(1 \mathrm{p}_{3 / 2}^{-1}\right)^{2}\right\rangle-0.9142\left|\left(1 \mathrm{p}_{1 / 2}^{-1}\right)^{2}\right\rangle
\end{aligned}
$$


$\left|\left(1 p_{3 / 2}^{-1}\right)^{2}\right\rangle$ and $\left|\left(1 p_{1 / 2}^{-1}\right)^{2}\right\rangle$ are harmonic oscillator wave functions. DCX cross sections were calculated with a ${ }^{14} \mathrm{C}$ wave function that included an s-d shell admixture [Fo-82] (not shown in this work), and provided very simliar resu'ts to those shown in this section.

The excltation function calculations are shown in Fig. V-7. The Efinal result, whlch includes the $\rho^{2}$-dependent interaction based on plon absorption and emlssion and the wave $f$ unction of Eq. V-20, agrees wth the data for $\mathrm{I}_{\pi}$, $180 \mathrm{MeV}$, and overestimates ie cross section by $\approx 50 \%$ for lower energles. A test of this calculation 13 provided by measuring forward angle cross sections for $T_{p}<100 \mathrm{MeV}$. Agreement with the solid curve would inticate that the ${ }^{14} \mathrm{C}\left(\pi^{+}, \pi^{-}\right)^{14} \mathrm{O}$ (DIAS) and $180\left(\pi^{+}, \pi^{-}\right)$Ne(DIAS) excitation functions have a stmilar shape, with the ${ }^{14} \mathrm{C}$ cross section peaked at $T_{\pi} \approx 70 \mathrm{MeV}$, while the $18_{0}$ data are peaked at $T_{\pi} \approx 120 \mathrm{MeV}$. Recently, reasurements of ${ }^{14} \mathrm{C}\left(\pi^{+}, \pi^{-}\right)^{14} \mathrm{O}(\mathrm{gs})$ at $T_{\pi}=50 \mathrm{MeV}$ \& t ve $\mathrm{d} \sigma / \mathrm{d} \Omega\left(0^{\circ}\right)=3.9 \pm 0.5 \mathrm{Hb} / \mathrm{sr}$ [Le-84], $1 \mathrm{n}$ excellent agreemeat with the calculation shown in Fig. V-7.

The $164-\mathrm{MeV} \quad \mathrm{C}$ angular distribution and calculations are shown In Fig. 8. As in the case of ${ }^{18} 0$ [L1-83], the effect of the $\rho^{2}$ dependent terms is to move the first minimum from that found in most lowest order calculatiors to a smaller angle. However, the lack of a minimum in the data is a feature not reproduced by this, (and not explained by any other) calculation. The inclusion of the nuclear structure Information of $E q . V-20$ ralses the overall cross section, and has only a minor effect on the position of the minimum. 


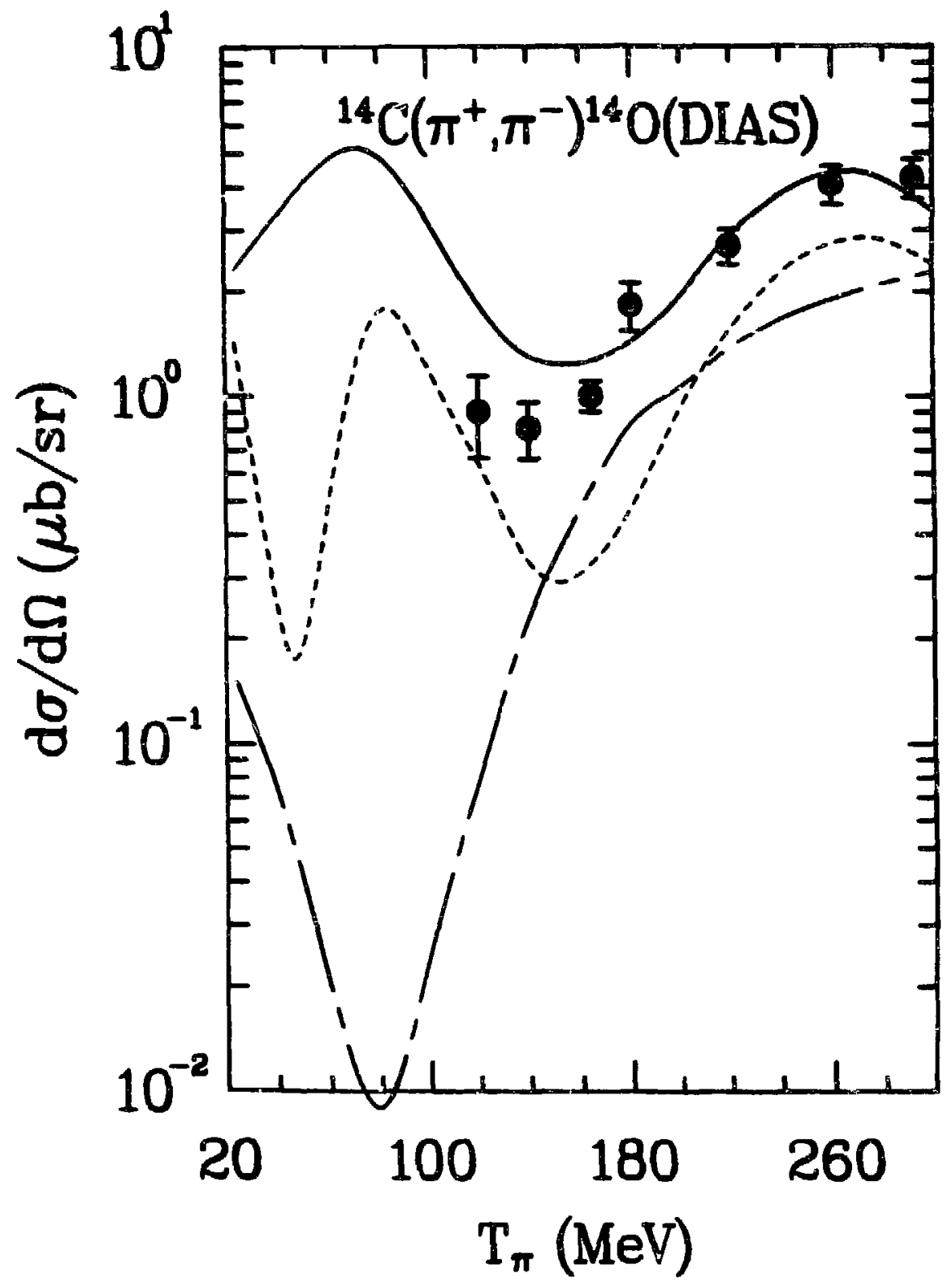

F1g. V-7: DCX coupled channels calculations of L. C. Liu [L1-84]. The long dashed curve includes no second-order optical-potential terms, and uses DME Hartree-Fock wave functions [Ne-72] (no configuration mixing) to describe the nuclear structure of ${ }^{14} \mathrm{C}$. The short dashed curve includes second-order optlcal-potential terms and the DME wave functions. The solid curve includes the second-order optical-potential terms and the core-excitation wave function of Eq. $\mathrm{V}-20$. 


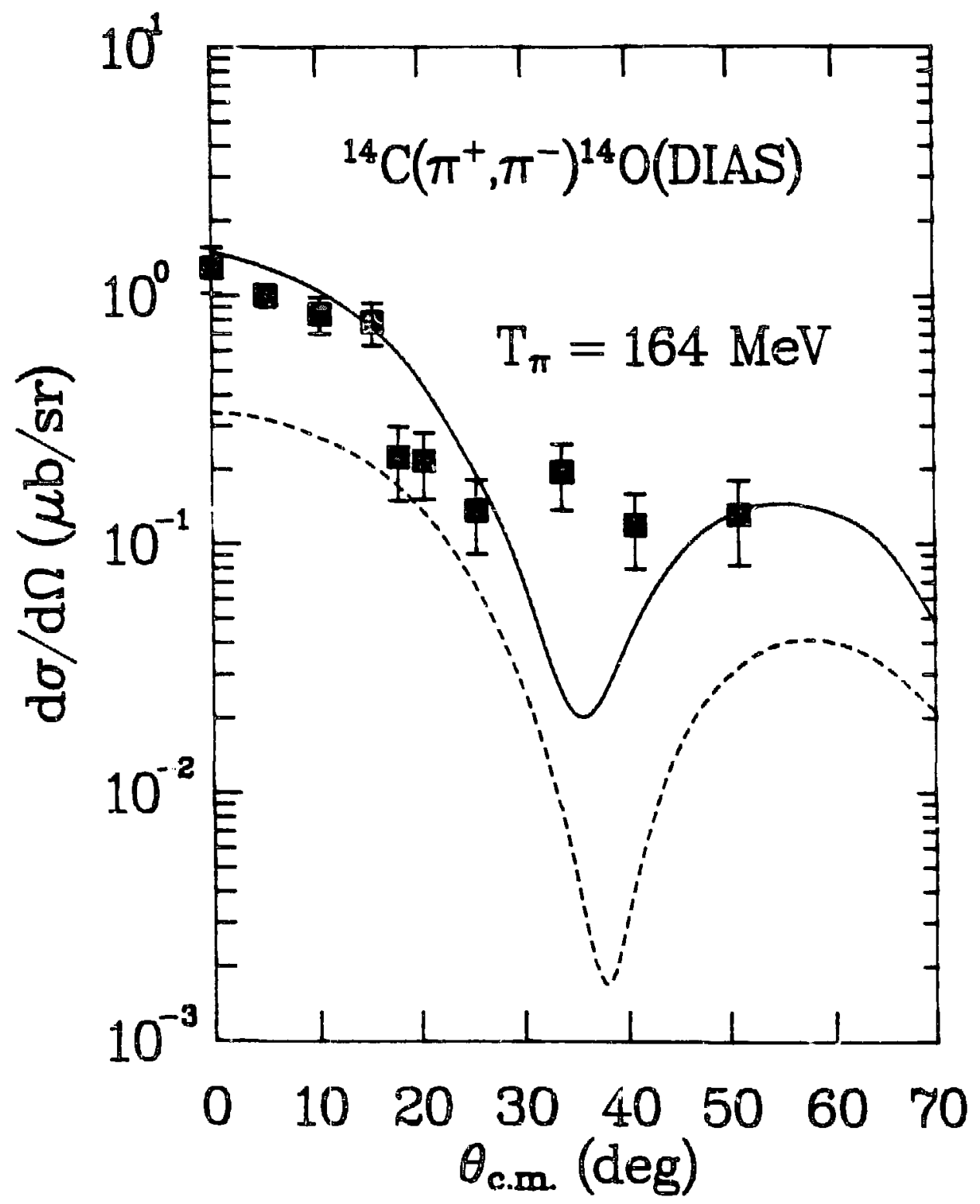

Fig. V-8: At $164 \mathrm{MeV}$ the the decrease of the forward-angle cross is reproduced by the calculation lncluding $\rho^{2}$ terms and the coreexcitation ${ }^{14} \mathrm{C}$ wave function of $\mathrm{Eq} \cdot \mathrm{V}-20$ (solid curve). The dashed curve has the same meaning as in Fig. $\mathrm{V}-7$. 
The situation at $292 \mathrm{MeV}$ is shown in Fig. V-9. The $\mathrm{p}^{2}$ terme and nuclear structure have the same general effects on the cross section. The agreement $1 \mathrm{~g}$ good, except at $50^{\circ}$, where the datum $1 \mathrm{~s}$ one order of magnitude greater than the calculation. It is speculated [L1-84] that this may be due to an inadequate treatment of Fermi motion, which would cause largest error at a momentum transfer comparable to the Ferms momentum, or nuclear structure detalls not contained in Eq. V-20. 


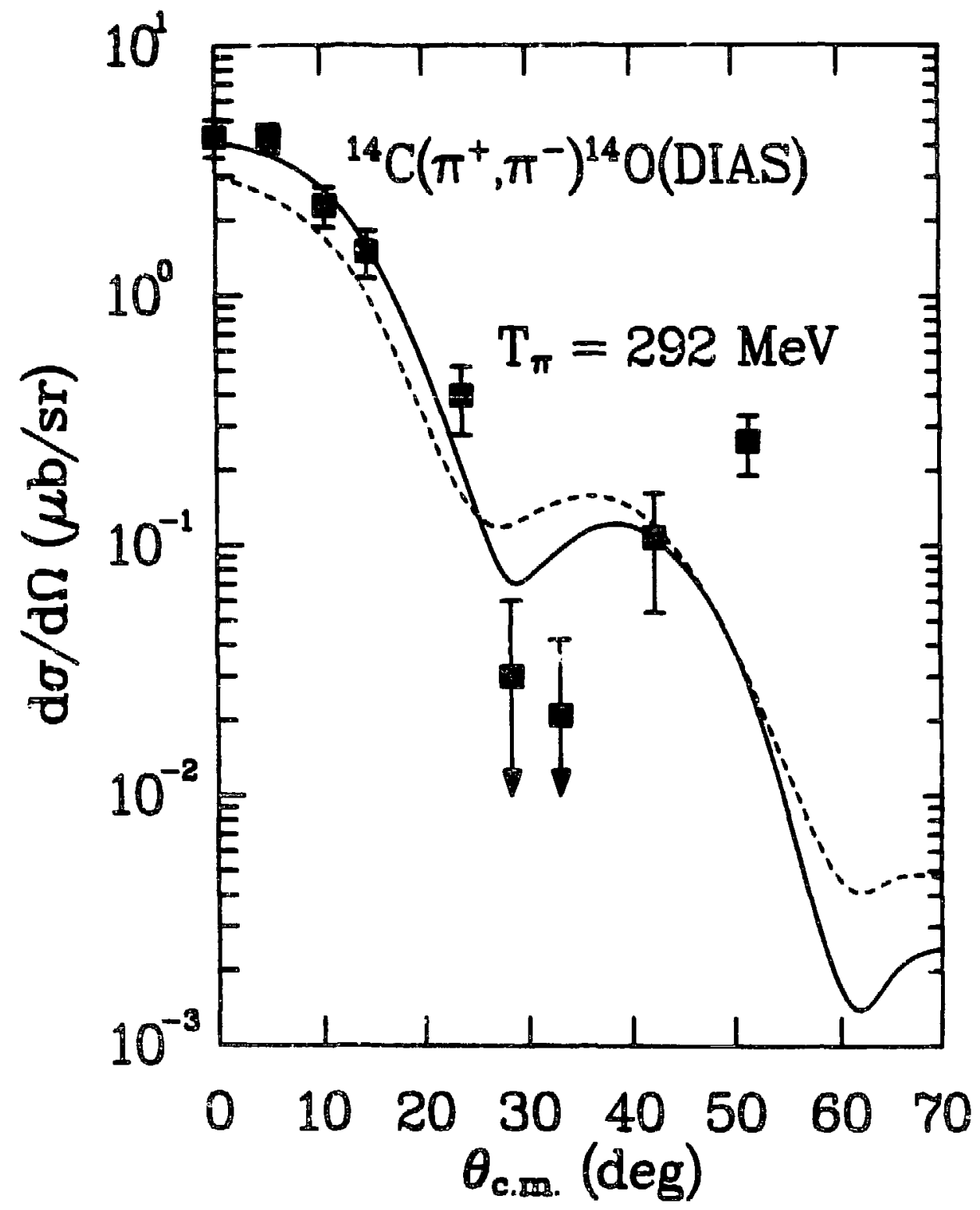

Fig. V-9: Comparison of data and calculations at $292 \mathrm{MeV}$. The curves have the same meaning as in FIg. $\mathrm{V}-7$. 


\section{SUMMARY AND CONCLUSIONS}

Over the energy range measured at EPICS (100 S $\left.T_{\pi} S 300 \mathrm{MeV}\right)$ there ar? two types of excltation functions for the DIAS transitions: those which monotonically Increase $\left({ }^{14} \mathrm{C},{ }^{48} \mathrm{Tl},{ }^{56} \mathrm{Fe}\right)$ and those which exh1bit local maxima near $140 \mathrm{MeV}\left(18_{0},{ }^{26} \mathrm{Mg},{ }^{42} \mathrm{Ca}\right)$.

Angular distributions exist only for the $T=1$ targets ${ }^{14} \mathrm{C},{ }^{18} 0$, and $26 \mathrm{Mg}$. At $292 \mathrm{MeV}$, where the minima appear at $q R=3.5$, the data can be explained by calculations which describe the reaction as sequential charge exchange through the respective Intermedigte analog states. At $164 \mathrm{MeV}$ the minlma are at $q R=1.7$, and the ${ }^{14} \mathrm{~g}$ data are roughly constant for larger momentum transfers. These features of the angular distributions are indicative of large second order effects near the $\Delta_{33}$ resonance energy.

In Chapter $V$ it was shown that in the model of Johnson and Siciliano, large two nucleon $\left(p^{2}\right)$ terms are needed to flt the data. The significance of the results are that one set of 1soscalar, 1sovector, and isotensor parameters are able to describe the mass and angular dependence of SCX and DCX over a wide range of $A$. The theory's most obvious fallure is the ${ }^{14} \mathrm{C}$ angular distribution.

Within the model of Liu, true plon absorption as well as nuclear structure detalls are responslble for producing the interest- 
Ing features of the DIAS data. However, here too the ${ }^{14} \mathrm{C} 164-\mathrm{MeV}$ angular distribution is not reproduced by the calculations.

The 164-MeV forward angle data show markedly more deviation $\left(x^{2} /\right.$ point $=7.0$ versus 2.5$)$ from the $(N-Z)(N-Z-1) A^{-10 / 3}$ mass dependence than at $292 \mathrm{MeV}$. The excltation functions Indicate that the transition to a smoother mass dependence occurs Eor $\mathrm{T}_{\pi} 2200 \mathrm{MeV}$.

For the nonanalog transitions studied, those to $140\left(0^{+}\right.$, $5.92 \mathrm{MeV}$ ) and $56 \mathrm{NI}(\mathrm{gs})$ have simflar features to $0^{+}+0^{+}$transitions on $T=0$ target nuclel. (The latter transftion is related to DCX on a $\mathrm{T}=0$ target, ${ }^{56 \mathrm{NI}}\left(\pi^{-}, \pi^{+}\right)^{56} \mathrm{Fe}(\mathrm{gs})$, through t1me-reversal symmetry.) The peaktng of the nonanalog excitation functions near $T_{\pi}=150 \mathrm{MeV}$, where the DIAS data exhlbit their anomalous behavior is a compelliag Indication that the reaction mechanism responsible for the nonanalog transitions is Interfering wh the simple sequential charge exchange mechanism for analog DCX. It is interesilng to note liat near 164$\mathrm{MeV}$, In the case of ${ }^{14} \mathrm{C},{ }^{56} \mathrm{Fe}\left(\pi^{+}, \pi^{-}\right)$, these nonanalog $\Delta J=0$ transitions are almost as strongly exclted as the DIAS transitions, establishing a connection between the monotonlc type of DIAS excitation function and the existence of a strong, low-lying, $0^{+}+0^{+}$ nonanalog transition. No such nonanalog transitions are seen in the $180\left(\pi^{+}, \pi^{-}\right)$and $26 \mathrm{Mg}\left(\pi^{+}, \pi^{-}\right)$spectra. Thus, an accurate theoretical degcription of analog DCX requires understanding DCX on $T=0$ target nuclel, since an approxtmate description of the $T=1$ nuclel studied is a $T=0$ core coupled to two neutrons. Such a unffied treatment would need to reproduce the observed mass dependences for nonanalog $\left(A^{-4 / 3}\right)$ and analog transitione. 
The ${ }^{14} \mathrm{C}\left(\pi^{+}, \pi^{-}\right)^{14} \mathrm{O}\left(2^{+}, 7.77 \mathrm{MeV}\right)$ data have shown the beginnings of systematic behavior for transitions to $2^{+}$states. The ininimum near $140 \mathrm{MeV}$ and the relatively large cruss sections near $300 \mathrm{MeV}$ are

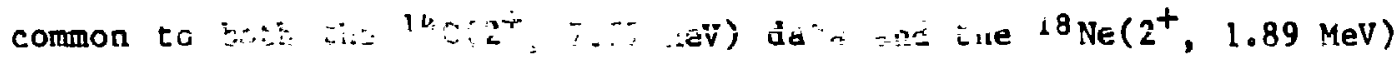
data (see also Append1X B).

The ${ }^{13} \mathrm{C}\left(\pi^{+}, \pi^{-}\right)^{13} \mathrm{O}(\mathrm{gs})$ angular distributions vary slowly between $0^{\circ}$ and $50^{\circ}$. The forward-angle excltation function distingulshes Itself from other nonanalog DCX (ground state) to (ground state) rransitions in that the excitation function is not peaked near $160 \mathrm{MeV}$. The transition to the $E_{x}=4.21 \mathrm{MeV}$ state exhibits features cormon to $\Delta J=0$ nonanalog DCX reactions. The excitation function is peaked near $160 \mathrm{MeV}$ and the angular distribution at $164 \mathrm{MeV}$ has a simple diffractive shape, with a minimum consistent with the strong absorption radius. These features suggest that $\mathrm{J}^{\pi}=1 / 2^{-}$for this state.

Measurements of analog DCX angular distributions for $T>1$ nuclel are needed to Investigate the Isospin dependence of the reaction, and test the 1sospin parameterization of the second-order $\pi-$ nucleus Interaction of Johnson and Siciliano. The 1sospin factors ( $T^{-1}, T^{-2}$ ) in Eq. $V-13$ can dasp second order contributions to the scattering amplitude, which would be manifest in new inierference features.

$$
\begin{aligned}
& \text { Recent angular-distribution measurements of the } \\
& 180\left(\pi^{+}, \pi^{-}\right)^{18} \mathrm{Ne}(\mathrm{gs}) \text { reaction at six new energles between } 100 \text { and } \\
& 292 \mathrm{MeV} \text { (Append1x B) show thot the transition to an anomalous angular } \\
& \text { distribution shape occurs suddenly over a narrow energy range: }
\end{aligned}
$$


$200<T_{\pi}<230 \mathrm{MeV}$. The striking simflarity of the $180\left(\pi^{+}, \pi^{-}\right)^{18} \mathrm{Ne}(8 \mathrm{~s})$ angular-distribution shape at $200 \mathrm{MeV}$ to that for $14 \mathrm{C}\left(\pi^{+}, \pi^{-}\right)^{14} \mathrm{O}(\mathrm{gs})$ at $164 \mathrm{MeV}$, along with the shapes of the excitation functions suggest that the two reactions possess 1dentical features, but are sisted by $\sim 40 \mathrm{MeV}$ with respect to each other. 
תPPENDIX A

TABULATION OF DATA FOR EXPERIMENT 558

Table A-1: Center-of-mass cross sections for ${ }^{14} \mathrm{C}\left(\pi^{+}, \pi^{-}\right)^{14} \mathrm{O}$ (DIAS).

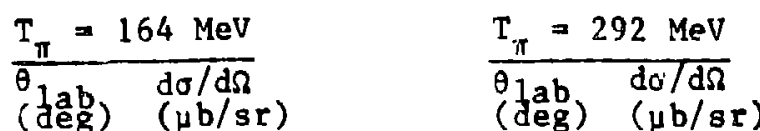

\begin{tabular}{llllll}
\hline 0 & $1.38 \pm 0.29$ & 0 & $4.54 \pm 0.79$ & 120 & $0.959 \pm 0.257$ \\
5 & $1.06 \pm 0.11$ & 5 & $4.51 \pm 0.59$ & 140 & $0.857 \pm 0.160$ \\
10 & $0.893 \pm 0.150$ & 10 & $2.42 \pm 0.45$ & 164 & $1.06 \pm 0.11$ \\
15 & $0.828 \pm 0.160$ & 14 & $1.58 \pm 0.35$ & 180 & $1.93 \pm 0.31$ \\
17.5 & $0.237 \pm 0.079$ & 23 & $0.424 \pm 0.131$ & 220 & $2.88 \pm 0.34$ \\
20 & $0.229 \pm 0.069$ & 27.5 & $0.032 \pm 0.032$ & 260 & $4.34 \pm 0.55$ \\
25 & $0.144 \pm 0.048$ & 32 & $0.022 \pm 0.022$ & 292 & $4.51 \pm 0.59$ \\
33 & $0.207 \pm 0.062$ & 41 & $0.114 \pm 0.057$ & & \\
40 & $0.126 \pm 0.042$ & 50 & $0.277 \pm 0.076$ & & \\
50 & $0.139 \pm 0.052$ & & & &
\end{tabular}

${ }^{\theta_{1 a b}}=5^{\circ}$

$\frac{\mathrm{T}}{\mathrm{T}} \mathrm{do} / \mathrm{d} \Omega$

(Thev) ( $\mu \mathrm{b} / \mathrm{sr}$ )

$120 \quad 0.959 \pm 0.257$

$140 \quad 0.857 \pm 0.160$

$164 \quad 1.06 \pm 0.11$

$180 \quad 1.93 \pm 0.31$

$220 \quad 2.88 \pm 0.34$

$260 \quad 4.34 \pm 0.55$

$292 \quad 4.51 \pm 0.59$ 
Table A-2: Center-of-mass cross sections for ${ }^{14} \mathrm{C}\left(\pi^{+}, \pi^{-}\right)^{14} \mathrm{O}\left(0^{+}, 5.92 \mathrm{MeV}\right)$.

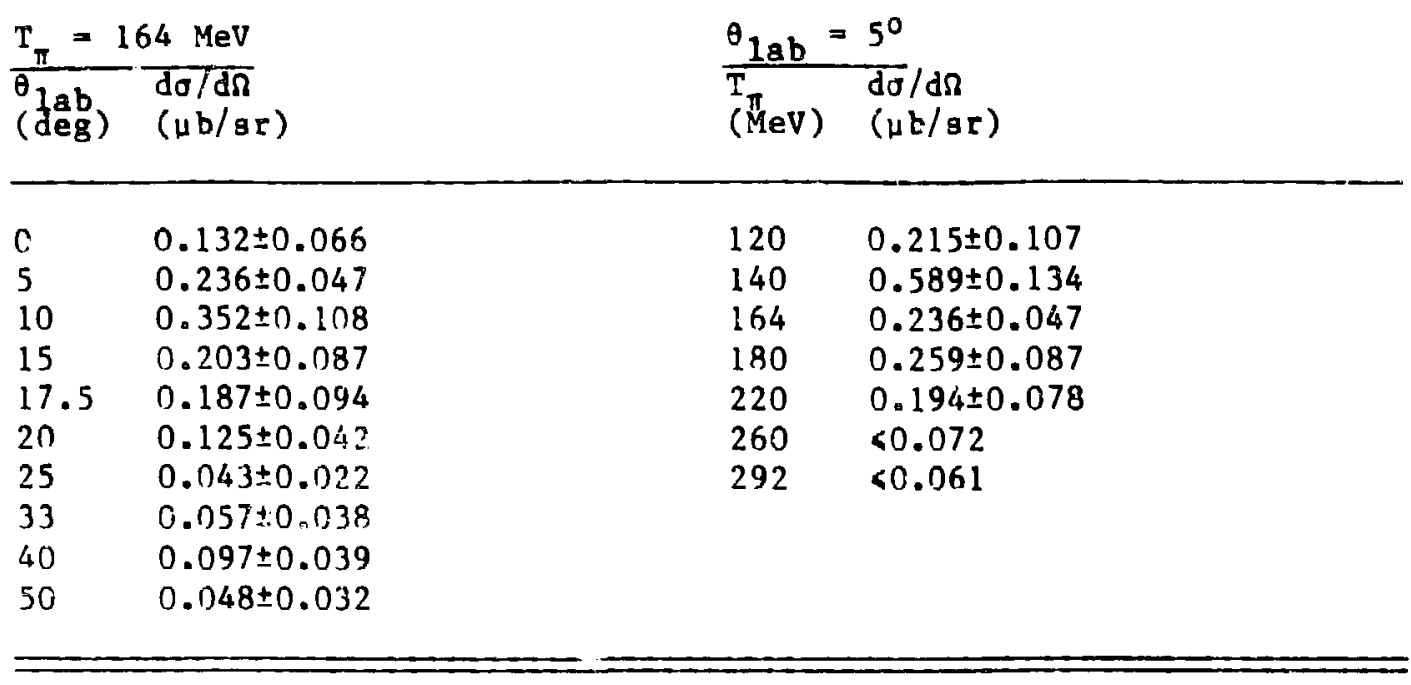


Table A-3: Center-of-mass cross sections for $\left.14 \mathrm{C}^{+}, \pi^{-}\right)^{14} \mathrm{O}\left(2^{+}, 7.77\right.$ $\mathrm{MeV}$ ).

$$
\frac{T_{\pi}=164 \mathrm{MeV}}{(\mathrm{deb}) \quad \begin{array}{l}
\mathrm{d \sigma} / \mathrm{d} \Omega \\
(\mu \mathrm{b} / \mathrm{sr})
\end{array}}
$$

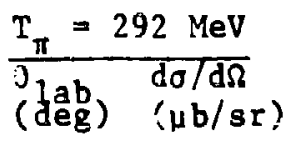

$0 \quad 0.571 \pm 0.286$

$5 \quad 0.477 \pm 0.179$

10

14

23

27.5

32

41

50 $\frac{\theta_{1 a b}-5^{0}}{(\pi / d \sigma / d \Omega} \frac{(\mu b / 8 r)}{(\pi / 2)}$

120

140

164

180

220

260

292
$0.480 \pm 0.144$

$0.172 \pm 0.074$

$0.123 \pm 0.037$

$0.461 \pm 0.126$

$0.485 \pm 0.149$

$0.475 \pm 0.204$

$0.477 \pm 0.179$

$33 \quad 0.163 \pm 0.054$

$40 \quad 0.205 \pm 0.056$

$50 \quad 0.047 \pm 0.031$

Table A-4: Center-of-mass cross sections for ${ }^{26} \mathrm{Mg}\left(\pi^{+}, \pi^{-}\right)^{26} \mathrm{Si}$ (DIAS).

$$
\frac{\mathrm{T}_{\pi}=16: \mathrm{MeV}}{\left(\mathrm{\theta}_{\mathrm{ab}} \mathrm{d \sigma} / \mathrm{d} \Omega\right.}
$$

$0 \quad 0.322 \pm 0.097$

$5 \quad 0.242 \pm 0.054$

$10 \quad 0.106 \pm(1.040$

$15 \quad 0.028 \pm 0.014$

$17.5 \quad 60.018$

$20 \quad 60.010$

$25 \quad 0.086 \pm 0.032$

$330.140 \pm 0.038$

$40 \quad 0.164 \pm 0.039$

$50 \quad 0.016 \pm 0.008$ $\frac{\theta_{1 \mathrm{ab}}=5^{\circ}}{(\mathrm{Mev}) \quad(\mu \mathrm{d} / \mathrm{sr})}$

120

$0.259 \pm 0.078$

$1640.242 \pm 0.054$

$180 \quad 0.206 \pm 0.061$ 
Table A-5: Center-of-mass cross sections for $56 \mathrm{Fe}\left(\pi^{+}, \pi^{-}\right)^{56} \mathrm{N1}$ at $\theta_{1 \mathrm{ab}}=5^{\circ}$.

\begin{tabular}{lll}
\hline$T_{\pi}(\mathrm{MeV})$ & $\begin{array}{l}\mathrm{d \sigma} / \mathrm{d} \Omega \\
\text { DLAS, } E_{\mathbf{X}}=9.6 \mathrm{MeV}\end{array}$ & $\begin{array}{l}\mathrm{d} \sigma / \mathrm{d} \Omega(\mu \mathrm{b} / \mathrm{sr}) \\
\mathbf{g} \cdot \mathrm{s} .\end{array}$ \\
\hline 140 & $0.033 \pm 0.027$ & $0.075 \pm 0.023$ \\
164 & $0.032 \pm 0.018$ & $0.053 \pm 0.014$ \\
220 & $0.161 \pm 0.036$ & $0.014 \pm 0.007$ \\
260 & $0.390 \pm 0.081$ & $0.014 \pm 0.014$ \\
292 & $0.323 \pm 0.077$ & 60.013 \\
\hline
\end{tabular}

Table A-6: Center-of-mass cross sections for ${ }^{13} \mathrm{C}\left(\pi^{+}, \pi^{-}\right)^{13} \mathrm{O}(\mathrm{gs})$.

\begin{tabular}{|c|c|c|c|c|c|}
\hline $\mathrm{T}_{1 \gamma}=$ & $54 \mathrm{MeV}$ & $T_{\pi}=$ & $92 \mathrm{MeV}$ & $\theta_{1 a b}$ & $5^{0}$ \\
\hline$\overline{(\mathrm{deg})}$ & $\begin{array}{l}\mathrm{d} \sigma / \mathrm{d} \Omega \\
(\mu \mathrm{b} / \mathrm{sr})\end{array}$ & $\left(\begin{array}{l}\mathrm{dab} \\
(\mathrm{deg})\end{array}\right.$ & $\begin{array}{l}d \sigma / d \Omega \\
(\mu b / s r)\end{array}$ & $(\mathrm{MeV})$ & $\begin{array}{l}\mathrm{d \sigma} / \mathrm{d} \Omega \\
(\mu \mathrm{b} / \mathrm{sr})\end{array}$ \\
\hline 0 & $0.063 \pm 0.021$ & 0 & $0.184 \pm 0.044$ & 120 & $0.198 \pm 0.034$ \\
\hline 5 & $0.141 \pm 0.021$ & & & & \\
\hline 10 & $0.095 \pm 0.016$ & 10 & $0.187 \pm 0.032$ & 164 & $0.141 \pm 0.021$ \\
\hline 15 & $0.130 \pm 0.019$ & 14 & $0.135 \pm 0.925$ & 180 & $0.083 \pm 0.019$ \\
\hline 17.5 & $0.116 \pm 0.020$ & 23 & $0.179 \pm 0.1319$ & 292 & $0.185 \pm 0.038$ \\
\hline 20 & $0.130 \pm 0.018$ & 27.5 & $0.188 \pm 0.020$ & & \\
\hline 25 & $0.102 \pm 0.017$ & 32 & $0.180 \pm 0.016$ & & \\
\hline 33 & $0.104 \pm 0.015$ & 41 & $0.153 \pm 0.016$ & & \\
\hline 40 & $0.127 \pm 0.017$ & 50 & $0.060 \pm 0.011$ & & \\
\hline 50 & $0.065 \pm 0.011$ & & & & \\
\hline
\end{tabular}


Table A-7: Center-of-mass cross sections for ${ }^{13} \mathrm{C}\left(\pi^{+}, \pi^{-}\right)^{13} \mathrm{O}\left(1 / 2^{-}, 4.21\right.$ $\mathrm{MeV})$.

\begin{tabular}{|c|c|c|c|}
\hline$\frac{T_{\pi}=}{\left(\mathrm{deg}^{\mathrm{ab}}\right)}$ & $\begin{array}{l}\frac{5 \mathrm{MeV}}{\mathrm{d} \sigma / \mathrm{d} \Omega} \\
(\mu \mathrm{b} / \mathrm{sr})\end{array}$ & $\frac{\theta_{1 a b}}{\frac{T}{(\pi \mathrm{eV})}}$ & $\begin{array}{l}\frac{5^{\circ}}{d \sigma / d \Omega} \\
(\mu b / s r)\end{array}$ \\
\hline 0 & $0.312 \pm 0.080$ & 120 & $0.030 \pm 0.079$ \\
\hline 5 & $0.325 \pm 0.047$ & 164 & $0.325 \pm 0.047$ \\
\hline 10 & $0.297 \pm 0.047$ & 180 & $0.170 \pm 0.049$ \\
\hline 15 & $0.195 \pm 0.043$ & 292 & $0.022 \pm 0.031$ \\
\hline 17.5 & $0.177 \pm 0.053$ & & \\
\hline 20 & $0.111 \pm 0.046$ & & \\
\hline 25 & $0.046 \pm 0.041$ & & \\
\hline 33 & $0.029 \pm 0.024$ & & \\
\hline 40 & $0.044 \pm 0.023$ & & \\
\hline 50 & $0.034 \pm 0.023$ & & \\
\hline
\end{tabular}


APPENDIX B

The Energy Dependence of ${ }^{18} 0\left(\pi^{+}, \pi^{-}\right)^{18} \mathrm{Ne}(\mathrm{gs})$

This paper (Los Alamos National Laboratory report \#LA-UR 84-3373) was submitted to Physlcal Review Letters In October 1984. 
The Energy Dependence of ${ }^{18} \mathrm{O}\left(7^{+}, \pi^{-}\right) 1{ }^{10} \mathrm{Ne}(\mathrm{gs})$

Peter A. Seldl, C. Fred Moore, and S. Mordechas

University of Texas at Austin, Austin, TX 7871?

R. Gilman, Kalvir S. Dhuga ${ }^{b}$, H. T. Forture, and J. D. Zumbro Untversity of Pennsylvania, Philadelphia, PA 19104

\section{L. Marris}

Los Alamos National Laboratory, Los Alamos, NM 87545

J. A. Faucett and G. R. Burleson

New Mexico State Unlversizy, Las Cruces, NM 88003

\section{ABSTRACT}

E1ght angular discributions weasured for ${ }^{18} \circ\left(\pi^{+}, \pi^{-}\right)^{18} \mathrm{Ne}(\mathrm{gB})$ across the $\Delta_{33}$ resonence show the detalls of the energy lependence of the reaction. At higher energies, the minimum 1 at $q=0.85 \mathrm{fm}^{-1}$, In agreement with simple sequential scatcering wodels, but at lower energles it is at $q=0.5$ $\mathrm{fm}^{-2}$, with the trangition occuring over a narrow energy range.

(IUCLEAR REACTIONS: ${ }^{18} \mathrm{O}\left(\pi^{+}, \pi^{-}\right) 18 \mathrm{Ne}\left(\mathrm{g} .6 ., \mathrm{E}_{\mathrm{X}}=1.89 \mathrm{MeV}\right) \mathrm{I}_{\pi}=100$ to $310 \mathrm{MeV}$, $\theta_{\text {lab }}-5^{\circ}$ to $40^{\circ}$; measured $\sigma\left(T_{\pi}, \theta_{1 a b}\right) . j$

PACS Numbers: $25 \cdot 80 . F$ m 
In plon-nucleus scattering, the qualitative (and of ten quantitative) features of any otrong inelantic trensitions sre well expleined within wodels which take melear atructure inforaation froe data on reactione such as (e, $\left.e^{-}\right)$ Ind $\left(p, p^{\circ}\right)$ dete and treat the r-nucleus intaraction in the distorted wave 1apulse epproxiation, However, this approach elgnificently underestiacted single-cherge-exchange (SCX) differential cross sections, ${ }^{2}$ and 1 te extension to double-charge-exchenge (DCX) reactions falls at $\Delta_{33}$ resonance energies. ${ }^{3}$ In particular, DCX angular distributions leading co double 1sobaric analos states (DIAS) at resonance energies have been shown to exh1bit forvard atrias at angles that are, within the siaplar nodels (sequential cherge exchange through the free plon-nucleon anplitude), Inconsisteat with the nuclear size.4,5 at higher energies, the sase reactions exhiblt angular distributions thet agree with simple calculations.

The anomalous angular distributions have often been interpreted as evidence for Interference of the saple DCX auplitude with a second aplitude of sladlar size. In Ref. 6, 1t was auggested that this second axplitude arises froa whatever reaction aechanise 1 te resonsible for the equivalently large differential cross sections observed for (necessarily non-anelog) DCX on self-confugate targets. In Ref. 7 , the anoualous pasition of the ainias is attributed to interference with higher-order (two-nucleon, usually called $\rho^{2}$ ) terms in the pion-nucleus optical potential. In that approech, the aagnitudes of the 1sovector and 1sotensor $\rho^{2}$ terms are adjusted to fit the $0^{\circ} \operatorname{sCX}$ and $5^{\circ}$ DCX date, and the resulting paramete provide good predictions of the angulardistribution shapes. The model of $21 \mathrm{u}^{\mathrm{B}, 9}$ gives good predictions of both angular dietributions and excitation functions by using core-excitation nuclear 
wave functions and $\rho^{2}$ cerms. The later are obtained from an anolysis of $\pi-A$ elastic scattering data and reflect the effects of true pion absorption.

In this letcer, we report. six new angular digtributions for the reaction $18_{0}\left(\pi^{+}, 8^{-}\right)^{18} \mathrm{Ne}(\mathrm{gs})$, which, when combined with previous measurements, 4,10 show the change in shape of the angular $\$$ istributions ag a function of energy. This is the must extensive study of $D C Y$ on a single nucleus, and ldentifies the energy regions in which the simple DCX amplicude is adequate to describe the daca, and the energy regions in which higher order processes become important. The measurements were made with the Energeclc Plon Channel and Spectrometer (EPICS) at the Clinton P. Anderson Meson Physics Fac1lity (LAMPF). Descriptions of the spectroveter, channel, and the modifications installed for forward-angle DCX measurements havo been presented elsewhere. $\downarrow$ A copper frame with 0.25-mil aluminized mylar windows contalned the $\mathrm{H}_{2} \mathrm{O}$ ice target which was enriched to $94 \%$ 1sotopic purity $\mathrm{H}_{2} 180$. The frame was constructed with a centered horizontal copper bar to enhance cooling of the tce. Physical measurement of the target thickness indicated an areal densicy of $0.95 \pm 0.01 \mathrm{~g} / \mathrm{cm}^{2} \mathrm{H}_{2} \mathrm{O}$, assuming a density of $1.12 \mathrm{~g} / \mathrm{cm}^{3}$. This value agreed well with an areal density obtained by comparing yields for $\left.{ }^{1} \mathrm{H}_{\left(\pi^{+}\right.}, \pi^{+}\right)$measured with a $\mathrm{CH}_{2}$ target $\left(73.58 \mathrm{mg} / \mathrm{cm}^{2}\right)$ and with the $\mathrm{H}_{2} \mathrm{O}$ target, of $\mathrm{xo}=0.93 \pm 0.03$ $\mathrm{g} / \mathrm{CO}^{2} \mathrm{H}_{2} \mathrm{O}$.

Background muon and electron events were eliminated from pion spectra by a combination ef the-of-flight tests, a Freon-l2 threshold Cherenkov detector to reject electrons, and a range-nuclear-interaction absorber that was adjusted to identify won events. 12 No background events under the states of interest were expected from DCX events in the target windows, frame, or contaminants. The $Q$ values for ${ }^{16} \mathrm{O}(-28.38 \mathrm{MeV}),{ }^{12 \mathrm{C}}(-31.96 \mathrm{MeV})$, and ${ }^{27} \mathrm{Al}(-16.38 \mathrm{MeV})$ are much 
wore negative than that for $1 \theta_{0}(-5.08 \mathrm{MeV})$. The copper $Q$ values $(-7.85 \mathrm{MeV}$ for ${ }^{63} \mathrm{Cu},-3.59 \mathrm{MeV}$ for ${ }^{65} \mathrm{Cu}$ ) are $81 \mathrm{milar}$ to that for ${ }^{10} \mathrm{O}$, but the greater plon energy loss in the copper frame ( $8.33 \mathrm{MeV})$ than in the 1 ce $(1.32 \mathrm{HeV})$ removes th1s background from under the states of lnterest. (Computer software gates werle, however, used to eliminate scattering events occuring in the copper bar.) The data were normalized by measuring glelds for ${ }^{\prime} \mathrm{H}\left(\pi^{+}, \pi^{+}\right)$at $\theta=40^{\circ}$ and comparing thed to cross sections based on the phase ghift fits of Rowe, Saloman, and Landau ${ }^{13}$. Ylelds weagured for ${ }^{\mathrm{I}} \mathrm{H}\left(\pi^{+}, \pi^{+}\right)$at $\theta=20,30$, and $40^{\circ}$ Indicated that, within the statistical uncertalnty of the yleld and uncertainty of the $\pi-p$ cross sections, the normalizarion factors are angle independent. The error bars shown in the figures represent the statistical uncertainty of the ${ }^{18}$. ve peak areas.

The ney : ${ }^{\circ}\left(\pi^{+*}, \pi^{-}\right): B_{N e}(g s)$ excication function daca are shown in Fig. 1 , along with the data from Ref. 4. Where overlap points exist the agreement with previous measurements 1s, in general, good. The new and old measurements within two iev of $100,180,230$, and $292 \mathrm{MeV}$ differ from their means by 1.4 standard deviacions.

An excitation function for the $18^{\mathrm{Ne}}\left(2^{+}, 1.89 \mathrm{MeV}\right)$ state $1 \mathrm{~s}$ also displayed 1n Fig. 1. We noze that these cross sections are almost independent of energy, except between 130 and $170 \mathrm{MeV}$, where cross sections are at least a factor of ten smaller, a largez decrease than in the transition to the ${ }^{18} \mathrm{Ne}(\mathrm{gs})$ gtate.

The new ground-state angular distrlbutlons are shown in Fig. 2, along with previously measured 164 - and $292-\mathrm{mall}$ dara, 4,10 ploted as a function of the momentum trangter, 9 . The shape of the $230-\mathrm{MeV}$ angular digtribution 1.t nearly identical to that of the 292-MeV data, wh a broad diffraction minimum at $q=0.85 \mathrm{fm}^{-1}$. The larger-angle data are suggestive of a second maximum a 
factor of 20 lower than the $5^{\circ}$ datum. At $200 \mathrm{MeV}$ the data are roughly constant for $q>0.5 \mathrm{fm}^{-1}$, and the cross section at the largest angle measured tas lacresed to be only a factor of 10 amaller than the forward-angle values. These feacures provide a smooth transicion $1 \mathrm{n}$ shape between 2.30 and $180 \mathrm{MgV}$. At $180 \mathrm{MeV}$ the minimum $1 \mathrm{~s}$ at $\mathrm{q}=0.5 \mathrm{fa}^{-2}$. The crose sections for $q>0.5 \mathrm{MeV}$ are Indicative of a relatively large second maximum. The shapea of the angular djotrloution at 164,172 , and $180 \mathrm{HeV}$ are very ofollar, and are clearly different froo those at htgher energies. Below the $\Delta_{33}$ resonance, at $120 \mathrm{MeV}$, the minloum is at a slightly larger momentum transfer. Because of the lower pion flux at lower energies and the liwited angular range of the DCX setup $\left(\theta<42^{\circ}\right)$, it was Impossible to determine the location of the first minimum of the 100-MeV angular distribution.

In an energy region Just above the $\Delta_{33}$ resonance (from $200<T_{\pi}<230 \mathrm{MeV}$ ) up to at least $292 \mathrm{MeV}$ the ${ }^{180}$ angular digtribution $1 \mathrm{~g}$ normal in the sense that the position of the minimum is consistent with a simple diffractive process. Thus, at these energles the reaction would appear to be dominated by sequentlal SCX via the intermediate analog state. Figure 3 shows angular distribution calculations for the higher energy region. The curves are from lowest-order calculacions with the code PIESDEX ${ }^{7}$ uging Harcree-Fock'th (Skyrme-III effective interaction) neutron, proton, and excess neutron densicles, and represent sequential charge exchange through the intermedlate analog stace. The theory correctly predicts angular-distributioli shapes at 230 and $292 \mathrm{MeV}$, and the departure from the dominance of the lowest order reaction mechanisu is apparent at 200 and $180 \mathrm{MeV}$. Not shown are calculatione with a ground gcate denaity generated from electron scattering parameterizations and $a\left(d_{5 / 2}\right)^{2}$ harmonic oscillator valence neutron density that predict minima at angles a few degrees 
larger than the sollc curve and aldilar overall magnitudes. Thus, reasonable variations in the densities do not significantly alier these calculations.

For eneigles across the $\Delta_{33}$ resunance, down to $120 \mathrm{MeV}$, the angular diatributions clearly exhibit forward oinima: evidence for additional dynamical effects. The rature of these effects is uncertaln, but some possibilitles are discussed in Ref. 8 and 15 . There is no evidence in our data to Indicace wherher or not there exists lower-energy reglon where the reaction will agaln agree with lowest-order DCX calculations. Aecent measurements ${ }^{16}$ of DCX on ${ }^{14} \mathrm{C}$ at $50 \mathrm{MeV}$ would seem to Indicate that no such region exists. At $50 \mathrm{MeV}$, $\mathrm{do} / \mathrm{d} \Omega\left(0^{\circ}\right)=3.9 \pm 0.5 \mathrm{~Wb} / \mathrm{sr}$ for the ${ }^{14} \mathrm{C}\left(\pi^{+}, \pi^{-}\right)^{14} \mathrm{O}(\mathrm{gs})$ reaction, roughly 20 times that calculaced in a gequential charge-exchange calculation in which the interwediate scace 15 the single analog $1 \mathrm{n}^{14} \mathrm{~N}$, and the angular distribution $1 \mathrm{~s}$ forward peaked, racher than exhlbiting the shallow forwird animum predicted by the calculation.

The shape of the $\left.18 \mathrm{O}^{+}, \pi^{-}\right) ! 8 \mathrm{Ne}(\mathrm{gs}) \quad 200 \mathrm{MeV}$ angular digtribution $1 \mathrm{~s}$ st illar to the ${ }^{14} \mathrm{C}\left(\pi^{+}, \pi^{-}\right) 140(\mathrm{gg})$ angular distribution 5 at $\mathrm{T}$ - $164 \mathrm{MeV}$, where the cross section 15 roughly constant for $q>0.4 \mathrm{fm}^{-1}$. The ${ }^{14} \mathrm{C}$ data have been perplexing becauge all orher $164 \mathrm{MeV}$ DCX angular distributions exhiblt welldefined, deep, forward minima. It is inceresting to speculate that $14 \mathrm{C}$ and $18_{0}$ have similar features shifted by $\sim 40 \mathrm{MeV}$. This speculation is gupported by the ghape of the excitation functions, which also exhibit similar shapes, shifted by $-40 \mathrm{MeV}$ with reapect to each other. The cause for this ghift is unknown. 
In concluston, these new $1{ }^{18} \mathrm{O}\left(\pi^{+}, \pi^{-}\right) 18 \mathrm{Ne}(89)$ data show that the onset of Interesting dynanical effects occur over $s \quad 30 \mathrm{MeV}$ incident kinetic energy range, which dramaically change the shape of the angular distributions. Tr. completeness of this teasurement will hopefully distingulsh between varled theorecical approaches to the perplexing DCX problew.

Th1s work has been supported in part by The Robert A. Welch Foundation, The National Selence Foundation, and The US Department of Energy. 


\section{REFERENCES}

a) permanent addresa: Ben Gurion Untversity of the Negev, Beer-Sheva, Israel.

b) present address: Neu Mexico Stace University, Las Cruces, NM 88003.

J. A. Carr, F. Pecrovich, D. Halderson, D. B. Holtkamp, W. B. Cotelngame, Phys. Rev. C27, 1636 (1983).

2 A. Doron, J. Alster, A. Ereil, S. Gilad, M. A. Motnegter, R. A. Anderson, H, W. Baer, J. D. Bowman, M. D. Cooper, F. H. Cverna, C. M. Hoffman, N. S. P. K1ng, M. J. Leitch, J. P. Piffarett1, P. R. Bevington, E. Winkelmann, and C. D. Goodman, Phys. Rev. Lett, 48,989 (1982); A. Doron, J. Alster, A. Ereil, M. A. Molnester, R. A. Anderson, H. W. Baer, J. D. Bowmar, M. D. Cooper, F. H. Cuerna, C. M. Hoffman, N. S. P. K1ng, M. J. Leltch, J. P. Piffarett1, and C. D. Goodman, Phys. Rev, C26, 189 (1982).

3 Gerald A. :11ller, Phys. Rev. C24, 221 (1981).

4 S. J. Greene, H. J. Bralthuatte, D. B. Holtkamp, W. B. Cottlngame, C. F. Moore, G. R. Burleson, G. S. Blanpled, A. J. Vizscas, G. H. Daw, C. L. Morris, and H. A. Thiessen, Phys. Rev. C 25, 927 (1982).

5 peter A. Se1dl, M. D. Broun, Rex R. K1ziah, C. Fred Moore, Helmut Baer, C. L. Morris, G. R. Burleson, H. B. Cotringame, Steven J. Greene, L. L. Bland, R. G1lman and H. T. Forcune, Phys. Rev. C30, 973 (1984).

G S. J. Greene, D. B. Holckamp, W. B. Cotringame, C. F. Moore, G. R. Burleson, C. L. Morris, H. A. Thlessen, and H. T. Fortune, Phys. Rev. C25, 924 (1982); R. Gllman, L. C. Bland, Peter A. Seldl, C. Fred Moore, C. L. Morris, Steven J. Greene, H. I. Fortune, Nuc. Phys. A, (to be published). 
7 Mikkel B. Johnson and E. R. Sielilieno, Phyg. Rev. C27, 1647 (1983); S. J. reene, C. J. Harvey, P. A. Seld1, R. Giloan, E. R. S1c1liano, and Mikkel B. Johnson, Phys. Rev. C (to be published).

8 L. C. L1u, Phys. Rev. C27, 1611 (1983).

9 Kamal K. Sech, H. Kaletka, S. Ivergen, A. Saha, D. Barlou, D. Sm1th, and L. C. L1u, Phys. Rev. Let5. 52, 894 (1984).

10 Kamal K. Seth, S. Iversen, H. Nann, M. Kalecka, J. H1rd, and H. A. Thlessen, Phys. Rev. Letr. 43, 1574 (1979).

1) H. A. Thlessen, J. C. Kallne, J. F. Amann, R. J. Peterson, S. J. Greene, S. L. Verbeck, G. R. Burleson, S. G. Iverson, A. W. Obst, Ramal K. Seth, C. F. Moore, J. E. Bolger, U. J. Bralchwalce, D. C. Slacer and C. L. Morris, Los ilamos Sclentific Laboratory Report No. LA-6663-MS, (1977); S. J. Greene, W. J. Bratthwalte, D. B. Holtkamp, H. B. Cottingawo, C. F. Moore, C. L. Morris, H. A. Thlessen, G. R. Burlegon, and G. S. Blanpled, Phys. Letr. 88B, 62 (1979); G. R. Burleson, G. S. Blanpled, G. H. Daw, A. J. Vlescas, C. L. Morris, H. A. Thieggen, S. J. Greene, W. J. Bra1thwatte, W. B. Cottingame, D. B. Holckamp, I. B. Moore, and C. F. Moore, Phys, Rev, C222, $1180(1980)$; S. J. Greene, PhD thes1s, The University of Texas at Austin, Los Alamor National Laboracory Report No. LA-8891-T, (1981).

12 C. L. Morr1s, J. F. Amann, R. L. Boudrle, N. Tanaka, S. J. Seestroum-Morr1s, L. C. Bland, P. A. Seldl, and R. Kiziah, (to be publ1shed). 

(1978).

14 M. Belner, H. Flocard, Nguyen yan G1al, and P. Quentin, Nucl. Phys. A238, $29(1975)$.

15 Mikkel B. Johnson, E. R. Siciliano, H. Tokl, and A. Hirzba, Phys. Rev. Letc. 52, $593(1984)$; E. Oeet, D. Strottman, M. J. Vicente-Vacas, and Ma We1-Hsing, Nuc. Phys. A408, 461 (1983); T. Karap1per1s, M. Kobayesh1, and M. H1raca, Phys. Lett. 144B, 23 (1984); Pervez Hoodbhoy, Roger A. Freedman, Gerald A. Miller, and Ernest M. Henley, Phys, Rev. C27, 277 (1983).

is M. J. Leitch, E. Plasetzky, H. W. Baer, J. D. Bowman, R. L. Burman, B. J. Drspesky, P. A. M. Gram, F. Irom, D. Robers, G. A. Rebka, J. N. Knudson, J. R. Comfort, V. A. Pinnick, D. H. Wright, and S. A. Hood, submitted to Phys. Rev. Letr. (1984) and Los Alamus National Laboracory Report LA-UR 34-2754; I. Navon, M. J. Lelech, D. A. Bryman, T. Numao, P. Schlatter, G. Azuelos, R. Poutlsgou, R. A. Burniam, M. Hasinoff, J. M. Poutissou, J. A. Macdonald, 3. E. Spuller, C. K. Hargrove, H. Mes, M. Blecher, K. Gotow, M. Molnegrer, H. Baer, Phys. Rev. Lett. 52, 105 (1984). 
FIGURE CAPTIONS

F1g. 1. Center-of-wass crose sections $\left(\theta_{\text {lab }}=5^{\circ}\right)$ for $10_{0}\left(\pi^{+}, \pi^{-}\right)^{18} \mathrm{Ne}(\mathrm{gs})$ (crosses froe this work and circles frow Ref. 4) and $18 \mathrm{O}\left(\pi^{+}, 7^{-}\right)^{18} \mathrm{Ne}\left(2^{+}, 1.89 \mathrm{MeV}\right)$ are plotted versus the pton energy in the

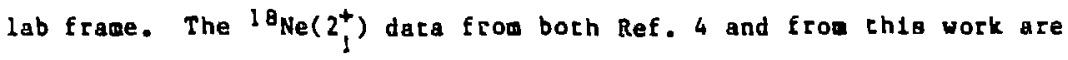
represented by squares.

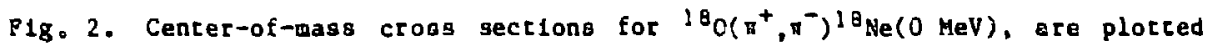
versus the wonentuw transfer, q. The incldent energles in MeV are Indlcated on the graph. Data for $q=0.70$ and $1.03 \mathrm{fa}^{-1}\left(\theta=30^{\circ}\right.$ and $45^{\circ}$ ) at $T_{\pi}=104 \mathrm{MeV}$ are from Ref. 10 . The datum for $T_{\pi}=292 \mathrm{MeV}$, $q=1.4018$ from ehis work, and all remaining data for $T_{n}=164$ and $292 \mathrm{MeV}$ are frow Ref. 4.

F18. 3. Center-of-mass cross sectlons for $180\left(\pi^{+}, \pi^{-}\right)^{18} \mathrm{Ne}(\mathrm{gs})$ are coopared to Lowest order PIESDEX calculations. 


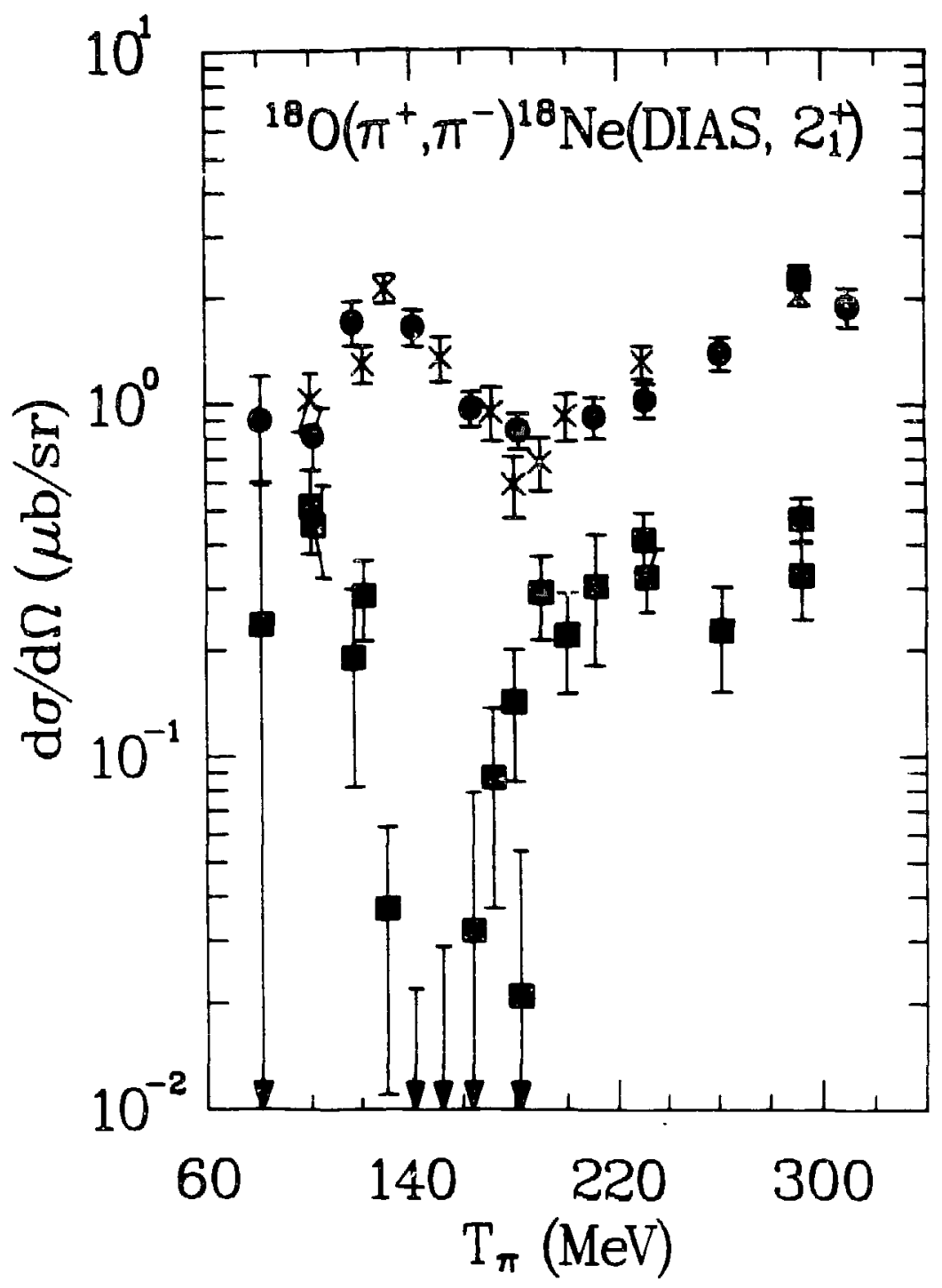

Fig. 1 


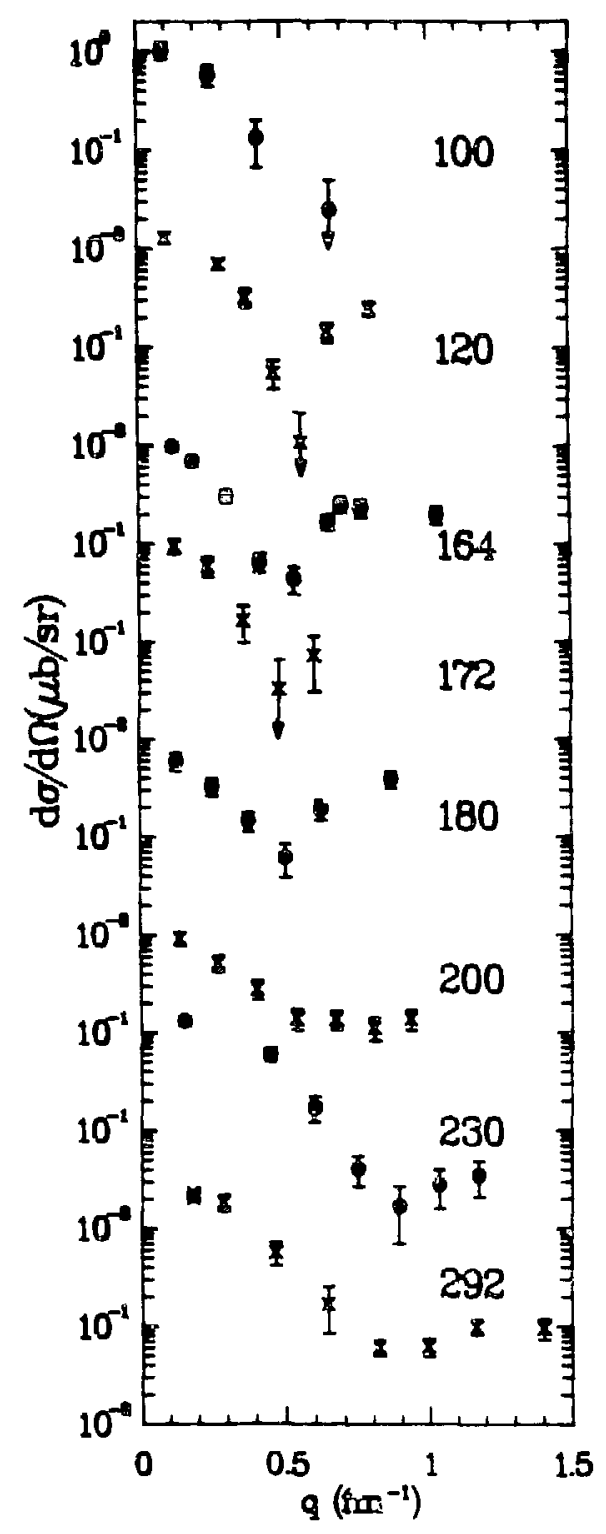

F1g. 2 


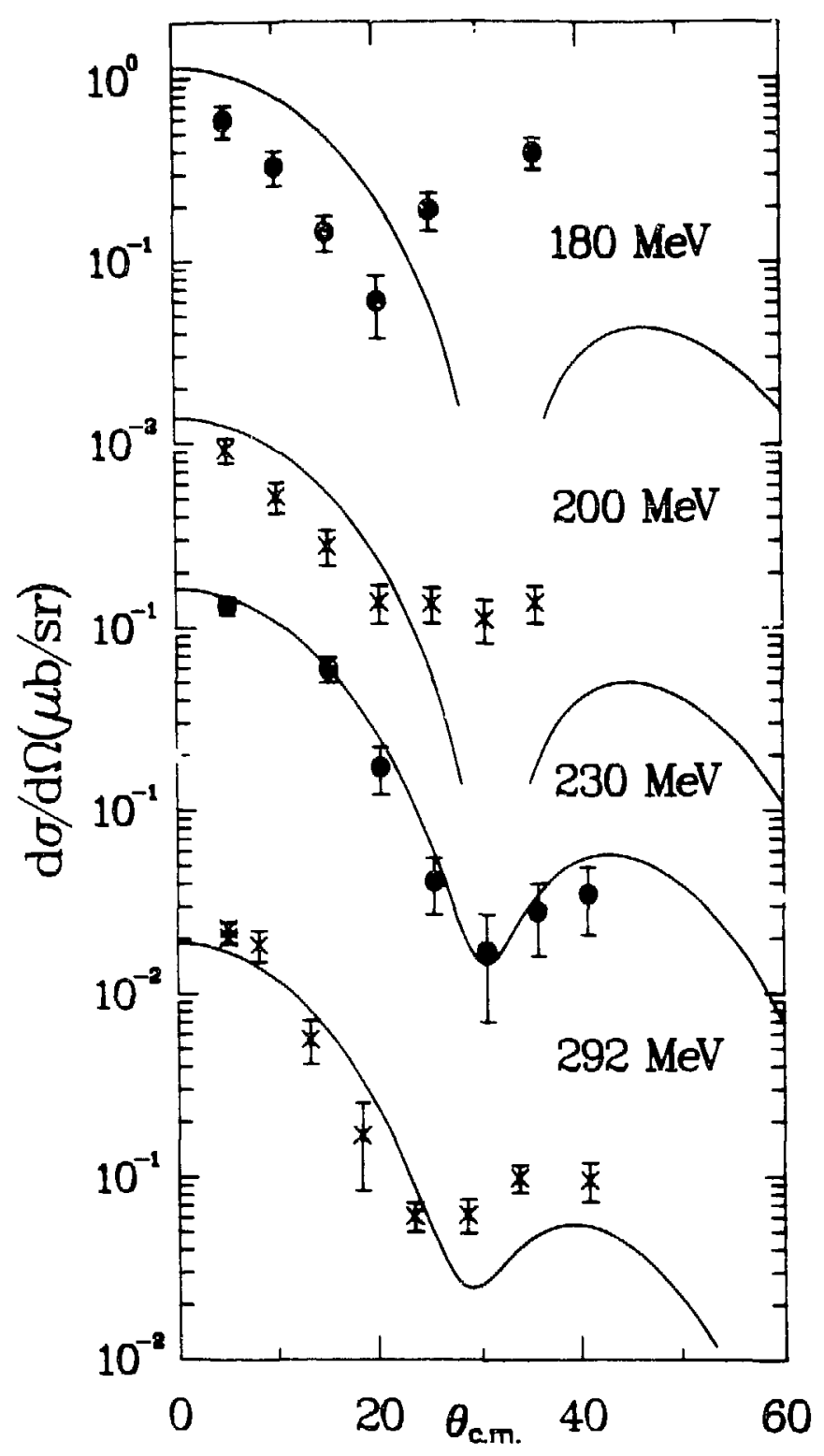

F1g. 3 


\section{APPENDIX C}

Dissertation Papers

"PIon Double Charge Eschange on $T=1$ Nucle1," Perer A. Seld1, Mark D. Brown, Rex R. Klzlah, C. Fred Moore, Helmut Baer, C. L. Morris, G. R. Burleson, H. B. Cottingame, Steven J. Greene, L. C. Bland, R. Gllman, and H. T. Fortune, Phys. Rev. C30, 973 (1984). "13 $\mathrm{C}\left(\pi^{+}, \pi^{-}\right)^{130}$ Near the $\Delta_{33}$ Resonance," Peter A. Seldl, Mark D. Brown, Rex R. KIzlah, C. Fred Moore, Helmut Baer, Christopher L. Morris, G. R. Burlegon, W. B. Cottingame, Steven J. Greene, L. C. Bland, R. Gilman, and H. T. Fortune, Phys. Rev. C30, 1076 (1984). "Observation of Analog and Non-Analog Transitions in the Reaction ${ }^{56} \mathrm{Fe}\left(\pi^{+}, \pi^{-}\right)^{56} \mathrm{N1}, "$ Peter A. Seldl, Rex R. K1zlah, Mark D. Brown, C. Fred Moore, C. L. Morris, H. Baer, Steven J. Greene, G. R. Burleson, W. B. Cottingame, and H. T. Fortune, Physical Review Letters 50, 1106 (1983). 


\section{ACKNOWLEDGEMENTS}

Much thanks goes to my advisor, C. Fred Moore, for h1s support during these past years. To Ron Gllman and Rex Klzlah, who not only gave much help during and after the experiment, but also provided encouragement and stimulating discussions, I express much gratitude.

The experiment would not have been a success without the asslstance of Richard Boudrle and the MP-10 staff who have made EPICS such a productive nuclear physics fac1l1ty. To the collaborators on Expertment 558: Mark Brown, Rex Klzlah, C. Fred Moore, Helmut Baer, Chrlg Morr1s, George Burleson, B111 Cott1ngame, Steve Greene, Les Bland, Ron Giiman, and H. Terry Fortune, I express my thanks. The winstruction of the new target cells by Joe Van Dyke, and the careful packing of the ${ }^{14} \mathrm{C}$ target by Helmut Baer, made the ${ }^{14} \mathrm{C}$ measurements safe.

I thank H. Terry Fortune and Chris Morris for the frultful discussions concerning the interpretation of DCX. The calculations of section $A$ of Chapter $V$ were made possible by Mikkel Johnson and Ed Slclliano, who have always made time to answer any questIons. I thank Lon Chang Llu for providing the calculations of section B of Chapter $\mathrm{V}$.

I thank Chris Morrls and John Zumbro for having carefully read the dissertation. 


\section{REFERENCES}

[Am-79] J. F. Amann, R. L. Boudrie, H. A. Thtessen, C. L. Morris, and L. E. Smith, IEEE Transactions in Nuclear Sclence NS-26, $4389(1979)$.

[Am-80] R. D. Amado, J.-P. Dedonder, and F. Lenz, Phys. Rev. C21, $647(1980)$.

[At-81] L. G. Atencio, J. F. Amann, R. L. Boudrie, C. L. Morris, Nuc1. Inst. Meth. 187,381 (1981).

[Ba-80] Helmut W. Baer, J. D. Bowman, M. D. Cooper, F。 H. Cverna, C. M. Hoffman, Mikkel B. Johngon, N. S. P. King, J. Plffarett1, E. R. Siclilano, J. Alster, A. Doron, S. Gllad, M. Molnester, P. R. Bevington, E. Winkelmann, Phys. Rev. Lett. 45, $982(1980)$.

[Be-75] M. Belner, H. Flocard, N. Van Gla1, and P. Quentin, Nucl. Phys. A238, 29 (1975).

[B1-83] L. C. Bland, R. G1lman, M. Carch1d1, K. Dhuga, C. L. Morris, H. T. Fortune, S. J. Greene, P. A. Seld1 and C. Fled Moore, Phys. Lett. 128B, 157 (1983).

[Bo-79] R. L. Boudrie, J. F. Amann, C. L. Morris, H. A. Thlessen, and L. E. Smith, IEEE Transactions in Nuclear Science NS $-26(1979)$. 
[Bu-78] R. L. Burman, M. P. Baker, M. D. Cooper, R. H. Heffner, D. M. Lee, R. P. Redwine, J. E. Spencer, T. Marks, D. J. Marlbruugh, B. M. Preedom, R. J. Holt, and B. Zeldman, Phys. Rev. C17, 1774 (1978).

[Bu-80] G. R. Burleson, G. S. Blanpled, G. H. Dew, A. J. Viescas, C. L. Morrls, H. A. Theissen, S. J. Greene, W. J. Bralthwalte, W. B. Cottingame, D. B. Holtkamp, I. B. Moore, and C. F. Moore, Phys. Rev. C22, 1180 (1980).

[Bu-n.d.] G. R. Burleson, and J. F. Amann, computer program CROS: (unpubl1shed) n.d.

[Ca-73] J. R. Carter, D. V. Bugg, and A. A. Carter, Nuc1. Phys. B58, 378 (1973).

[Ch-69] D. T. Chlvers, E. M. Rimmer, B. W. Allardyce, R. C. Witcomb, J. J. Domingo, and N. W. Tanner, Nusl. Phys. Al26, 129 (1969).

[Co-65] S. Cohen, and D. Kurath, Nucl. Phys. 73, 1 (1965).

[Co-72] D. R. F. Cochran, P. N. Dean, P.A. M. Gram, E. A. Knapp, E. R. Martin, D. E. Nagle, R. B. Perkins, W. J. Schlaer, H. A. Thlessen, and E. D. Therfot, Phys. Rev. D6, 3085 (1972).

[Co-78] P. Couvert, G. Bruge, R. Beurtey, A. Boudard, A. Chaumeaux, M. Garcon, D. Garreta, P. C. Gugelot, G. A. Moss, S. Platchkov, J. P. Tabet, Y. Terrien, J. Thirion, L. Bimbot, Y. Le Bornec, and B. Tat1scheff, Phys. Rev. Lett. 41,530 (1978). 
[de-74] C. W. de Jager, H. de Vries, and C. de Vries, At. Data Nucl. Data Tables 14, 479 (1974)。

[Do-82] A. Doron, J. Alster, A. Erell, M. A. Molnester, R. A. Anderson, H. W. Baer, J. D. Bownan, M. D. Cooper, F. H. Cverna, C. M. Hoffman, N. S. P. KIng, M. J. Leltch, J. P. P1ffarett, and C. D. Goodman, Phys. Rev. C26, 189 (1982)。

[E1-74] R. A. Elgensteln and G. A. M1ller, Computer Phys. Comm. $\underline{8}$, $130(1974)$.

[E1-8̀ ] J. Elsenberg and Koltun, Theory of Meson Interactlons with Nucle1, (John Wiley and Sons, New York, 1980).

[Ev-72] D. Evers, W. Assmann, K. Rudolph and S. J. Skorka, Nucl. Phys. A198, 268 (1972).

[Fo-82] H. T. Fortune, and G. S. Stephans, Phys. Rev. C25, 1 (1982)。

[G1-83] R. GIlman, et. al., EPICS experiment $780,(1983)$.

[G1-84a] R. Gilman, H. T. Fortune, Kalv1r 3. Dhuga, Peter H. Kutt, L。 C. Bland, Rex R. Klzlah, C. Fred Moore, Peter A. Seldl, C. L. Morr1s, and W. B. Cottingame, Phys. Rev. C29, 2395 (1984).

[G1-84b] R. G1iman, L. C. Bland, Peter A. Seldl, C. Fred Moore, C. L. Mnry 9 , Steven J. Greene, H. T. Fortune, submitced to Phys. Rev. C (1984).

[Gr-79] S. J. Greene, W. J. Bralthwalte, D. B. Holtkamp, W. B. Cottingame, C. F. Moore, C. L. Morris, H. A. Theissen, G. R. Burleson, and G. S. Blanpled, Phys. Lett. 88B, 62 (1979). 
[Gr-81] S. J. Greene, PhD thes1s, The Unlversity of Texas at Austin (1981); and Los Alamos Natlonal Laboratory Report \# $\mathrm{LA}-8891-\mathrm{T},(1981)$.

[Gr-82a] S. J. Greene, W. J. Bralthewalte, D. B. Holtkamp, W. B. Cottlngame, C. F. Moore, G. R. Burleson, G. S. Blanpled, A. J. Vlescas, G. H. Daw, C. L. Morris, and H. A. Theissen, Phys. Rev. C 25, 927 (1982).

[Gr-82b] S. J. Greene, D. B. Holtkamp, W. B. CottIngame, C. F. Moore, G. R. Burleson, C. L. Morris, H. A. Thiessen, and H. T. Fortune, Phys. Rev. C25, 924 (1982);

[Gr-83] S. J. Greene, W. B. Cottingame, G. R. Burleson, L. C. Bland, R. Gilman, H. T. Fortune, C. L. Morr1s, D. B. Holtkamp, and C. Fred Moore, Phys. Rev. C27, 2375 (1983).

[Gr-84] S. J. Greene, C. J. Harvey, P. A. Seldl, R. Gllman, E. R. Slelliano, and M. B. Johnson, (accepted by Phys. Rev. C).

[Ha-84] Carol J. Haryey, H. W. Baer, J. A. Johnstone, C. L. Morr1s, S. J. Seestrom-Morris, D. Dehnhard, D. B. Holtkamp, and S. J. Greene, (submitted to Phys. Rev. C).

[In-78] Q. Ingram, E. Boschitz, L. Pflug, J. Z1chy, J. P. Albanese, and J. Arvleux, Phys. Lett. 76B, 173 (1978).

[Ir-83] F. Irom, J. R. Comfort, R. Jeppesen, J. J. Kraughaar, R. A. Klstinen, W. Tew, J. L. Ullmann, H. W. Beer, J. D. Bowman, M. D. Cooper, E. Plasetzky, U. Sennhauser, A. Erell, M. A. Molnester, E. R. S1c1liano, Phys. Rev, C28, 2565 (1983). 
[Ja-75] F. James and M. Roos, Computer Phys. Comm. 1C, 343 (1975).

[.Jo-80] M. B. Johnson, Phys. Rev. C22, 192 (1980).

[Jo-83a] M. B. Johnson and F. R. S1c1ltano, Phys. Rev, C27, 730 (1983).

[Jo-83b] M. B. Johnson and E. R. S1c111ano, Phys. Rev. C27, 1647 (1983).

[Jo-84] M. B. Johnson, E. R. Slcillano, H. Tok1, and A. W1rzba, Phys. Rev。 Jett. 52, $59 j$ (1984).

[Ka-83] M. O. Kaletka, PhD thes1s, Northwestern Unfvera1ty; and Los Alamos National Laboratory Report \# LA-9947-T (1983).

[Le-84] M. J. LeItch, E. Plasetzky, H. W. Baer, J. D. Bowman, R. L. Burman, B. J. Dropesky, P. A. M. Gram, F. Irom, D. Roberts, G. A. Rebka, J. N. Knudison, J. R. Comfort, V. A. P1nnick, D. H. Wright, and S. A. Wood, submitted to Phys. Rev. Lett. (1984) and Los Alamos Natlonal Laboratory Report LA-UR $84-2754$.

[L1-81] L. C. L1u, Phys. Rev. C,23, 814 (1981).

[L1-83] L. C. L1u, Phys. Rev. C27, 1611 (1983).

[L1-84] L. C. I.1u, private comunication, (1984).

[M1-81] G. A. M1ller, Phys. Rev. C24, 221 (1981).

[M1-84] Gerald A. M1ller, "Searching for S1x-Quark Cluster Components of Nuclear Wave Functiong with the Pion-Nucleus Double-Charge-Exchange Reaction", Univers1ty of Washington, unpublished, (1984). 
[Mo-80] C. L. Morris et al., Phys. Rev. Lett. 45, 1233 (1980).

[Mo-82a] C. L. Morris, H. T. Fortune, L. C. Bland, R. Gilman, S. J. Greene, W. B. Cottingame, D. B. Holtkamp, G. R. Burleson and C. Fred Moore, Phys. Rev. C 25, 3218 (1982).

[Mo-82b] C. L. Morris, Nucl. Inst. Meth. 196, 263 (1982).

[Mo-83] see, for example, C. L. Morr1s et. al., Phys. Rev. C28, 2165 (1983); J. A. Carr et. al., Phys. Rev. C27, 1636 (1983); S. I. Seestrom-Morris et. al., Phys. Rev. C26, 594 (1982); Kenneth G. Boyer et. al., Phys. Rev. C24, 598 (1981); Christopher L. Morris et. al., Phys. Rev. C24, 231 (1981); D. F. reesaman et. al., Phys. Rev. C23, 2635 (1981); S. Iversen et, al., Phys. Lett. 82B, 51 (1979).

[Mo-84] C. L. Morris, J. F. Amann, R. I. Boudrie, N. Tanaka, S. J. Seestrom-Morr1s, L. C. Bland, P. A. Seld1, R. Kłz⿺ah, (to be publ1shed).

[MP-80] "LAMPF Users Handbook", C11nton P. Anderson Meson Phys1cs Fac1lity, MP-DO-1-UHB (Rev.), (1980).

[Na-74] H. Nann and W. Benenson, Phys. Rev. C 10, 1880 (1974).

[Ne-72] J. W. Negele, and D. Vautherin, Phys. Rev. C5, 1472; C11, $1031(1975)$.

[01-80] C. Dlmer, D. F. Geesaman, B. Zeldman, S. Chakravart1, T.-S. I. Lee, R. L. Boudrie, R. H. Stemssen, J. F. Amann, C. L. Morr1s, H. A. Thefssen, G. R. Burleson, M, J. Devereux, R. E. Segal, and L. W. Swensen, Phys. Rev. C21, 254 (1980). 
[Ra-83] W. D. M. Rae, A. Etchegoyen, N. S. Godwin and B. A. Brown, OXBASH, The Oxford-Buenos Alres Shell Model Code, 1983, (unpublished).

[Ro-78] G. Rowe, M. Salomon and R. H. Landau, Phys. Rev. C 18, 584 (1978).

[Se-80] K. K. Seth, in "Intermediate-Energy Nuclear Chemistry Workshop", Los Alamos National Laboratory, Report no. LA-8835-C (1980).

[Se-81] S. J. Seestrom-Morr1s, PhD disgertation, University of Minnesota (1981); Los Alamos National Laboratory Report * LA-8916-T .

[Se-84] P. A. Seldl, R. R. K121ah, M. K. Brown, C. Fred Moore, C. L. Morris, H. Baer, S. J. Greene, G. R. Burleson, W. B. Cottingame, L. C. Bland, R. Gilman and H. T. Fortune, Phys. Rev. C30, 973 (1984).

[Sen-83] U. Sennhauser, E. Plasetzky, H. W. Baer, J. D. Bowman, M. D. Cooper, H. S. Mat1s, H. J. Zlock, J. Alster, A. Erell, M. A. Molnester, and F. Irom, Phys. Rev. Lett. 51, 1324 (1983).

[Set-84] Kamal R. Seth, M. Kaletka, S. Iversen, A. Saha, D. Barlow, D. Smlth, and L. C. L1u, Phys. Rev。 Lett. 52, $894(1984)$.

[S1-76] D. C. Slater, Los Alamos National Laboratory, unpublished.

[Th-70] H. A. Theissen et al., LOs Alamos Scientific Laboratory Report No. LA-4534-MS (1970); H. A. Theissen, J. C. Kallne, J. F. Amann, R. J. Peterson, S. J. Greene, S. L. Verbeck, G. R. Burleson, S. G. Iverson, A. W. Obst, R. K. Seth, C. F. 
Moore, J. E. Bolger, W. J. Bralthewalte, D. C. Slater and C. L. Morris, Los Alamos Sclentific Laboratory Report No. LA-6663-MS, 1977 (unpubl1shed).

[Wa-79] J. B. Walker, and G. A. Rebka, Jr., Los Alamos Natlonal Laboratory, Report LA-7731-MS (1979).

FU.S. GOVERMMENT PRINTING OFFICE:1885-576-034/20022 